UNIVERSIDADE DE SÃO PAULO

FACULDADE DE FILOSOFIA, CIÊNCIAS E LETRAS DE RIBEIRÃO PRETO

DEPARTAMENTO DE FÍSICA

PROGRAMA DE PÓS-GRADUAÇÃO EM FÍSICA APLICADA À MEDICINA E BIOLOGIA

PRISCILLA FREDDI

\title{
Interações entre complexos de interesse farmacológico e modelos de membrana
}

Dissertação apresentada ao Programa de Pós-Graduação em Física Aplicada à Medicina e Biologia da Faculdade de Filosofia, Ciências e Letras de Ribeirão Preto da Universidade de São Paulo, para a obtenção do título de Mestre em Ciências. 


\section{PRISCILLA FREDDI}

\section{Interações entre complexos de interesse farmacológico e modelos de membrana}

Dissertação apresentada ao Programa de Pós-Graduação em Física Aplicada à Medicina e Biologia da Faculdade de Filosofia, Ciências e Letras de Ribeirão Preto da Universidade de São Paulo, para a obtenção do título de Mestre em Ciências. Orientador: Antonio José da Costa Filho

VERSÃO CORRIGIDA 
AUTORIZO A REPRODUÇÃO E DIVULGAÇÃO TOTAL OU PARCIAL DESTE TRABALHO, POR QUALQUER MEIO CONVENCIONAL OU ELETRÔNICO, PARA FINS DE ESTUDO E PESQUISA, DESDE QUE CITADA A FONTE.

Freddi, Priscilla

Interações entre complexos de interesse farmacológico e modelos de membrana. Ribeirão Preto, 2013.

83 p.: il.; $30 \mathrm{~cm}$

Dissertação de Mestrado, apresentada à Faculdade de Filosofia, Ciências e Letras de Ribeirão Preto/USP. Área de concentração: Física Aplicada à Medicina e Biologia.

Orientador: da Costa Filho, Antonio José.

1. Complexos de cobre 2. Espectroscopia 3. Modelos de membrana 
Dedico esta dissertação aos meus pais. Amo vocês! 


\section{AGRADECIMENTOS}

Quando penso nesta seção da dissertação, a que considero mais difícil de escrever, pelo medo de esquecer de alguém importante ou de não agradecer apropriadamente e principalmente pelo medo de escrever demais (risos). Pensando nisso me recordo de duas frases que resumem tanto a ideia da seção em si, como tudo o que acredito.

“Entre os pecados maiores que os homens cometem, ainda que alguns digam que é a soberba, eu digo que é a falta de agradecimento.", Dom Quixote de La Mancha.

"Sonho que se sonha só, é só um sonho que se sonha só, mas sonho que sonha junto é realidade.", Raul Seixas.

A primeira pessoa que quero agradecer é uma das pessoas que posso dizer que mais me conhece e que mais esteve presente em todo o processo de pesquisa e escrita do meu trabalho, meu namorado Luis Felipe (Nó). Quero agradecer todo apoio e carinho, todas as broncas e conselhos e por sempre estar ao meu lado. Por ter me aguentado em todas as crises (risos..), me compreendido. E principalmente por todas as conversas e piadinhas que só a gente entende.

Outra pessoa que jamais poderia ficar fora de meus agradecimentos é o meu orientador, Antonio Costa, o famoso Jabah. Obrigada pela oportunidade e confiança dadas a mim, sem ao menos me conhecer. Por toda a paciência e todo o ensinamento, tanto na parte da ciência e pesquisa, quanto na vida, pois me ensinou que uma pessoa pode ser muito boa profissionalmente, sem deixar a humildade, a família e amigos de lado.

Agradeço também aos meus pais por todo o ensinamento, todas as broncas e principalmente, por terem sido diferentes dos pais dos meus amigos, terem sido os pais que meus amigos queriam ter! Que além de me guiarem para um caminho melhor, sempre estavam presentes para fazer o mesmo com meus amigos/irmãos. Por serem os pais que sempre estavam abertos a qualquer tipo de conversa. E acima de tudo muito obrigada por me amarem e sempre me apoiarem em todas as minhas decisões, confiando no caminho que escolhi para mim, mesmo sem entender e conhecer totalmente esse mundo e vida que escolhi.

Não posso esquecer-me de falar aqui da minha irmã Pércia, que apesar das briguinhas habituais de irmã, que temos até hoje (risos) e que mesmo tendo escolhido um 
caminho na vida quase que oposto ao meu (cozinheira de mão cheia!), sempre esteve presente, me ouvindo e apoiando.

A todo o pessoal do Laboratório de Biofísica Molecular (São Carlos e Ribeirão Preto) muito obrigada pela ajuda e ensinamentos. Obrigada em especial ao Rafael, Fernando, Fábio e Paty por sempre me ajudarem na preparação de amostras e medidas, quando precisei.

Ainda falando dos queridos amigos do laboratório: Haroldo, Ana, Assuero, Natasha, Rafael, Mariana (Pops), Felipe e Bianca, obrigada pelos conselhos e por sempre ouvirem as minhas alegrias e reclamações, por todos os bares, pizzadas e companhia. Sempre levando ao pé da letra o lema "Work hard, party hard!".

Sem esquecer dos amigos da graduação da Unesp Rio Claro que fizeram parte do meu caminho até aqui, agradeço por todas as noites em claro, seja de estudo ou de baladas, todas valeram muito a pena! Em especial às pessoas que mais foram presentes em minha vida nesta época, aos queridos do clube da Lulu: Marília (Lulu), Alexandre (Toba), Henrique (Torto), Leandro (Tranco) e Adriano que mesmo estando distantes agora, fizeram toda a diferença na minha vida rio clarense. Ainda em Rio Claro, não posso esquecer da Júlia (Julião!), melhor companheira de casa que se pode ter, sempre com seus banquetes pra me animar e sem esquecer do nosso saudoso Saci, que era o mais divertido da casa! À Nathália (Marissol) e Taína por nossa maratona nerd-atleta, melhor ano de graduação de todos, cheios de planos, festas, estudos, passeios no shopping com "cappuccino da alegria" e principalmente muitas conversas. (P.S.: Mais um capítulo para nosso livro Marissoca!)

Não posso deixar de agradecer também às minhas amigas lindas da época de escola e da vida toda. Agradeço todo o apoio e compreensão por eu não ser mais tão presente em suas vidas, devido à correria do dia-a-dia e da distância entre nós e que mesmo sem entender muito bem o que faço, sempre estão na torcida pelo meu sucesso. Muito obrigada por continuarem a serem minhas amigas, mesmo depois que eu ficar louquinha.. (risos) Jéssika, Mariana, Ana Carolina e a minha melhor prima/amiga Francieli.

Às novas amigas e por um tempo companheiras de mesmo teto, Mariana e Leila, pelas conversas, jantinhas e por não terem me achado louca quando ficava dias dentro do quarto, escondida do mundo (risos).

Ah e aos amigos que quando saio de Urupês se apossam de minha mãe (risos) e também cuidam dela, Ednei e Elisa, amigos de copo (risos). E ao meu eterno irmãozinho Luiz Cesar. 
Agradeço também à Carolina Noble, muito obrigada Carol, por ter me ajudado na minha dificultosa amizade com a química e à sua orientadora Prof ${ }^{a}$ Dra. Gianela Fachinni por sempre ter respondido prontamente meus emails e dúvidas.

À Prof ${ }^{a}$. Dra. María H. Torre, por ter gentilmente cedido os complexos utilizados neste trabalhado.

Ao Prof. Dr. Pietro Ciancaglini pelo concedimento no uso do DSC e à sua aluna Juliana pela ajuda no uso do aparelho.

À FFCLRP pelo suporte e a CAPES e FAPESP pela concessão de bolsa de mestrado e pelo apoio financeiro para a realização desta pesquisa. 
"Never give up, for that is just the place and time that the tide will turn."

Harriet B. Stowe 


\section{RESUMO}

FREDDI, P. Interações entre complexos com interesse farmacológico e modelos de membrana. 2013. 83 f. Dissertação (Mestrado em Ciências) - Faculdade de Filosofia, Ciências e Letras de Ribeirão Preto, Universidade de São Paulo, Ribeirão Preto, 2013.

Sulfonamidas e seus diferentes derivados são extensivamente utilizados na medicina devido a suas propriedades farmacológicas, tal como sua atividade antibacteriana. Propriedades toxicológicas e farmacológicas modificadas vêm sendo observadas quando essas sulfonamidas são administradas nas formas de complexos metálicos. Neste trabalho, utilizamos as moléculas sulfadimetoxina (4-p-aminobenzenosulfonamida-2,6dimetoxipirimidina) e sulfisoxazol (N(1)-(3,4-dimetil-5-isoxazolil)sulfanilamida) complexados com Cu(II) para acessar seus mecanismos de interação com modelos de membranas lipídicas. Foram feitos experimentos de calorimetria diferencial de varredura (DSC) e de ressonância paramagnética eletrônica (RPE) em soluções contendo os complexos de cobre na presença de modelos de membranas biológicas compostos por fosfolipídios e, no caso de RPE, contendo sondas magneticamente ativas. Amostras foram preparadas utilizando-se o fosfolipídio dipalmitoilfosfatidilcolina (DPPC) e, para os experimentos de RPE, contendo também derivados de DPPC marcados com sonda magnética disposta ao longo da cadeia acila ( $n$-PCSL, onde $n=5,12$ e 16). Os resultados de DSC mostram que ambos os complexos alteram tanto a transição de fase principal quanto a pré-transição dos fosfolipídios componentes do modelo de membrana, indicando assim a existência de interação e de maior desordenamento da membrana na presença dos complexos de cobre. Os espectros de RPE mostram que os complexos de cobre afetam, principalmente, a fase gel dos fosfolipídios e maiores alterações são percebidas em posições da membrana mais próximas à interface membrana-solvente. Nossos dados indicam que interações não-específicas entre os complexos de cobre e membranas podem ser um mecanismo utilizados pelo fármaco para vencer as barreiras físicas da célula.

Palavras-chave: Complexos de cobre. Espectroscopia. Modelos de membrana. 


\begin{abstract}
FREDDI, P. On the interactions between pharmacologically-relevant compounds and model membranes. 2013. 83 f. Dissertação (Mestrado em Ciências) - Faculdade de Filosofia, Ciências e Letras de Ribeirão Preto, Universidade de São Paulo, Ribeirão Preto, 2013.

Sulfonamides and their different derivatives are extensively used in Medicine due to their pharmacological properties, such as antibacterial activity. Modified toxicological properties have been observed when those sulfonamides are administered in the form of metal complexes. In this work, we used the molecules sulfadimethoxine (4-paminobenzenesulfonamido-2,6-dimethoxypyrimidine) and sulfisoxazole (N (1) - (3,4dimethyl-5-isoxazolyl) sulfanilamide) complexes with $\mathrm{Cu}(\mathrm{II})$ to assess their mechanism of interaction with lipid model membranes. Differential Scanning Calorimetry (DSC) and Electron Paramagnetic Resonance (EPR) experiments were carried out to monitor the influence of the complexes on the lipid thermotropic behavior. Samples consisting of the multilamellar vesicles of dipalmitoylphosphatidylcholine (DDPC) and, in the case of EPR, spin labeled phospholipids were used as models for the membrane. DSC results showed that the presence of the complexes affects both the pre-transition and the main phase transition of the lipids in the membrane. A disordering effect is evidenced by the decrease in $T_{m}$ and $T_{p}$ values. ESR results showed that the major alterations are detected in the lipid gel phase and for the labels positioned close to the lipid-water interface. Overall our results indicate that non-specific interactions between the complexes and the membrane might be a mechanism used by the drugs to overcome the physical barriers found in the cell.
\end{abstract}

Keywords: Copper complexes. Spectroscopy. Model membranes. 


\section{LISTA DE FIGURAS}

FIGURA 1 - ESTRUTURA GERAL DAS SULFONAMIDAS

FIGURA 2 - ESTRUTURAS QUímicAS DAS SULFONAMIDAS UTILIZADAS NESTE TRABALHO: (A) SULFISOXAZOL E (B) SULFADIMETOXINA. 21

Figura 3 - Estruturas químicas dos complexos utilizados neste trabalho (A) [Cu(SUlFisOXAZOL) $\left.{ }_{2}\left(\mathrm{H}_{2} \mathrm{O}\right)_{4}\right]$ E (B) [CU(SULFADIMETOXINA) $)_{2}$.

Figura 4 - (A) MOdelo de MOSAICO FLUIDO PARA A ESTRUTURA DA MEMBRANA. A CADEIA ACILA NO INTERIOR DA MEMBRANA FORMA UM FLUIDO, REGIÃO HIDROFÓBICA. AS PROTEÍNAS INTEGRAIS FLUTUAM NESTE "MAR" DE LIPÍDIO, MANTIDAS POR INTERAÇÕES HIDROFÓBICAS COM SUAS CADEIAS LATERAIS DE AMINOÁCIDOS APOLARES. PROTEÍNAS E LIPÍDIOS SÃO LIVRES PARA SE MOVEREM LATERALMENTE NO PLANO DA BICAMADA, MAS OS MOVIMENTOS PARA AS FACES DA MESMA SÃO RESTRITOS. AS PORÇÕES DE CARBOIDRATOS ANEXADAS A ALGUMAS PROTEÍNAS E LIPÍDIOS NA MEMBRANA PLASMÁTICA SÃO EXPOSTAS À SUPERFíCIE EXTRACELULAR DA MEMBRANA. FIGURA AdAPTADA DE (38). (B) ESQUEMA ILUSTRATIVO dA MEMBRANA MODELO. BICAMADA LIPÍDICA FORMADA PELA EXPOSIÇÃO DOS FOSFOLIPÍDIOS A UM MEIO AQUOSO, DEVIDO A SEU CARÁTER ANFIFÍLICO.

FigURA 5 - ESTRUTURAS QUíMICAS DO FOSFOLIPÍDIO (A) 1,2-DIPALMITOIL-SN-GLICERO-3-FOSFOCOLINA (DPPC) E DOS LIPÍDIOS MARCADOS (B) 1-PALMITOIL-2-(5-DOXIL ESTEAROIL) FOSFATIDILCOLINA (5-PCSL), (C) 1-PALMITOIL-2-(12-DOXIL ESTEAROIL) FOSFATIDILCOLINA (12-PCSL) E (D) 1- PALMITOIL-2-(16-DOXIL ESTEAROIL) FOSFATIDILCOLINA (16-PCSL). FIGURA ADAPTADA DE (48).

FiguRA 6 - TERMOGRAMA DE UM BIOPOLÍMERO HIPOTÉtICO. A DIFERENÇA DE CAPACIDADE CALORÍFICA ( $\triangle C_{P}$ ) DO EVENTO TÉRMICO É CARACTERIZADA PELA TEMPERATURA DE TRANSIÇÃO DE FASE ( $T_{M}$, TEMPERATURA DE MELTING), ONDE A CAPACIDADE CALORÍFICA ATINGE UM MÁxIMO. A ENTALPIA CALORIMÉTRICA, $\Delta \mathrm{H}_{\text {CAL }}$ É A ÁREA SOB A CURVA, QUE É DEPENDENTE COM A TEMPERATURA DA CAPACIDADE CALORÍFICA DA AMOSTRA À PRESSÃO CONSTANTE. FIGURA ADAPTADA DE (53).

FIGURA 7 - TRANSIÇÕES DE FASE DE VESÍCULAS LIPÍDICAS DE DPPC. O EVENTO 1 SE REFERE À CHAMADA PRÉ-TRANSIÇÃO, SURGIDA DA CONVERSÃO DA FASE GEL $L_{B^{\prime}}$ PARA A FASE RIPPLED $P_{B^{\prime}}$ E O EVENTO 2, DENOMINADO DE TRANSIÇÃO PRINCIPAL, SURGE DA CONVERSÃo dA FASE $P_{B^{\prime}}$ PARA A FASE LÍQUIDO-CRISTALINO, L $\mathrm{L}_{A}$. FIGURA ADAPTADA DE (49).

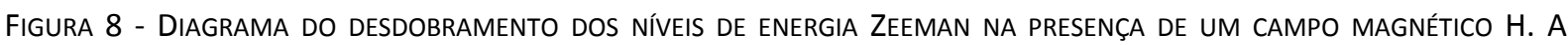

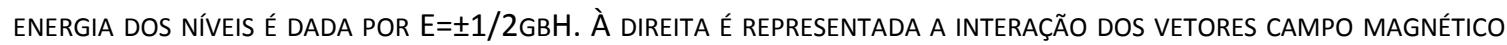
(PRETO) E MOMENTO DE DIPOLO MAGNÉTICO DE SPIN (VERMELHO). ABAIXO ESTÁ REPRESENTADO O ESPECTRO DE ABSORÇÃO, BEM COMO A PRIMEIRA DERIVADA DESTE. FIGURA ADAPTADA DE (59).

FIGURA 9 - ESTRUTURA QUÍMICA GERAL DE UM RADICAL NITRÓXIDO E REPRESENTAÇÃO DO SISTEMA DE COORDENADAS MOLECULAR EM QUE SE DETERMINAM OS TENSORES MAGNÉTICOS TíPICOS NA ESPECTROSCOPIA DE RPE. FIGURA ADAPTADA DE (60). 39

FIGURA 10 - ESQUEMA ILUSTRATIVO DOS MARCADORES DE SPIN 5-PCSL INTERCALADOS COM FOSFOLIPÍDIOS EM BICAMADAS. A LINHA TRACEJADA REFERE-SE À REGIÃO MAIS FORTEMENTE MONITORADA PELA SONDA DE SPIN.

FIGURA 11 - ANISOTROPIA ESPECTRAL DE UM MARCADOR DE SPIN ORIENTADO EM UM MONOCRISTAL. CAMPO MAGNÉTICO EXTERNO APLICADO NA DIREÇÃO (A) X, (B) Y E (C) Z. FIGURA ADAPTADA DE (59).

FIGURA 12 - ANISOTROPIA DO ESPECTRO DE RPE DO MARCADOR DE SPIN EM VÁRIAS CONDIÇÕES: (A) ESPECTRO OBTIDO DE AMOSTRA POLICRISTALINA OU SOLUÇÃO CONGELADA, (B) ESPECTRO DE UM RADICAL NITRÓXIDO EM UMA DISPERSÃO LIPÍDICA, E (C) ESPECTRO ISOTRÓPICO, RADICAL EM UMA SOLUÇÃO NÃO VISCOSA. FIGURA ADAPTADA DE (59). 
FIGURA 13 - ESPECTROS DE RPE DE UM RADICAL NITRÓXIDO EM UM AMBIENTE LEVEMENTE ANISOTRÓPICO, APRESENTANDO AS DEFINIÇÕES DOS PARÂMETROS EMPÍRICOS UTILIZADOS PARA A ANÁLISE DOS MESMOS, NA INVESTIGAÇÃO DA DINÂMICA E ORDEM DO RADICAL NITRÓXIDO EM MEMBRANAS, EM DOIS REGIMES DE MOVIMENTO: (A) RÁPIDO E (B) LENTO.

Figura 14 - TeRmogramas de DSC ILUSTRANdo o EFEITO dos COMPLEXOS CU-SDM E CU-SFZ NO COMPORTAMENTO TERMOTRÓPICO DE VESÍCULAS DE DPPC.

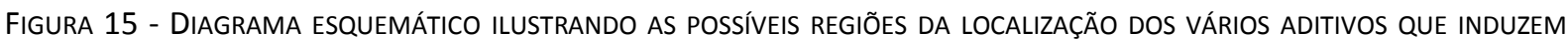
QUALITATIVAMENTE PERFIS DE TRANSIÇÃO DE FASE DISTINTOS QUANDO INCORPORADOS À BICAMADA DO DIPALMITOIL LECITINA. SOLUTOS DO TIPO D PODEM ESTAR LOCALIZADOS NA REGIÃO PRÓXIMA À INTERFACE, TIPO B NA REGIÃO DO GLICEROL, TIPO A NA REGIÃO DO METILENO E TIPO C PRÓXIMOS AO CENTRO DA BICAMADA. FIGURA ADAPTADA DE (45)......

FIGURA 16 - DESTAQUE DO PICO REFERENTE À TRANSIÇÃO DE FASE PRINCIPAL NO TERMOGRAMA DE DSC NA AUSÊNCIA E NA PRESENÇA DOS COMPLEXOS.

FIGURA 17 - DESTAQUE DO PICO DA PRÉ-TRANSIÇÃO DO FOSFOLIPÍDIO DPPC NO TERMOGRAMA DE DSC NA AUSÊNCIA E NA PRESENÇA DOS COMPLEXOS.

FiguRA 18 - MEDIDAS de RPE COM VARIAÇÃo de teMPERATURA dOS MOdELOS DE MEMBRANA CONTENDO DPPC E A SONDA 5PCSL.

FIGURA 19 - ESPECTROS DE RPE DO MARCADOR 5-PCSL EM DISPERSÃO LIPÍDICA DE DPPC NA PRESENÇA DO COMPLEXO CU-SDM.55

FIGURA 20 - ESPECTROS DE RPE DO MARCADOR 5-PCSL EM DISPERSÃO LIPÍDICA DE DPPC NA PRESENÇA DO COMPLEXO CU-SFZ. . 56

FIGURA 21 - ESPECTROS DE RPE DO MARCADOR 5-PCSL EM DISPERSÕES LIPÍDICAS DE DPPC ANTES E DEPOIS DA ADIÇÃO DOS COMPLEXOS COBRE-SULFONAMIDAS EM DUAS DIFERENTES TEMPERATURAS, 30 E $45{ }^{\circ} \mathrm{C}$. AS LINHAS PONTILHADAS SÃO GUIAS PARA AJUDAR NA PERCEPÇÃO DAS MUDANÇAS ESPECTRAIS.

FIGURA 22 - DEPENDÊNCIA COM A TEMPERATURA DO DESDOBRAMENTO HIPERFINO MÁXIMO E DO PARÂMETRO DE ORDEM EFETIVO (INSERÇÃO) DO MARCADOR DE SPIN 5-PCSL INCORPORADO EM VESÍCULAS DE DPPC, SEM E COM A ADIÇÃO DO COMPLEXO CUSDM.

FIGURA 23 - DEPENDÊNCIA COM A TEMPERATURA DO DESDOBRAMENTO HIPERFINO MÁXIMO E DO PARÂMETRO DE ORDEM EFETIVO (INSERÇÃO) DO MARCADOR DE SPIN 5-PCSL, INCORPORADO EM VESÍCULAS DE DPPC, SEM E COM A ADIÇÃO DO COMPLEXO CU-SFZ.

Figura 24 - MEDIDAS DE RPE COM VARIAÇÃo DE TEMPERATURA dOS MOdELOS DE MEMBRANA CONTENDO DPPC E A SONDA 12 PCSL.

FIGURA 25 - ESPECTROS DE RPE DO MARCADOR 12-PCSL EM DISPERSÃO LIPÍDICA DE DPPC NA PRESENÇA DO COMPLEXO CU-SDM.

FIGURA 26 - ESPECTROS DE RPE DO MARCADOR 12-PCSL EM DISPERSÃO LIPÍDICA DE DPPC NA PRESENÇA DO COMPLEXO CU-SFZ.63

FIGURA 27 - ESPECTROS DE RPE DO MARCADOR DE SPIN 12-PCSL EM DISPERSÕES LIPÍDICAS DE DPPC ANTES E DEPOIS DA ADIÇÃO DOS COMPLEXOS COBRE-SULFONAMIDAS EM DUAS TEMPERATURAS, $30 \mathrm{E} 45^{\circ} \mathrm{C}$. 64

FiguRA 28 - DEPENDÊNCIA DO PARÂMETRO $\mathrm{H}_{+1} / \mathrm{H}_{0}$ COM A TEMPERATURA DO MARCADOR DE SPIN 12-PCSL EM DPPC SEM E COM A ADIÇÃO DOS COMPLEXOS CU-SDM E CU-SFZ.

FIGURA 29 - ESPECTROS DE RPE DO MARCADOR 16-PCSL EM DISPERSÃO LIPÍDICA DE DPPC. 
FIGURA 30 - ESPECTROS DE RPE DO MARCADOR 16-PCSL EM DISPERSÃO LIPÍDICA DE DPPC NA PRESENÇA DO COMPLEXO CU-SDM.

FIGURA 31 - ESPECTROS DE RPE DO MARCADOR 16-PCSL EM DISPERSÃO LIPÍDICA DE DPPC NA PRESENÇA DO COMPLEXO CU-SFZ.68

FIGURA 32 - ESPECTROS DE RPE DO MARCADOR DE SPIN 16-PCSL EM DISPERSÕES LIPÍDICAS DE DPPC, SEM E COM A ADIÇÃO DOS COMPLEXOS COBRE-SULFONAMIDAS EM DUAS TEMPERATURAS, $30 \mathrm{E} 45^{\circ} \mathrm{C}$.

FIGURA 33 - DEPENDÊNCIA DOS PARÂMETROS $\mathrm{H}_{+1} / \mathrm{H}_{0}$ E H-1 $/ \mathrm{H}_{0}$ (INSERÇÃO) COM A TEMPERATURA DO MARCADOR DE SPIN 16-PCSL EM DPPC, SEM E COM A ADIÇÃO DO COMPLEXO CU-SDM.

FIGURA 34 - DEPENDÊNCIA DOS PARÂMETROS $\mathrm{H}_{+1} / \mathrm{H}_{0}$ E H-1/ $\mathrm{H}_{0}$ (INSERÇÃo) COM A TEMPERATURA DO MARCADOR DE SPIN 16-PCSL EM DPPC, SEM E COM A ADIÇÃO DO COMPLEXO CU-SFZ. 


\section{LISTA DE TABELAS}

TABELA 1 - TABELA EXPLICATIVA SOBRE A COORDENAÇÃO ENTRE OS LIGANTES SULFONAMIDAS E O ÍON DE COBRE. . 22

TABELA 2 - DADOS TERMODINÂMICOS OBTIDOS DA ANÁLISE DOS TERMOGRAMAS DE DSC DA PRÉ-TRANSIÇÃO E DA TRANSIÇÃO PRINCIPAL DAS VESÍCULAS DE DPPC NA AUSÊNCIA E NA PRESENÇA DOS COMPLEXOS, ONDE TP É A TEMPERATURA DA PRÉ-TRANSIÇÃO E TM DA TRANSIÇÃO PRINCIPAL. 


\section{LISTA DE ABREVIATURAS E SIGLAS}

\begin{tabular}{|c|c|}
\hline RPE & Ressonância Paramagnética Eletrônica \\
\hline DSC & Calorimetria Diferencial de Varredura (do inglês, Differential Scanning \\
\hline \multicolumn{2}{|c|}{ Calorimetry) } \\
\hline n-PCSL & 1-Palmitoil-2-(n-doxil estearoil) Fosfatidilcolina $(n=5,12$ e 16) \\
\hline SDM & Sulfadimetoxina ou 4-p-aminobenzenosulfonamida-2,6-dimetoxipirimidina \\
\hline SFZ & Sulfisoxazol ou N(1)-(3,4-dimetil-5-isoxazolil)sulfanilamida \\
\hline $\mathrm{Cu}$ & Cobre \\
\hline$\Delta \mathbf{H}_{\text {cal }}$ & Entalpia calorimétrica da transição de fase principal \\
\hline$\Delta \mathrm{H}_{\mathrm{VH}}$ & Entalpia de van't Hoff \\
\hline$\Delta \mathbf{S}$ & Variação da entropia da transição de fase principal na $T_{M}$ \\
\hline$\Delta T_{1 / 2}$ & Largura da transição principal à meia altura \\
\hline A MÁx & Desdobramento hiperfino máximo \\
\hline$A_{\text {MIN }}$ & Desdobramento hiperfino mínimo \\
\hline$h_{+1} / h_{0}$ & Razão entre as amplitudes das linhas de campo baixo e central \\
\hline$h_{-1} / h_{0}$ & Razão entre as amplitudes das linhas de campo alto e central \\
\hline $\mathrm{L}_{\alpha}$ & Fase lamelar líquido-cristalino \\
\hline $\mathbf{L}_{\beta^{\prime}}$ & Fase gel lamelar tilted \\
\hline
\end{tabular}


Fase gel lamelar rippled

$S_{\text {EFF }}$

Parâmetro de ordem efetivo

$T_{M}$

Temperatura de transição de fase principal ou temperatura de melting

$T_{p}$

Temperatura da pré-transição 


\section{SUMÁRIO}

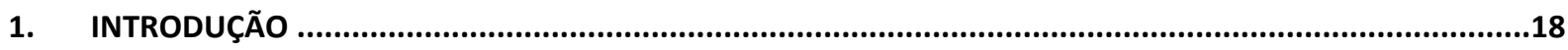

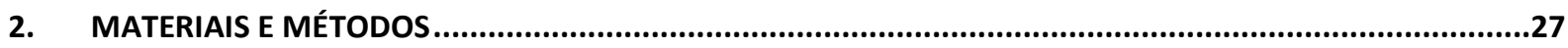

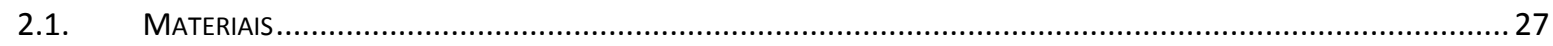

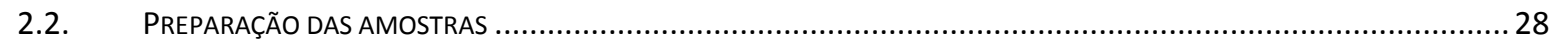

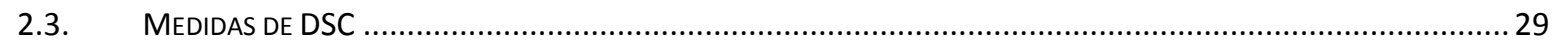

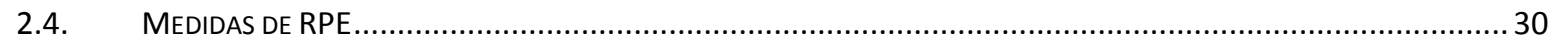

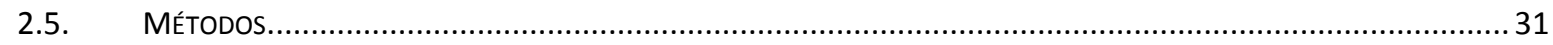

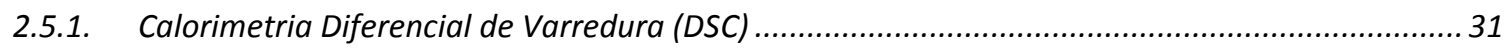

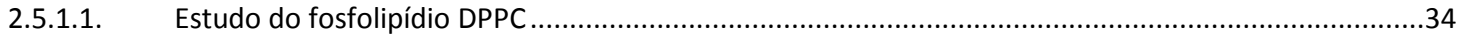

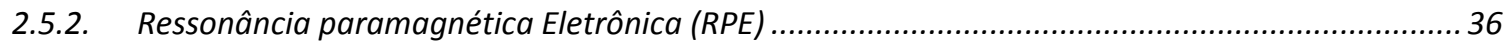

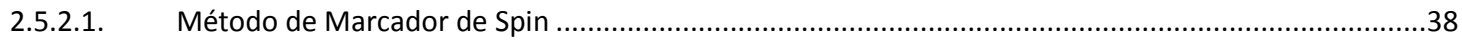

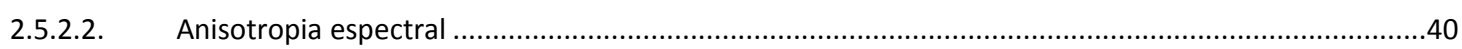

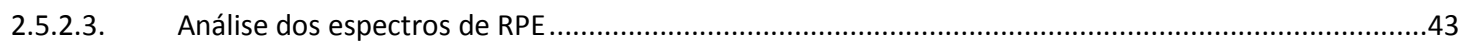

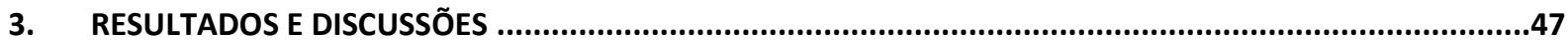

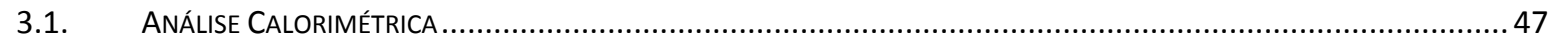

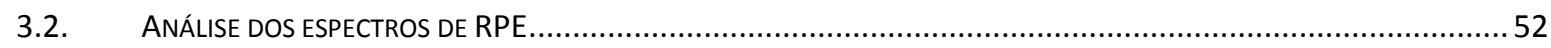

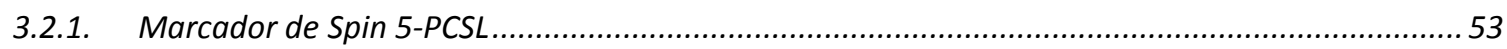

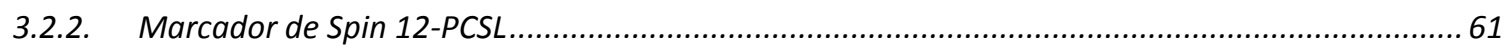

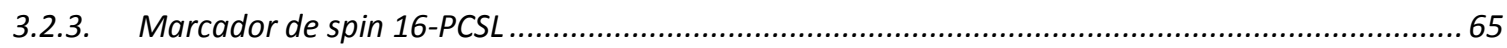

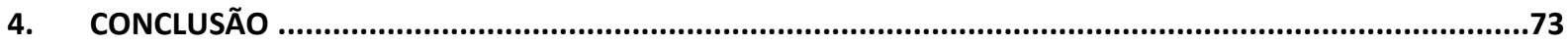

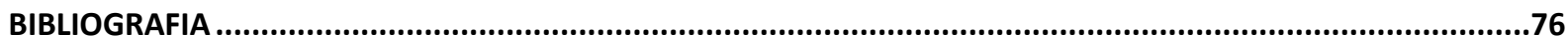




\section{Introdução}

No século passado iniciou-se uma grande corrida em busca de novas descobertas na área da farmacologia. Com o avanço da ciência e a possibilidade do melhor entendimento de diversas doenças, até então desconhecidas, surgiu a necessidade da criação de novos fármacos e estratégias terapêuticas. A multidisciplinaridade é o maior trunfo para o sucesso desses novos estudos, tendo parceiros em diversas áreas da ciência, como na Biofísica, Biologia Molecular, Bioquímica, Medicina, Físico-química, Fisiologia, Neurobiologia, Patologia, Química Biológica, Inorgânica e Orgânica, assim como a Matemática e a Computação.

A pesquisa de fármacos é muito ampla, envolvendo várias linhas a serem seguidas, como, por exemplo, estudos da funcionalidade de proteínas, busca por seus inibidores, o isolamento de compostos que tenham princípios ativos contra algum mal e ainda a sintetização de complexos com interesse farmacológico. Estes compostos são altamente utilizados hoje em dia e grande parte dos fármacos existentes é sintetizada em laboratório. Dentro dessa gama de novos complexos, nasceram os compostos de coordenação com metais. Existem relatos de mais de 5 mil anos sobre o interesse de uso de metais na Medicina e no tratamento de doenças. Os egípcios utilizavam o cobre para a purificação da água, nos anos 3 mil antes de Cristo, e os árabes e chineses acreditavam que o ouro, por ser um metal nobre, trazia benefícios à saúde. Mas o estudo de complexos metálicos na Medicina só ganhou impulso com o trabalho de Paul Ehrlich, considerado o criador da quimioterapia, que introduziu um medicamento obtido a partir de várias combinações de arsênico para o tratamento da sífilis, sendo esta droga a mais bem sucedida até o aparecimento da penicilina e dos antibióticos na década de 1940 (1).

Atualmente sabe-se que muitos metais são essenciais para o organismo vivo. Estimase que aproximadamente um terço de todas as proteínas e enzimas requerem íons metálicos como cofatores para sua função biológica (2). Os metais de transição exibem diferentes estados de oxidação, o que faz com que possam interagir com um número maior de moléculas carregadas negativamente, levando a um aumento considerável das possibilidades de desenvolvimento de compostos com potencial aplicação farmacológica e 
que podem oferecer oportunidades terapêuticas únicas. Pesquisas têm mostrado um significativo progresso na utilização de complexos metálicos como drogas para tratar várias doenças humanas, como carcinomas, linfomas, diabetes, desordens neurológicas e para o controle de infecções e atividade anti-inflamatória $(3,4)$. Esses complexos apresentam a atividade desejada, que não é observada no ligante sozinho, o que leva a pensar que a importância do ponto de vista farmacológico não se deve à presença do metal ou do ligante, mas sim da estrutura e das propriedades químicas da espécie que formam entre si (5). Por esta razão, os estudos de compostos bioinorgânicos farmacologicamente ativos são necessários para que se obtenha conhecimento estrutural e químico completo de cada complexo, para, assim, se tentar entender os mecanismos de ação e, eventualmente, obter novos compostos com melhores atividades e eficiência.

Dentre os metais de transição com funções biológicas, o cobre é um dos que tem posição de destaque. $\mathrm{O}$ cobre é um metal de transição com três estados de oxidação: $\mathrm{Cu}_{0}$, $\mathrm{Cu}_{+1}$ e $\mathrm{Cu}_{+2}$, sendo o estado cúprico o mais encontrado nos sistemas biológicos. Em 1928, descobriu-se que a anemia era uma decorrência da deficiência de cobre na dieta em animais, mostrando assim que este era um elemento biológico essencial (6). É o terceiro metal em maior concentração no organismo vivo, perdendo apenas para o ferro e zinco (7), e está envolvido em muitos processos e funções importantes (8-10). Sua maior concentração está no fígado, seguido do cérebro, rim e coração (11).

Proteínas e enzimas com sítios metálicos de cobre são responsáveis pelo transporte de elétrons (proteínas azuis), armazenamento e transporte de oxigênio (hemocianina), oxidoredutases (oxidases, redutases, hidroxilases e superóxido dismutases) e hidroxilases (fosfotases) $(2,12)$. Também têm influência na expressão de genes em células de mamíferos (13), mielinização de nervos e ação endorfina, com a deficiência do cobre prejudicando a imunidade $(14,15)$.

Compostos de cobre, em particular, complexos de $\mathrm{Cu}(\mathrm{II})$, apresentam importante interesse farmacológico, uma vez que muitos deles apresentam um número considerável de efeitos, incluindo anti-inflamatório, anti-ulceroso, anti-convulsionante e até mesmo atividade anti-tumoral (16). A deficiência deste elemento é normalmente causada pelo baixo armazenamento no nascimento, pela dieta inadequada, baixa absorção ou ainda por doenças como a chamada Doença de Menke, que é hereditária e afeta os níveis de cobre no 
organismo (17). Sua falta pode provocar anomalia no sistema ósseo, pois inibe a produção de enzimas envolvidas no entrelaçamento das fibras de colágeno, afeta a estabilidade e quantidade de colágeno, comprometendo o crescimento e a qualidade dos pelos e ainda neutropenia, uma diminuição no número de neutrófilos (18).

O excesso do metal também é prejudicial à saúde, pois em montantes excessivos é extremamente tóxico para o organismo (19). A chamada Doença de Wilson, uma doença hereditária autossômica recessiva, leva o paciente a acumular cobre nos tecidos, principalmente no cérebro e fígado e acarreta sintomas neuropsiquiátricos e desordens hepáticas. Doenças como encefalia espongiforme (mal da vaca louca) e mal de Alzheimer também estão diretamente ligadas a proteínas que possuem sítios de Cu(II) em sua estrutura $(20,21)$.

As configurações distorcidas (tetraédrica, quadrado piramidal e quadrado planar) em torno do centro metálico representam de alguma forma a configuração estrutural mais comum em complexos de $\mathrm{Cu}(\mathrm{II})$. Estas geometrias facilitam, por exemplo, a rápida transferência de elétrons, já que não requerem mudanças estruturais significativas, ao se variar o estado de oxidação do metal durante a realização de processos observados em proteínas azuis (22).

Neste trabalho foram estudados complexos de cobre contendo sulfonamidas. Estas moléculas e seus derivados são extensivamente utilizados na Medicina devido às suas propriedades farmacológicas, como atividade antibacteriana, anti-anidrase carbônica, diurética, hipoglicêmica, atividade antitireoidiana, antitumoral, entre outras (23). Elas interferem na utilização do ácido p-aminobenzóico (PABA) na biossíntese do ácido tetrahidrofólico, que é um fator essencial para o crescimento de bactérias no metabolismo (24). Ao longo dos anos, surgiram diversas estirpes de bactérias resistentes à droga, mas isso não parou com seu uso, pois as sulfonamidas ainda são consideradas para o tratamento de, por exemplo, nocardiose e principalmente para o tratamento do trato urinário e infecções com bactérias resistentes a meticilina. A figura 1 mostra a estrutura geral de uma sulfonamida. 


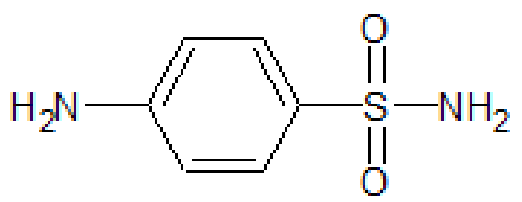

Figura 1 - Estrutura geral das sulfonamidas.

Propriedades farmacológicas e toxicológicas modificadas têm sido observadas quando algumas dessas sulfonamidas são administradas na forma de seus complexos metálicos $(25,26)$. Por exemplo, Ni(II)-Sulfadimetoxina (27) e Cu(II)-Sulfacetamida (28) mostram maior atividade anti-microbial que os ligantes sozinhos. Muitos estudos de coordenação com $\mathrm{Cu}(\mathrm{II})$, tem mostrado a versatilidade destes ligantes e a importância de seus complexos na coordenação química $(29,30)$.

Em particular, neste trabalho foram estudados dois complexos formados a partir de $\mathrm{Cu}(\mathrm{II})$ e as sulfonamidas sulfisoxazol [ou N(1)-(3,4-dimetil-5-isoxazolil)sulfanilamida $\left(\mathrm{C}_{11} \mathrm{H}_{13} \mathrm{~N}_{3} \mathrm{O}_{3} \mathrm{~S}\right)$ ] e sulfadimetoxina [ou 4-p-aminobenzenosulfonamida-2,6-dimetoxipirimidina $\left.\left(\mathrm{C}_{12} \mathrm{H}_{14} \mathrm{~N}_{4} \mathrm{O}_{4} \mathrm{~S}\right)\right]$, cujas estruturas químicas são apresentadas na figura 2 .<smiles>Cc1noc(NS(=O)(=O)c2ccc(N)cc2)c1C</smiles>

(a)<smiles>COc1cc(NS(=O)(=O)c2ccc(N)cc2)nc(OC)n1</smiles>

(b)

Figura 2 - Estruturas químicas das sulfonamidas utilizadas neste trabalho: (a) Sulfisoxazol e (b) Sulfadimetoxina.

Cada um dos complexos, quando em solução aquosa, se coordena de uma maneira diferente devido às suas diferenças estruturais, o que é mostrado na Tabela 1. 
Tabela 1 - Tabela explicativa sobre a coordenação entre os ligantes sulfonamidas e o íon de cobre.

\begin{tabular}{ccccc}
\hline Amostra & $\begin{array}{c}\text { Número } \\
\text { de } \\
\text { Ligantes }\end{array}$ & $\begin{array}{c}\text { Número de } \\
\text { Moléculas } \\
\text { de } \mathrm{H}_{2} \mathrm{O}\end{array}$ & $\begin{array}{c}\text { Fórmula } \\
\text { Empírica }\end{array}$ & Nome do Complexo \\
\hline $\begin{array}{c}\text { Sulfadimetoxina } \\
\text { Sulfisoxazol }\end{array}$ & 4 & - & $\mathrm{C}_{24} \mathrm{H}_{30} \mathrm{O}_{9} \mathrm{~N}_{8} \mathrm{~S}_{2} \mathrm{Cu}$ & {$\left[\mathrm{Cu}(\text { Sulfadimetoxina) })_{2}\right]$} \\
\hline
\end{tabular}

Na figura 3 são apresentadas as estruturas dos complexos formados.

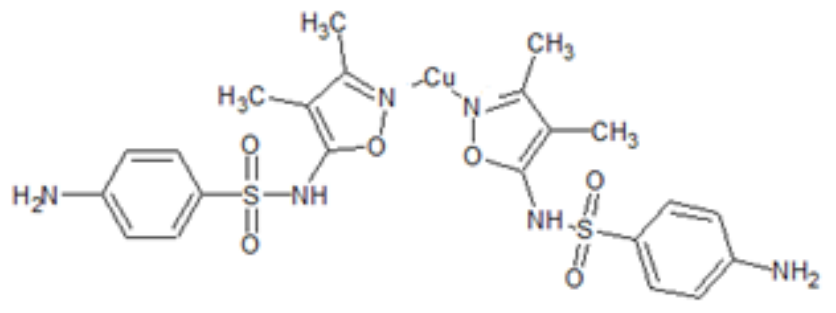

(a)

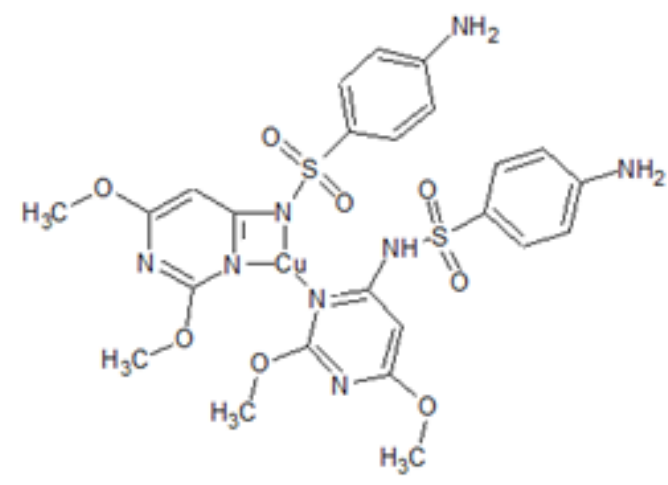

(b)

Figura 3 - Estruturas químicas dos complexos utilizados neste trabalho (a) $\left[\mathrm{Cu}(\text { Sulfisoxazol })_{2}\left(\mathrm{H}_{2} \mathrm{O}\right)_{4}\right]$ e (b) $\left[\mathrm{Cu}(\text { Sulfadimetoxina })_{2}\right]$.

O conhecimento detalhado do modo de ação desses complexos pode contribuir para o desenvolvimento de possíveis fármacos. Um evento importante e fundamental na interação com tecidos biológicos em um nível molecular é a associação com membranas. A relevância dos estudos das interações complexo-membrana fundamenta-se nos possíveis envolvimentos de ligações desses complexos a proteínas de membranas e/ou na indução de modificações na estrutura lipídica, fazendo com que algum sinal extracelular seja transduzido para o meio intracelular, e/ou nos processos de interação não-específica dos complexos com a membrana lipídica e que permitam sua permeação para o interior celular.

Mais especificamente, as interações entre os complexos e lipídios podem influenciar na ação dos receptores e/ou outras proteínas de membrana, que são componentes do mecanismo de transdução do sinal celular (31), podem estar envolvidas nos próprios 
mecanismos de ação da membrana (32), além de a membrana lipídica poder ser o próprio alvo, já que grande número de drogas se liga ativamente às bicamadas, podendo interferir nas reações lipídio/proteína, até mesmo descartando proteínas periféricas (33) e ainda influenciar no processo de formulação de lipossomos e na liberação da droga pelos lipossomos (34). Percebe-se, portanto, a relevância dos estudos dessas interações para um entendimento mais detalhado de seus mecanismos de ação, bem como as modificações induzidas por eles em membranas biológicas.

Os processos biológicos geralmente envolvem vários eventos complexos. Para que se ganhe informação sobre a contribuição de cada componente em um dado processo biológico pode-se buscar estudar eventos independentes e controlados, utilizando para este fim, sistemas simplificados, que contenham algumas das características fundamentais e conhecidas do processo. Em fenômenos que envolvem membranas celulares, muito tem se entendido a partir da utilização de miméticos dessas membranas, que carreguem composições representativas de fosfolipídios e outras moléculas relevantes para aquilo que se quer investigar.

Os fosfolipídios são um grupo de lipídios que contém uma grande variedade de moléculas. A presença nas moléculas fosfolipídicas de regiões hidrofílicas (solúveis em água) e hidrofóbicas (insolúveis em água, porém solúveis em outros meios orgânicos) confere a propriedade anfifílica da estrutura, que influencia grandemente no seu comportamento físico-químico, sendo os blocos de construção de todas as membranas biológicas. Estas são basicamente compostas por um arranjo fosfolipídico em bicamada, onde há regiões apolares de moléculas lipídicas, que ficam no meio da bicamada e de suas cabeças polares que estão viradas para fora da bicamada, interagindo com a fase aquosa de cada lado (figura 4a). As proteínas são incorporadas na bicamada, mantidas por interações hidrofóbicas entre os seus domínios hidrofóbicos e a membrana lipídica. Algumas proteínas sobressaem em ambos os lados da membrana e algumas são expostas somente a um lado da mesma, dando assim um caráter de unilateralidade. As unidades individuais de lipídio e proteína na membrana formam um mosaico fluido com um padrão, que ao contrário do mosaico de cerâmica, é livre para mudar constantemente. A membrana mosaica é fluida por causa da interação nãocovalente entre os componentes, deixando moléculas individuais de lipídios e proteínas livres para se moverem lateralmente no plano da membrana (35). 
Logo, a estrutura de bicamada fosfolipídica em meio aquoso pode ser selecionada como um modelo simples e próximo de membranas biológicas (figura 4b). Este modelo de membrana pode conter apenas um único lipídio sintético ou uma mistura de vários lipídios sintéticos e/ou naturais $(36,37)$.
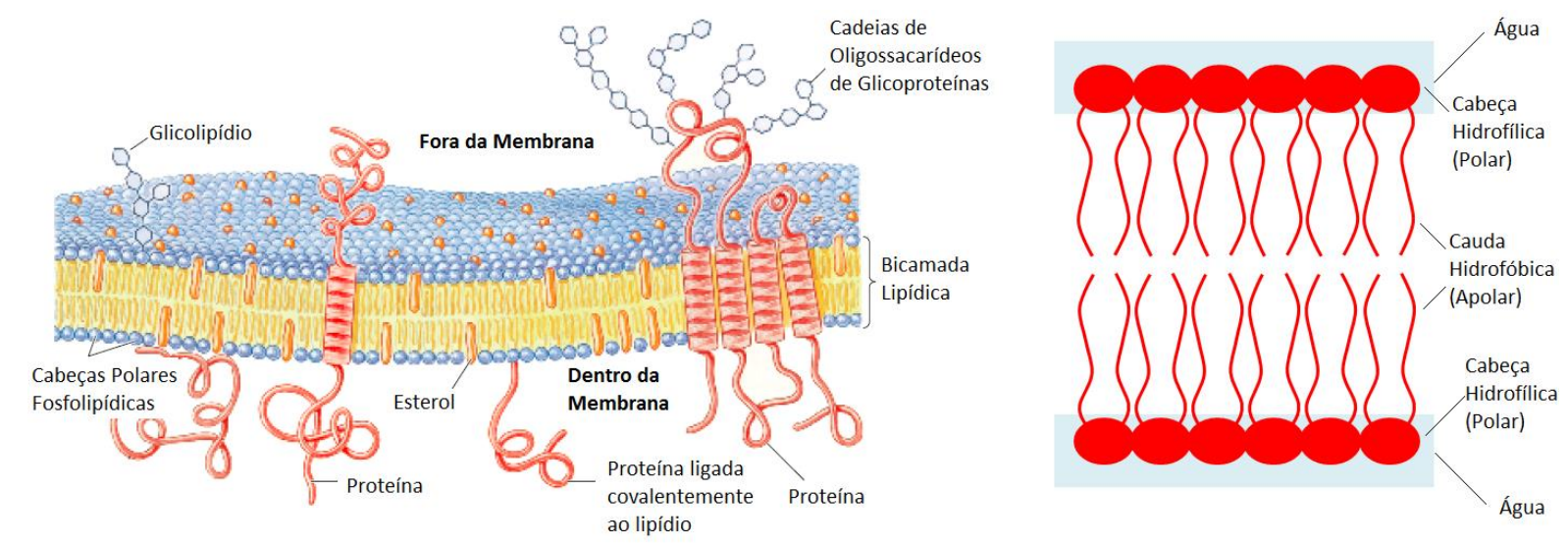

Figura 4 - (a) Modelo de mosaico fluido para a estrutura da membrana. A cadeia acila no interior da membrana forma um fluido, região hidrofóbica. As proteínas integrais flutuam neste "mar" de lipídio, mantidas por interações hidrofóbicas com suas cadeias laterais de aminoácidos apolares. Proteínas e lipídios são livres para se moverem lateralmente no plano da bicamada, mas os movimentos para as faces da mesma são restritos. As porções de carboidratos anexadas a algumas proteínas e lipídios na membrana plasmática são expostas à superfície extracelular da membrana. Figura adaptada de (38). (b) Esquema ilustrativo da membrana modelo. Bicamada lipídica formada pela exposição dos fosfolipídios a um meio aquoso, devido a seu caráter anfifílico.

Em modelos de membrana compostos de uma única espécie lipídica, os fosfolipídios são caracterizados por uma temperatura de transição de fase $\left(T_{M}\right)$, na qual, em geral, a membrana passa de uma fase gel, onde a cadeia hidrocarbonada do lipídio está em um estado ordenado, para uma fase de líquido cristalino, onde as moléculas ficam com movimentos mais livres e os grupos hidrofílicos agrupados tornam-se completamente hidratados (39). O comprimento e a saturação da cadeia lipídica influenciam o valor de $T_{M}$. O arranjo estrutural adotado pelos fosfolipídios é, portanto, caracterizado por uma dinâmica molecular que muito influencia o seu papel fisiológico. Por exemplo, membranas compostas por lipídios distintos podem exibir diferentes níveis de fluidez na mesma temperatura (40, 41). Em face disso, aqui se convenciona falar em uma estrutura dinâmica da membrana lipídica. 
Para o estudo da estrutura dinâmica das membranas lipídicas e da sua interação com os complexos podem ser utilizadas diferentes técnicas físicas, como calorimetria, fluorescência, espectroscopia de absorção, ressonâncias magnética nuclear e paramagnética eletrônica, dentre outras (34, 42-44).

Dentre estas técnicas, a calorimetria é a única que mede diretamente a termodinâmica das interações que estabilizam as estruturas das macromoléculas biológicas, permitindo a caracterização completa do sistema. Estudos de transição de fase e variação do comportamento termotrópico das vesículas lipídicas na presença de agentes externos são obtidos através da calorimetria de varredura diferencial (DSC, do inglês Differential Scanning Calorimetry). Os parâmetros termodinâmicos obtidos através dessa técnica podem levar a uma maior compreensão dos mecanismos envolvidos nas interações compostos-membranas (45).

A ressonância paramagnética eletrônica (RPE), por sua vez, tem dado contribuições significativas na identificação e caracterização de fases lipídicas em diferentes sistemas e no estudo de interações fármacos-lipídios, peptídeos-lipídios, etc. Esta técnica é de grande utilidade nos estudos das interações e permite monitorar, por exemplo, a penetração de moléculas através da membrana. Sondas paramagnéticas na forma de derivados de fosfolipídios, denominadas marcadores de spin, são incorporadas nos sistemas e com o uso de sondas adequadas, a estrutura das bicamadas, assim como a dinâmica das cadeias acila dos fosfolipídios em diferentes profundidades, podem ser monitoradas. Modificações das propriedades das membranas quando da interação com os complexos são evidenciadas por mudanças nos espectros de RPE (46).

Neste trabalho apresentamos o estudo das interações entre modelos de membranas biológicas e complexos de cobre-sulfonamidas com interesse farmacológico. Para isso, foram utilizadas as técnicas de DSC e RPE, no intuito de investigar os efeitos induzidos pelos compostos na estrutura e dinâmica das cadeias lipídicas das membranas, bem como no comportamento termotrópico das bicamadas lipídicas. Para tal, as etapas desenvolvidas serão detalhadas e organizadas nesta dissertação ao longo das próximas seções. Iniciamos no capítulo 2 com a apresentação das etapas experimentais, como a descrição da preparação das amostras, detalhes dos equipamentos utilizados na caracterização e uma breve explicação sobre os fundamentos teóricos das técnicas utilizadas, como o DSC, RPE e 
um pouco sobre a técnica de marcador de spin. No capítulo 3 serão descritos os resultados obtidos e uma discussão geral dos dados. E por fim no capítulo 4 serão discutidas as informações obtidas e detalhadas dos capítulos anteriores e as conclusões finais. 


\section{Materiais e Métodos}

Neste capítulo são descritos todos os procedimentos envolvidos na preparação das amostras para as medidas de DSC e RPE, algumas considerações teóricas sobre as técnicas empregadas e as metodologias utilizadas para o tratamento e análise dos dados experimentais obtidos.

\subsection{Materiais}

O fosfolipídio 1,2-dipalmitoil-sn-glicero-3-fosfocolina (DPPC) e os marcadores de spin em diferentes posições da cadeia acila 1-palmitoil-2-estearoil-(n-doxil)-fosfatidilcolina ( $n=5$, 12 e 16-PCSL) foram adquiridos comercialmente das empresas Avanti Polar Lipids, Inc. (Alabaster, AL) e Sigma Chemical Co. (St. Louis, MO). Todos esses materiais foram utilizados sem outros procedimentos de purificação que não aqueles realizados pelos respectivos fabricantes.

Os complexos utilizados, já mencionados anteriormente no capítulo 1, Cu-SDM e CuSFZ, foram cedidos pela Prof ${ }^{a}$ María H. Torre, da Universidade de La República do Uruguai e são sintetizados rotineiramente por nossos colaboradores através de procedimentos que envolvem a interação dos ligantes com uma solução de $\mathrm{Cu}(\mathrm{II})$, segundo o protocolo das referências (29) e (47).

Abaixo temos as estruturas químicas do fosfolipídio e dos marcadores de spin utilizados neste trabalho. As estruturas dos complexos estão apresentadas na figura 3 do capítulo 1. 


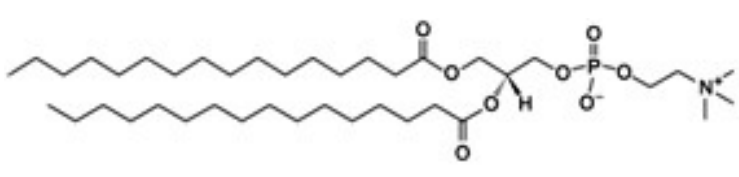

(a)

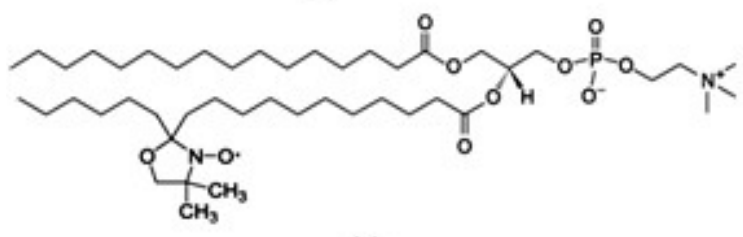

(c)

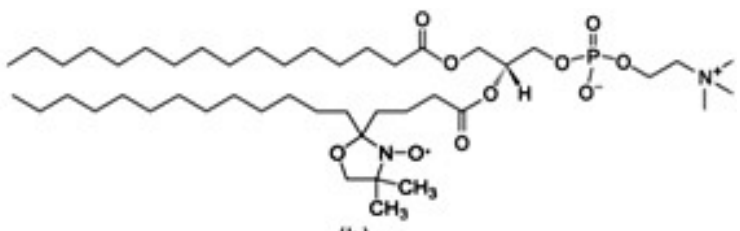

(b)

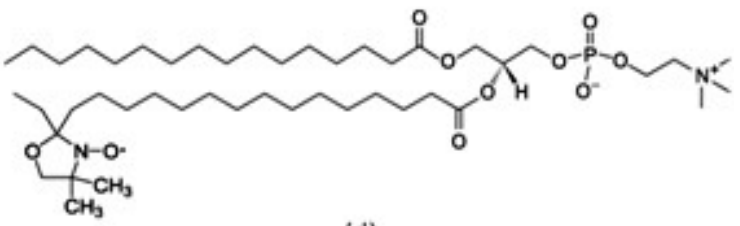

(d)

Figura 5 - Estruturas químicas do fosfolipídio (a) 1,2-dipalmitoil-sn-glicero-3-fosfocolina (DPPC) e dos lipídios marcados (b) 1-palmitoil-2-(5-doxil estearoil) fosfatidilcolina (5-PCSL), (c) 1-palmitoil-2-(12-doxil estearoil) fosfatidilcolina (12-PCSL) e (d) 1- palmitoil-2-(16-doxil estearoil) fosfatidilcolina (16-PCSL). Figura adaptada de (48).

\subsection{Preparação das amostras}

Nesta seção é descrito o procedimento para a preparação de todas as amostras a serem utilizadas nos experimentos, tanto de RPE, como de DSC.

Primeiramente são feitas soluções em clorofórmio dos lipídios e marcadores de spin. A massa total de lipídios em cada preparação foi de $0,5 \mathrm{mg}$ para as medidas de RPE e 0,7 mg para as medidas de DSC e a concentração de marcador de spin é calculada em 0,5 mol\% do lipídio presente na amostra. Em seguida, as soluções preparadas são misturadas em tubos cônicos de vidro, sendo que para as medidas de RPE são misturados lipídio e marcador de spin e para as medidas de DSC são usadas somente as soluções de lipídio. Após a mistura, a solução final é evaporada sob um fluxo de nitrogênio, até a total evaporação e a formação de um filme fino nas paredes do tubo. Este filme é então deixado em um dessecador conectado a uma bomba a vácuo, por no mínimo 2 horas, para que todo o solvente seja eliminado. 
Por outro lado, as soluções dos complexos cobre-sulfonamidas são preparadas em água deionizada. Para ajudar na solubilização dos complexos em água, as soluções são deixadas por aproximadamente 12 minutos em um sonicador.

Uma vez retirados os tubos de vidro contendo os filmes de lipídios do ambiente a vácuo, estes são hidratados com volume adequado de água deionizada ou com a solução de água deionizada mais um dos complexos estudados. No caso de amostra contendo vesículas lipídicas e complexos, foi usada uma proporção de complexo:lipídio de 1:5, sendo a concentração final de lipídios de $10 \mathrm{mg} / \mathrm{mL}$ para as medidas de RPE e $1 \mathrm{mg} / \mathrm{mL}$ para as medidas de DSC.

\subsection{Medidas de DSC}

O efeito dos complexos de cobre nas transições de fase das vesículas de DPPC foi observado usando o calorímetro N-DSC II da Calorimetry Science Corporation, que se encontra no Departamento de Química da Faculdade de Filosofia, Ciências e Letras de Ribeirão Preto (FFCLRP), no Laboratório de Nanotecnologia Aplicada: Sistemas Miméticos de Biomembranas, coordenado pelo Prof. Dr. Pietro Ciancaglini. Todas as amostras foram preparadas conforme o procedimento acima descrito. Em cada experimento, foi utilizada uma taxa de fornecimento de calor às amostras de $0,33{ }^{\circ} \mathrm{C} / \mathrm{min}$ em um intervalo de $10 \mathrm{a}$ $60{ }^{\circ} \mathrm{C}$. Foram realizadas duas varreduras, uma para o aquecimento e outra para o resfriamento da amostra.

A manipulação e análise dos termogramas, que envolveram a subtração da resposta calorimétrica do tampão, correção da linha de base e integração dos picos calorimétricos provenientes das transições de fase das vesículas de DPPC, foram realizadas usando-se o software CPCalc, fornecido pela Science Corporation. 


\subsection{Medidas de RPE}

As medidas de RPE foram realizadas nos espectrômetros Jeol JES FA200, que se encontra no Departamento de Física da FFCLRP/USP, no Laboratório de Biofísica Molecular, e no espectrômetro Varian E109, disponível no Instituto de Física de São Carlos (ISFC/USP), no Grupo de Biofísica Molecular "Sérgio Mascarenhas". Ambos os equipamentos operam em banda $X(9,4 \mathrm{GHz})$, no modo de onda contínua $(\mathrm{CW})$ e possuem controladores de temperatura. As medidas de RPE dos compostos em membranas foram feitas com os lipídios da membrana marcados. Medidas com diversos marcadores de spin (5, 12 e 16-PCSL) foram usadas para monitorar alterações na estrutura e dinâmica dos fosfolipídios quando da presença dos complexos. Para as medidas, as amostras foram transferidas para tubos capilares da marca Satelit (diâmetro de 1,5 mm e volume de $50 \mu \mathrm{L}$ ) para garantir a concentração da dispersão lipídica em uma de suas extremidades. Esse procedimento é usualmente utilizado com o intuito de aumentar a relação sinal-ruído das amostras nas medidas de RPE através da diminuição do excesso de água no tubo de medida.

Os parâmetros de operação do equipamento comuns a todas as amostras foram: varredura do campo magnético de $160 \mathrm{G}$, tempo de varredura de 2 minutos, frequência de modulação de $100 \mathrm{kHz}$, constante de tempo de 0,064 s, potência de microondas de $10 \mathrm{~mW}$ e amplitude de modulação do campo de $1 \mathrm{G}$. O capilar com a amostra foi colocado em um tubo de quartzo contendo um banho de óleo mineral comercial e posicionado no centro da cavidade ressonante. O óleo mineral dentro dos tubos de quartzo foi utilizado para garantir a estabilização da temperatura da amostra dentro do capilar e aumentar a confiabilidade das medidas. A variação da temperatura se concentrou no intervalo de 20 a $55{ }^{\circ} \mathrm{C}$, pois a membrana modelo utilizada (DPPC) possui transição de fase principal em torno de $41^{\circ} \mathrm{C}$. 


\subsection{Métodos}

Nesta seção são apresentadas as considerações teóricas sobre as técnicas empregadas no estudo da interação dos complexos com modelos de membranas, que foram utilizadas para o tratamento dos dados experimentais e obtenção dos resultados.

\subsubsection{Calorimetria Diferencial de Varredura (DSC)}

A calorimetria diferencial de varredura é a técnica mais utilizada para se determinar efeitos térmicos em uma variedade de materiais, incluindo sistemas biologicamente relevantes. Ela mede diretamente as mudanças de calor que ocorrem em biomoléculas durante uma variação controlada de temperatura e, com isso, é possível se determinar dados termodinâmicos absolutos para transições termicamente induzidas (49).

Esta técnica pode elucidar os fatores que contribuem para o enovelamento e estabilidade das biomoléculas, incluindo interações hidrofóbicas, ligação de hidrogênio, entropia conformacional e ambiente físico. Por isso, é frequentemente utilizada no estudo de estabilidade e enovelamento de proteínas, caracterização de membranas, lipídios, ácidos nucleicos e sistemas micelares, na avaliação dos efeitos das mudanças estruturais na estabilidade de moléculas, entre outros (50).

É também aplicada em estudos de transições de fase lipídicas, tanto em modelos de membranas quanto em membranas biológicas e em suas interações com pequenas moléculas, como hormônios, peptídeos, drogas e fármacos (51). O conhecimento dos efeitos causados por estas pequenas moléculas através da sua interação com membranas pode ser de fundamental importância na elucidação dos seus mecanismos de ação. Podem tanto apresentar os próprios lipídios como alvo específico, quanto introduzir mudanças estruturais e dinâmicas na estrutura da membrana, por exemplo, segregando domínios, que podem 
disparar sinais através de mudanças conformacionais em proteínas, possibilitando o acionamento de algum outro mecanismo ou evento biológico intracelular importante (52).

A DSC fornece informação acurada e rápida sobre as propriedades físicas e energéticas de um material. Ela verifica e mede a diferença de temperatura entre uma cela contendo a amostra de interesse e uma cela com um material de referência (a solução tampão utilizada na preparação da amostra, por exemplo), esta diferença de temperatura é calibrada em unidade de potência (quantidade de calor por unidade de tempo $-d q / d T$ ), que é, na realidade, uma diferença no fluxo de calor entre a cela da amostra relativa à cela da referência à pressão constante. As duas celas são mantidas na mesma temperatura por aquecimento diferencial. Até mesmo pequenas diferenças de temperatura entre elas acionam um dispositivo que aumenta ou diminui a quantidade de energia enviada para a amostra para manter a temperatura desta igual à da cela da referência. Se a capacidade calorífica da amostra é maior que a da referência, deve-se fornecer energia mais rapidamente para a cela da amostra. Se uma transição de fase ocorre na amostra, muita energia deve ser transferida para a mesma até que a transição de fase se complete e a temperatura comece a aumentar novamente. O resultado obtido na DSC é uma medida da energia transferida para a amostra. Em um único experimento pode-se determinar o ponto de transição médio, a entalpia e a mudança de capacidade calorífica.

A capacidade calorífica a pressão constante pode ser definida por:

$$
C_{p}=(\partial q / \partial T)_{p}
$$

onde T é a temperatura e q é o calor absorvido a pressão constante. Se a temperatura varia de $T_{0}$ a $T_{1}$, a entalpia calorimétrica da reação é:

$$
\Delta H_{c a l}=\int_{T_{0}}^{T 1} C_{p}(T) d T
$$

e pode ser determinada através da área sob a curva do termograma. 
O termograma ilustrado na figura 6 mostra um pico que evidencia uma mudança de fase e a diferença na linha de base, antes e depois dessa transição, reflete a diferença das capacidades caloríficas das duas fases.

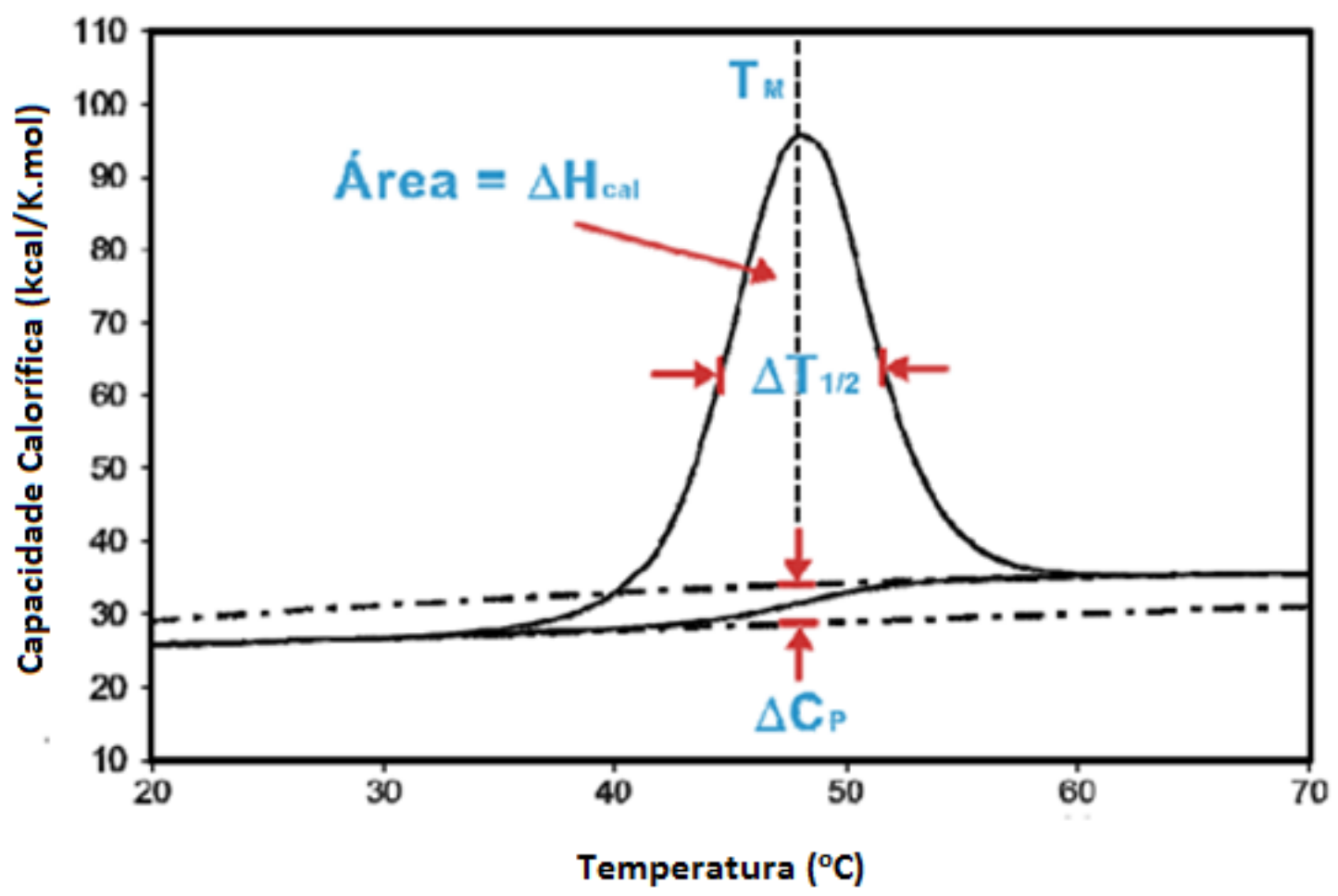

Figura 6 - Termograma de um biopolímero hipotético. A diferença de capacidade calorífica $\left(\Delta C_{P}\right)$ do evento térmico é caracterizada pela temperatura de transição de fase $\left(T_{M}\right.$, temperatura de melting), onde a capacidade calorífica atinge um máximo. A entalpia calorimétrica, $\Delta \mathrm{H}_{\mathrm{cal}}$, é a área sob a curva, que é dependente com a temperatura da capacidade calorífica da amostra à pressão constante. Figura adaptada de (53).

Através do termograma podemos encontrar mais alguns parâmetros termodinâmicos importantes que caracterizam uma molécula biológica, como a temperatura de transição de fase, $T_{M}$, que é aquela na qual a capacidade calorífica atinge um máximo. Outro parâmetro importante está relacionado com o grau de cooperatividade do processo experimentado pelas moléculas na amostra. Quanto menor a largura em temperatura à meia altura na curva de transição, $\Delta T_{1 / 2}$, maior será a cooperatividade naquele processo termodinâmico. Os valores de $\Delta T_{1 / 2}$ podem variar desde cerca de $0,1{ }^{\circ} \mathrm{C}$, para fosfolipídios sintéticos muito puros 
até 10 a $15{ }^{\circ} \mathrm{C}$ para membranas biológicas. Dos valores de $T_{M}$ e $\Delta T_{1 / 2}$, podemos determinar a entalpia de van't Hoff, $\Delta \mathrm{H}_{\mathrm{VH}}$, para uma transição de fase em um fosfolipídio (54):

$$
\Delta H_{V H} \cong 6,9 \frac{T_{M}^{2}}{\Delta T_{1 / 2}}
$$

A razão entre as entalpias calorimétricas e de van't Hoff nos fornece o valor da unidade de cooperatividade (55), n:

$$
n=\frac{\Delta H_{V H}}{\Delta H_{c a l}} \propto \frac{1}{\Delta T_{1 / 2}}
$$

Este parâmetro é uma medida indireta do grau de cooperação intermolecular entre os fosfolipídios em uma vesícula (56), por exemplo.

Resumindo, a técnica de DSC é uma ferramenta analítica de fácil manuseio e comparativamente mais simples e muito útil no estudo termodinâmico de transições de fase lipídicas, permitindo o entendimento de mudanças entálpica e entrópica que ocorrem quando um biopolímero passa por um evento termodinamicamente induzido e os efeitos causados por agentes externos quando interagem com ele.

\subsubsection{Estudo do fosfolipídio DPPC}

Como neste trabalho utilizamos um modelo de membrana constituído pelo fosfolipídio DPPC, apresentamos nesta seção uma breve descrição do seu comportamento termotrópico (57). O fosfolipídio DPCC quando totalmente hidratado e completamente equilibrado pela incubação prolongada à baixa temperatura possui uma forma altamente ordenada e condensada, que é a chamada fase cristalina (fase $L_{c}$ ), na qual a cadeia hidrocarbônica está totalmente estendida e a região interfacial da bicamada lipídica é parcialmente desidratada. Nesta fase, o grupo fosfato está relativamente imóvel. Após o 
aquecimento, a fase $L_{c}$ passa por uma transição (a subtransição) para a fase gel tilted (fase $\left.L_{B}{ }^{\prime}\right)$, por volta de $21,2^{\circ} \mathrm{C}$, onde há um aumento na mobilidade do grupo fosfato e uma maior penetração de água na região interfacial. Aquecendo-se mais a fase $L_{b}{ }^{\prime}$, tem-se um progressivo aumento da mobilidade da cabeça do fosfolipídio e, eventualmente, a conversão para a fase gel rippled (fase $P_{b}{ }^{\prime}$ ), em torno de $34,2{ }^{\circ} \mathrm{C}$, que é a chamada pré-transição. Nessa fase, a superfície da bicamada tem a aparência de ondulações. Com um aquecimento adicional a fase $P_{b}{ }^{\prime}$ induz a fusão cooperativa das cadeias acila, onde ocorre à transição principal desta fase para a fase líquido-cristalino, a fase $L_{\alpha}$, que ocorre em torno de $41,4{ }^{\circ} \mathrm{C}$ para o DPPC. Na figura abaixo está representado todo esse processo de transição (57).

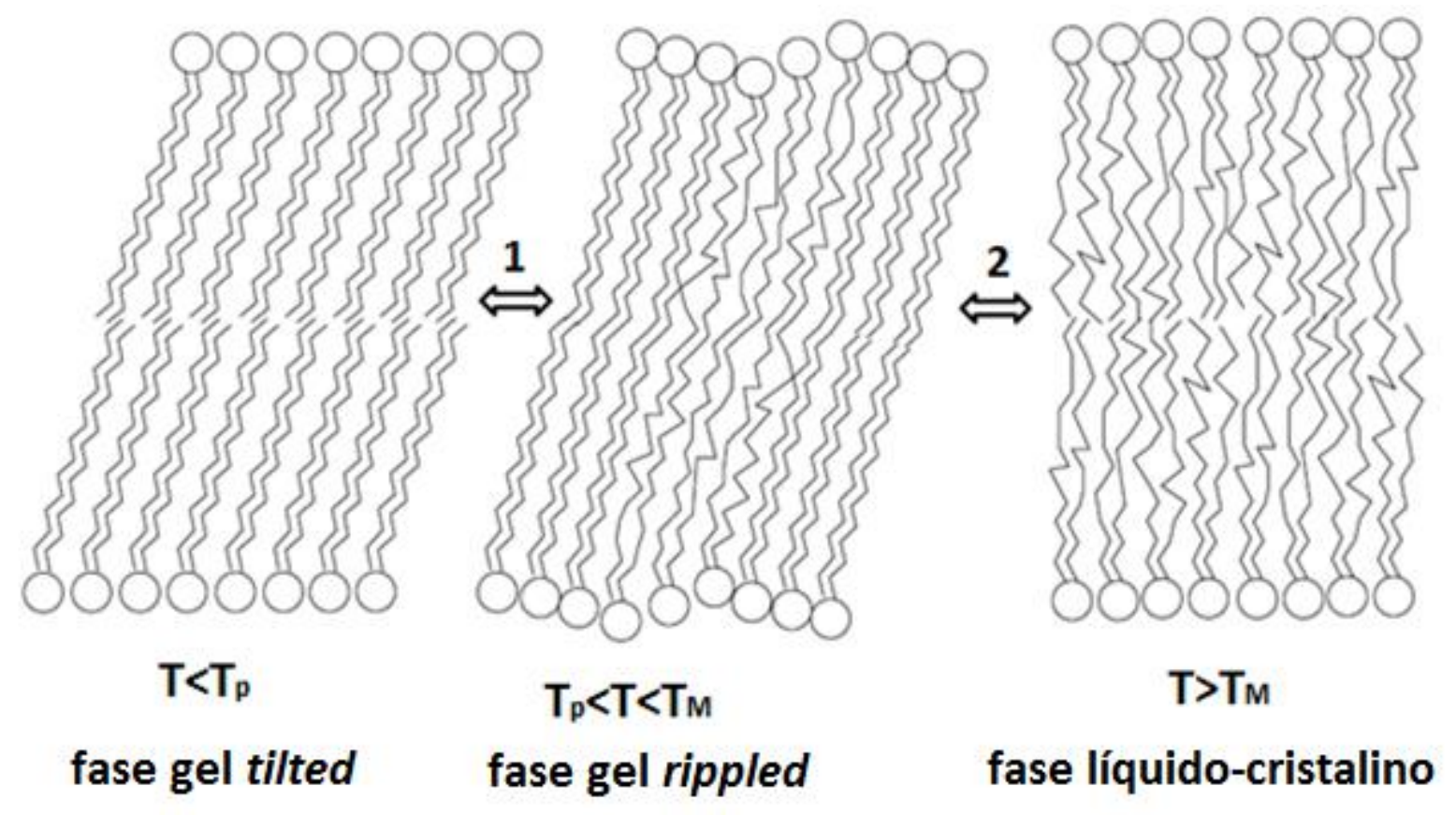

Figura 7 - Transições de fase de vesículas lipídicas de DPPC. O evento 1 se refere à chamada pré-transição, surgida da conversão da fase gel $L_{\beta^{\prime}}$ para a fase rippled $P_{\beta^{\prime}}$ e o evento 2, denominado de transição principal, surge da conversão da fase $P_{\beta^{\prime}}$ para a fase líquidocristalino, $\mathrm{L}_{\alpha}$. Figura adaptada de (49). 


\subsubsection{Ressonância paramagnética Eletrônica (RPE)}

A ressonância paramagnética eletrônica lida com a interação entre radiação eletromagnética e momentos magnéticos associados ao elétron (58). Esta espectroscopia é uma técnica que só pode ser aplicada a sistemas que possuem elétrons desemparelhados, ou seja, que possuem momento angular de spin diferente de zero e se baseia na interação do momento magnético associado com o componente magnético da radiação eletromagnética, ocorrendo à transição entre diferentes estados de spin. A transição é dependente do desdobramento do momento de dipolo magnético do elétron, $\mu_{\mathrm{e}}$, em diferentes níveis de energia pela interação com um campo magnético externo $H$, denominada interação Zeeman, que é mostrada na figura 8. A condição de ressonância para que haja a transição entre os dois níveis é obedecida quando:

$$
h v=g \beta H=\Delta E
$$

onde $\mathrm{h}$ é a constante de Planck, $v$ é a frequência da radiação eletromagnética, $\mathrm{H}$ é o campo magnético, $\beta$ o magnéton de Bohr e g, uma constante de proporcionalidade cujo valor depende das espécies magnéticas em consideração, valendo 2,00232 para um elétron livre. 


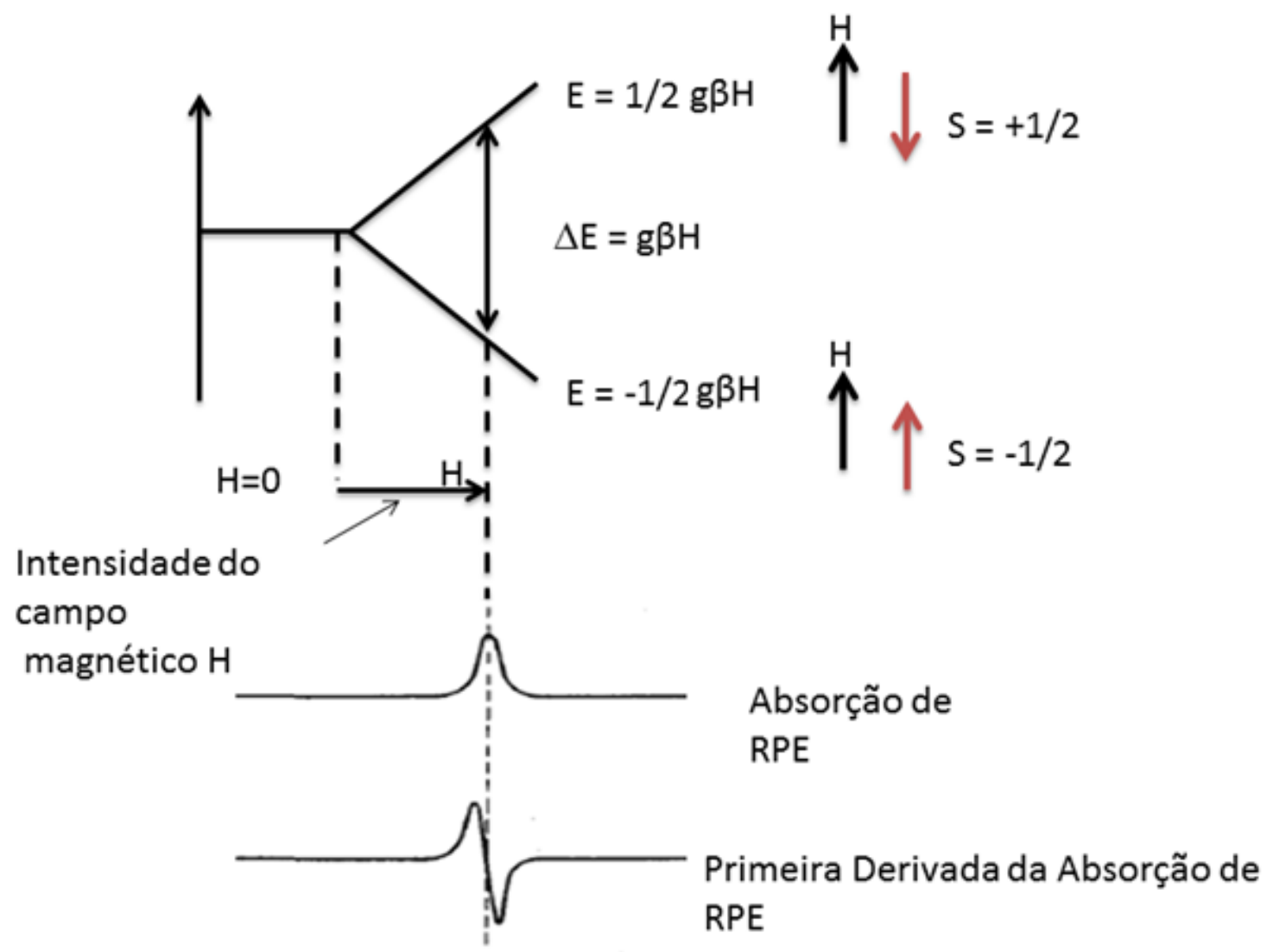

Figura 8 - Diagrama do desdobramento dos níveis de energia Zeeman na presença de um campo magnético $\mathrm{H}$. A energia dos níveis é dada por $\mathrm{E}= \pm 1 / 2 \mathrm{~g} \beta \mathrm{H}$. À direita é representada $\mathrm{a}$ interação dos vetores campo magnético (preto) e momento de dipolo magnético de spin (vermelho). Abaixo está representado o espectro de absorção, bem como a primeira derivada deste. Figura adaptada de (59).

As transições entre os níveis de energia Zeeman envolvem a reorientação do spin eletrônico. Essas transições envolvem radiação eletromagnética na frequência de microondas e ao contrário de muitas técnicas espectroscópicas, nas quais a frequência da radiação eletromagnética incidida na amostra é variada, na espectroscopia de RPE, por particularidades do hardware da técnica, a frequência da radiação eletromagnética é fixa e o campo magnético externo é variado. 


\subsubsection{Método de Marcador de Spin}

Como dito anteriormente, a aplicação da espectroscopia de RPE exige a presença de elétrons desemparelhados no sistema em estudo. No entanto, a maioria dos sistemas biológicos é diamagnética, ou seja, não possuem momento de dipolo magnético não-nulo, não produzindo assim sinais de RPE. Um recurso muito utilizado atualmente para se estudar tais sistemas através desta técnica, proposto originalmente por Mc Connel e colaboradores em 1965 (59), envolve a utilização do método de marcadores ou sondas de spin. Duas vantagens deste método são a sua especificidade e a simplicidade dos espectros de RPE obtidos.

O marcador de spin é uma molécula orgânica portadora de um radical livre paramagnético estável, podendo a princípio ser qualquer espécie paramagnética, porém na prática, as sondas de spin são geralmente do tipo nitróxido, ou seja, moléculas que contém um fragmento paramagnético N-O. Este fragmento é introduzido em moléculas maiores e feito estável em condições de $\mathrm{pH}$ e temperatura fisiológicas. A estrutura química do radical nitróxido é apresentada na figura 9. O elétron desemparelhado está distribuído na ligação $\mathrm{N}-\mathrm{O}$ e o radical pode ser anexado a uma molécula maior através de $R_{1}$ e $R_{2}$, sendo sua notável estabilidade devida, em parte, pela proteção estérica da ligação NO pelos quatro grupos metila adjacentes. Devido a isto, as outras partes da mesma molécula podem ser facilmente modificadas sem o envolvimento do elétron desemparelhado do grupo NO, formando assim os diversos marcadores de spin de radicais nitróxidos (60). 


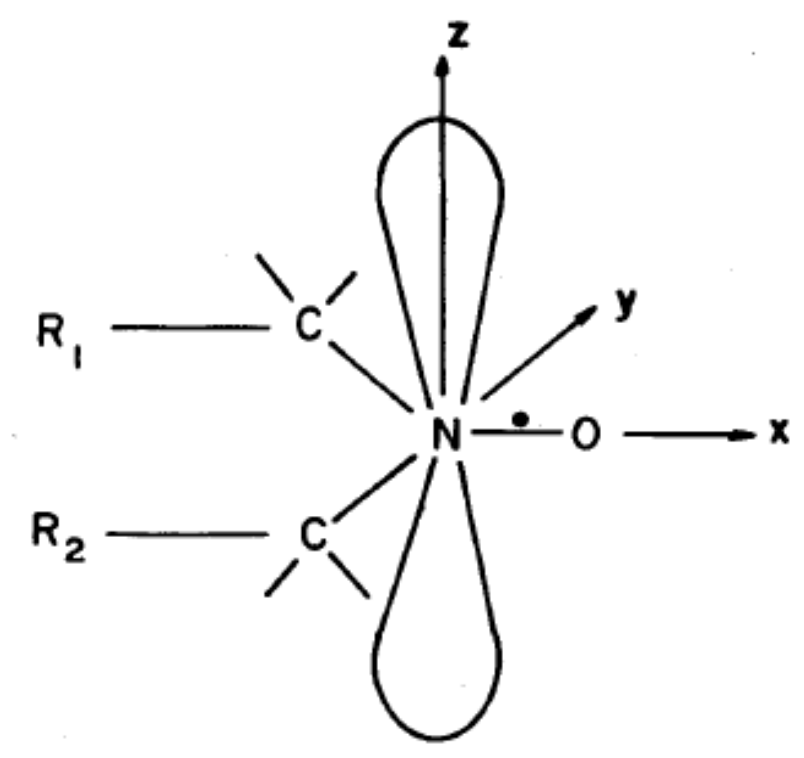

Figura 9 - Estrutura química geral de um radical nitróxido e representação do sistema de coordenadas molecular em que se determinam os tensores magnéticos típicos na espectroscopia de RPE. Figura adaptada de (60).

A localização do marcador de spin no sistema em que está inserido pode, normalmente, ser bem definida e o espectro pode ser utilizado de muitas maneiras. A informação mais simples que o espectro contém é a concentração de spins, usado para acompanhar a incorporação de moléculas marcadas ou mudanças da concentração em função do tempo. Análises das posições e formas das linhas, tanto em sistemas isotrópicos (soluções líquidas) quanto em anisotrópicos (cristais líquidos, membranas, sólidos) podem fornecer informações sobre a taxa de movimento da sonda e sobre a estrutura, ordem, viscosidade e polaridade do sistema em si (34).

Como estamos interessados no estudo de interações de pequenas moléculas com modelos de membranas, é comum utilizar o grupo N-O ligado a fosfolipídios, ácidos graxos ou seus derivados, com o objetivo de monitorar a estrutura dinâmica do ambiente lipídico em torno do marcador. Para isso, os marcadores são intercalados fisicamente em bicamadas lipídicas como mostrado na figura 10. O ordenamento e a dinâmica do marcador no sistema de interesse refletem contribuições tanto da estrutura molecular em torno do centro paramagnético quanto da fluidez desse microambiente.

Neste trabalho, o marcador consiste de um fosfolipídio contendo o radical nitróxido, ligado covalentemente à molécula repórter, outra designação para estas sondas de spin, 
fundamentada no fato de que uma vez inseridos nos sistemas biológicos, essas moléculas dão informações sobre o meio em que se encontram, assim reportando-os.

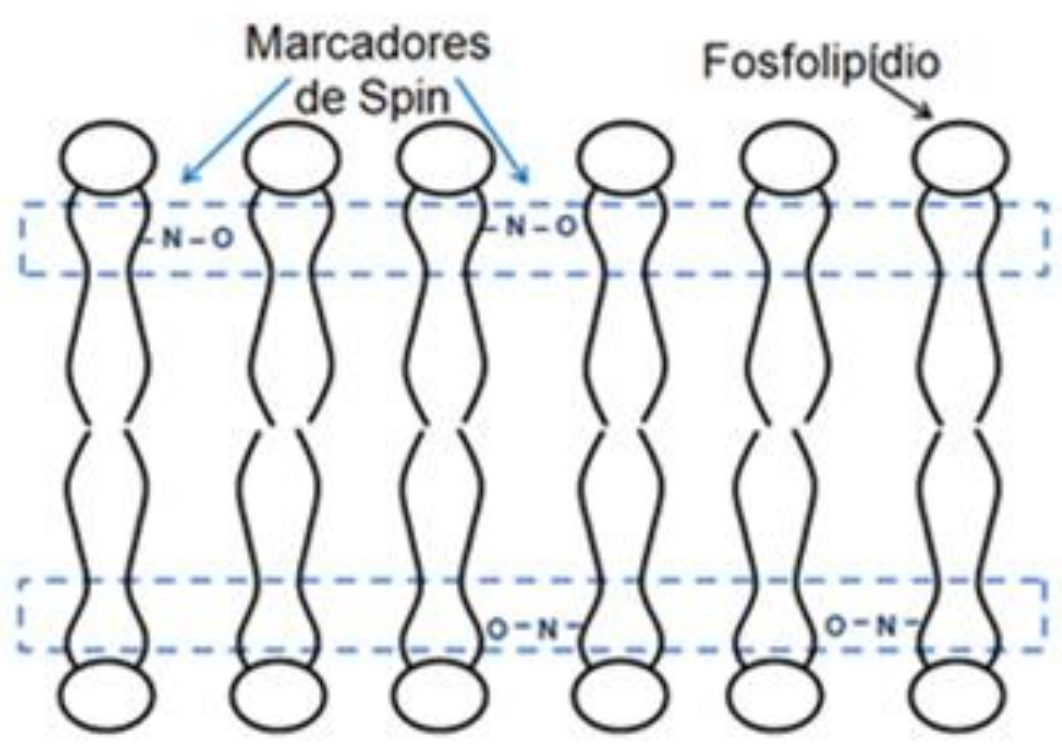

Figura 10 - Esquema ilustrativo dos marcadores de spin 5-PCSL intercalados com fosfolipídios em bicamadas. A linha tracejada refere-se à região mais fortemente monitorada pela sonda de spin.

\subsubsection{Anisotropia espectral}

Uma das características do espectro de RPE é que em muitos casos a posição e o desdobramento das linhas dependem da direção do campo magnético externo em relação aos eixos moleculares. A anisotropia espectral é muito importante na interpretação do espectro de íons de metais de transição e é também a base fundamental da utilização do método de marcadores de spin.

Os efeitos do desdobramento anisotrópico e os valores de g são mais facilmente entendidos considerando o espectro de um nitróxido introduzido em um cristal. A anisotropia espectral é normalmente especificada pelos três valores das componentes principais do tensor giromagnético $(\mathrm{g})$ e do tensor hiperfino $(\mathrm{A})$ que representa a interação 
entre os momentos magnéticos do núcleo de nitrogênio e do elétron desemparelhado. Tais tensores são descritos usualmente em um sistema cartesiano molecular, de tal maneira que o eixo x está ao longo da ligação NO, o eixo $z$ ao longo do orbital $2 p \pi$ e o eixo y perpendicular a ambos, como mostrado na figura 9. Os eixos principais de ambos os tensores, g e A, normalmente coincidem, porém, esta coincidência não é obrigatória.

Quando se aplica um campo magnético externo nas direções moleculares do radical nitróxido, observam-se comportamentos espectrais distintos. Estas mudanças estão relacionadas à perda de simetria do orbital atômico do átomo de nitrogênio do radical, produzindo interações distintas ao longo destas direções particulares. Se o campo magnético externo for aplicado ao longo do eixo z da molécula, onde estão localizadas $80 \%$ da densidade eletrônica, temos um maior desdobramento da constante de acoplamento hiperfino. Por outro lado, a constante hiperfina é menor quando o campo é aplicado ao longo das direções $x$ e y. $O$ fator $g$ também se modifica com a direção de aplicação do campo magnético. A componente $g_{z z}$ geralmente possui o menor valor, porque é a direção em que o elétron experimenta um ambiente químico que mais se aproxima de um elétron livre, ao passo que $g_{x x}$ é a componente que possui a maior diferença em relação ao fator $g$ do elétron livre. A figura 11 mostra a dependência do fator $\mathrm{g}$ e do desdobramento hiperfino com relação à direção do campo magnético aplicado.

O espectro de RPE de nitróxidos é bastante sensível ao ambiente no qual a molécula se encontra, em particular, à velocidade de tombamento da molécula (tempo de correlação rotacional, $\tau_{C}$ ). No caso do radical estar girando em solução, a forma do espectro se modifica de acordo com os diferentes regimes de movimento e a anisotropia do espectro não aparece, a molécula está num movimento rápido isotrópico $\left(\tau_{C}<10^{-9} \mathrm{~s}\right)$ e o espectro consiste neste caso de três linhas finas bem resolvidas equidistantes e de igual intensidade, pois ocorre uma média temporal dos valores de g e do desdobramento hiperfino. Os valores medidos correspondem aos valores médios, isto é,

$$
\begin{aligned}
& A_{0}=\frac{1}{3}\left(A_{x x}+A_{y y}+A_{z z}\right) \\
& g_{0}=\frac{1}{3}\left(g_{x x}+g_{y y}+g_{z z}\right)
\end{aligned}
$$




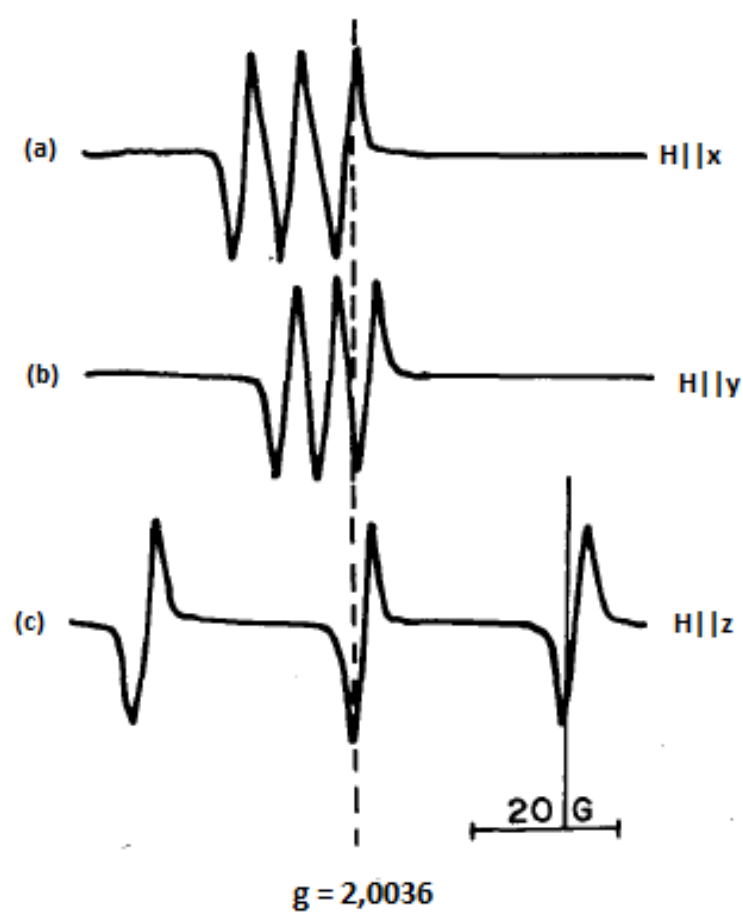

Figura 11 - Anisotropia espectral de um marcador de spin orientado em um monocristal. Campo magnético externo aplicado na direção (a) x, (b) y e (c) z. Figura adaptada de (59).

A velocidade de tombamento de um radical nitróxido determina as larguras relativas das linhas dos espectros: são estreitas para movimentos rápidos e se alargam à medida que o movimento se torna mais lento. A figura 12 mostra a dependência de espectros de RPE com o aumento de $\tau_{\mathrm{C}}$ devido ao aumento da viscosidade do meio. 


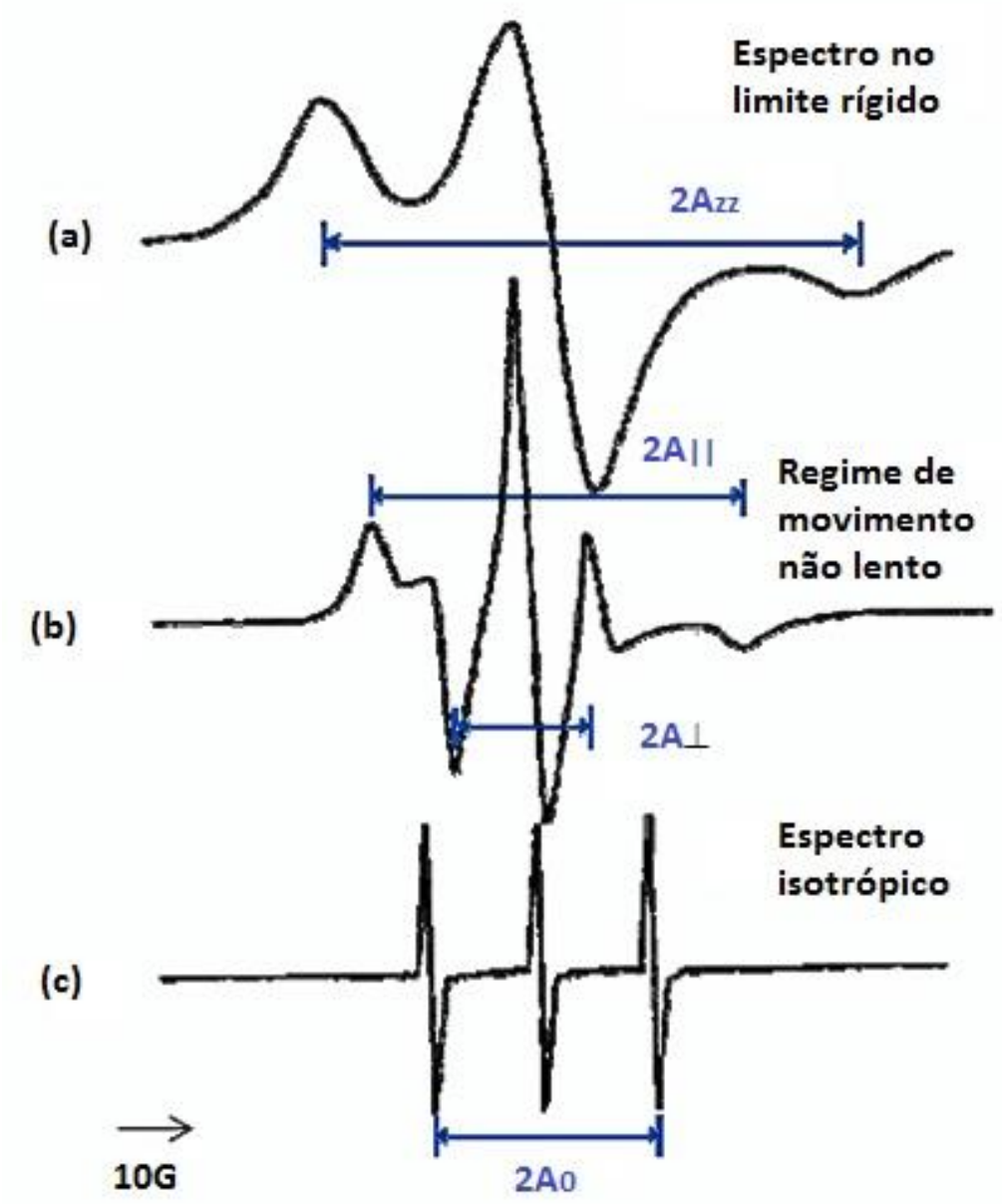

Figura 12 - Anisotropia do espectro de RPE do marcador de spin em várias condições: (a) espectro obtido de amostra policristalina ou solução congelada, (b) espectro de um radical nitróxido em uma dispersão lipídica, e (c) espectro isotrópico, radical em uma solução não viscosa. Figura adaptada de (59).

\subsubsection{Análise dos espectros de RPE}

Obtidos os espectros de RPE, duas metodologias são utilizadas para a análise dos dados experimentais: a análise convencional, baseada na definição de alguns parâmetros empíricos sobre o próprio espectro de RPE (60) e a utilização de simulações espectrais (61). 
Neste trabalho utilizamos apenas a análise convencional dos espectros, cuja metodologia será detalhada a seguir.

Na aplicação do método do marcador de spin em solução, um dos parâmetros mais importantes na análise dos resultados é o tempo de correlação rotacional, que reflete a dinâmica molecular. Existem várias teorias envolvendo a definição de parâmetros nos espectros que conduzem a fórmulas práticas para efetuar a avaliação do tempo de correlação do radical no sistema estudado. Geralmente são distinguidos três intervalos relativos ao grau de movimento do radical. Na região de movimento rápido onde o tempo de correlação, $\tau_{c}$, é menor de $10^{-9} \mathrm{~s}$, a sensibilidade dos espectros às mudanças de $\tau_{c}$ é muito boa e a maneira prática de avaliá-lo é a mais simples de todas. No regime de movimento lento, onde $10^{-9} \mathrm{~s}<\tau_{\mathrm{C}}<10^{-7} \mathrm{~s}$, o método ainda apresenta boa sensibilidade, no entanto, para obter avaliações melhores tem sido usada a técnica de simulação de espectros. A região de movimento "rígido" ( $\left.\tau_{\mathrm{C}}>10^{-7} \mathrm{~s}\right)$ é aquela em que os espectros apresentam menos sensibilidade.

É bem conhecido que alguns parâmetros empíricos definidos sobre o espectro de RPE podem nos fornecer informações valiosas a respeito da dinâmica e da estrutura dos marcadores de spin em membranas. Contudo, a escolha destes parâmetros depende do marcador de spin utilizado e de sua sensibilidade à temperatura, bem como da precisão das medidas do espectro.

O espectro da figura $12 \mathrm{c}$ apresenta três linhas estreitas de igual altura, onde as alturas das linhas de campo alto, central e baixo, são representadas, normalmente, por $\mathrm{h}_{-1}$, $h_{0}$ e $h_{+1}$, respectivamente. Onde os índices $-1,0$ e +1 se originam do número quântico do nitrogênio, $m_{1}$, que caracteriza cada uma das ressonâncias, que são mostrados na figura 13. As razões das amplitudes $h_{+1} / h_{0}$ e $h_{-1} / h_{0}$ são os melhores parâmetros a serem usados na análise dos espectros de sistemas com movimento anisotrópico, para marcadores de spin que possuem grande mobilidade. Um fato importante que deve ser mencionado é que para sondas monitoradas mais próximas ao centro da bicamada, a temperatura de transição principal do lipídio é mais abrupta que para as sondas próximas a superfície. Isto ocorre devido à variação da fluidez da membrana na temperatura de transição ser menos sensível á região dos marcadores próximos à superfície. A amplitude da linha de campo alto se estreita mais com o aumento da temperatura do que a amplitude da linha de campo baixo, fazendo 
com que o parâmetro $h_{-1} / h_{0}$ seja mais sensível do que $h_{+1} / h_{0}$ para análises acima da temperatura de transição. Quanto mais isotrópico o espectro, maior a fluidez e menor o empacotamento da membrana, nos dando ambas as razões se aproximando da unidade. Esses parâmetros são frequentemente utilizados com o marcador 16-PSCL, pois para os marcadores da cadeia acila de lipídios é o que apresenta maior mobilidade.

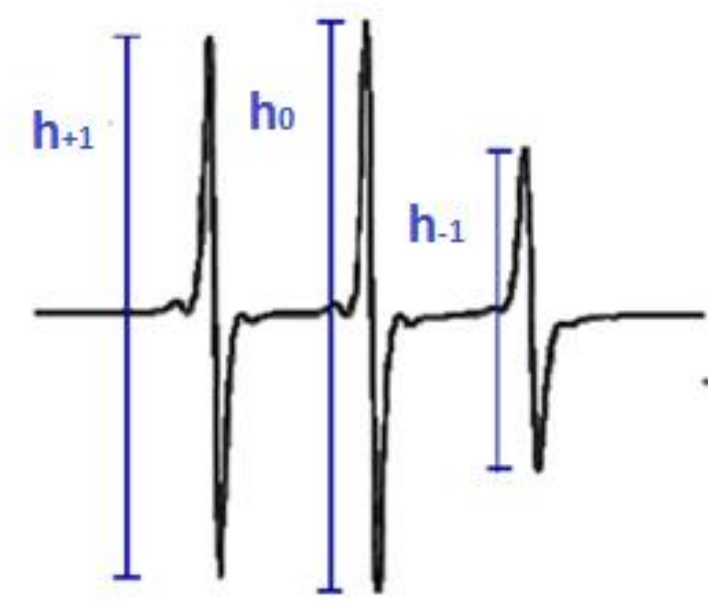

(a)

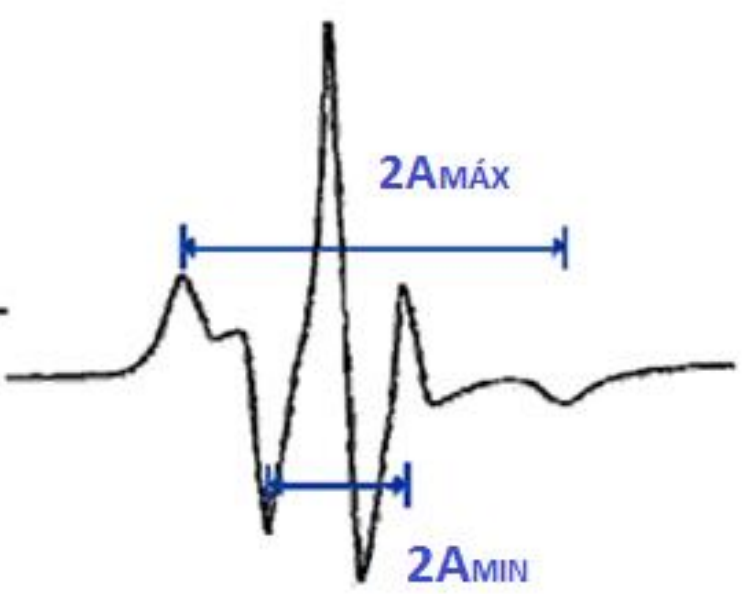

(b)

Figura 13 - Espectros de RPE de um radical nitróxido em um ambiente levemente anisotrópico, apresentando as definições dos parâmetros empíricos utilizados para a análise dos mesmos, na investigação da dinâmica e ordem do radical nitróxido em membranas, em dois regimes de movimento: (a) rápido e (b) lento.

O desdobramento hiperfino máximo ( $\left.A_{M A ́ x}\right)$ também pode ser obtido diretamente do espectro de RPE. Este parâmetro aumenta com a viscosidade ou empacotamento do microambiente sentido pelo marcador e diminui gradualmente com o aumento da temperatura até a temperatura de transição de fase do lipídio, onde ocorre uma queda abrupta de seu valor, indicando uma mudança de fase, no caso da fase gel para a fase fluida da cadeia hidrocarbônica da bicamada e, consequentemente, uma redução de seu empacotamento. Este tipo de análise é aplicado para marcadores que possuem um regime de movimento mais restrito. Ainda para estes espectros altamente anisotrópicos, as mudanças no empacotamento das cadeias acila e na polaridade da região monitorada por 
estes marcadores podem ser quantificadas através da determinação do parâmetro de ordem efetivo $\left(S_{E F F}\right)$ e do desdobramento hiperfino isotrópico $\left(a_{0}\right)$ através da expressão:

$$
S_{E F F}=\frac{A_{\| /}-A_{\perp}}{A_{z z}-(1 / 2)\left(A_{x x}+A_{y y}\right)} \frac{a_{0}^{\prime}}{a_{0}}
$$

onde $a_{0}=\frac{A_{\|}+2 A_{\perp}}{3}$ é o fator de correção da polaridade do solvente, $a_{0}^{\prime}=\frac{A_{x x}+A_{y y}+A_{z z}}{3}$ é a constante hiperfina isotrópica num sistema molecular rígido, $A_{\|}=A_{M A ́ x}$ é o desdobramento hiperfino máximo diretamente medido no espectro (figura 13b) e

$$
A_{\perp}=A_{M I N}+1,4\left[1-\frac{A_{\| /}-A_{M I N}}{A_{z z}-\frac{1}{2}\left(A_{x x}+A_{y y}\right)}\right]
$$

onde $2 \mathrm{~A}_{\mathrm{MIN}}$ é a medida de desdobramento hiperfino mínimo.

Na próxima seção serão mostrados os resultados e discussões obtidos através da utilização das metodologias acima citadas. 


\section{Resultados e Discussões}

Neste capítulo apresentamos os resultados experimentais obtidos a partir das medidas de DSC e RPE da interação dos complexos com a membrana modelo constituída do fosfolipídio DPPC. São discutidos os efeitos dos complexos no comportamento termotrópico das vesículas de DPPC a partir dos resultados dos estudos calorimétricos e dos resultados do estudo espectroscópico através de parâmetros empíricos obtido dos espectros de RPE.

\subsection{Análise Calorimétrica}

Para examinar a interação dos complexos com a membrana modelo, foi determinado o comportamento de fase das vesículas lipídicas na ausência e na presença dos complexos. Primeiramente, verificamos a temperatura em que ocorre o processo de transição de fase da bicamada lipídica constituída unicamente por DPPC, analisando-se a variação no valor de entalpia correspondente a mudanças na capacidade calorífica dos fosfolipídios, como mostrado na figura 14 . Em $34,2{ }^{\circ} \mathrm{C}$, temos a temperatura de pré-transição, que, como já mencionado anteriormente, é uma transição menos energética e cooperativa, que provém da conversão da fase gel lamelar $L_{B^{\prime}}$ para a fase gel rippled $P_{B^{\prime}}$ (evento 1 da figura 7 ). Em $41{ }^{\circ} \mathrm{C}$, temos uma segunda transição, a transição principal, que surge da conversão da fase gel rippled para a fase lamelar líquido-cristalina $L_{\alpha}$, que é mais energética e apresenta uma maior cooperação intermolecular entre os fosfolipídios das vesículas de DPPC, concordando, em boa aproximação, com dados da literatura $(34,49,57)$.

As mudanças estruturais nas bicamadas causadas por agentes externos podem provocar variações na temperatura de transição de fase do lipídio. A variação na entropia da transição e o aumento na largura da curva são causados pela diminuição da cooperatividade 
da transição e as alterações do empacotamento lipídico das bicamadas levam a mudanças no comportamento termotrópico dos lipossomos (62).

A figura 14 mostra os termogramas das vesículas de DPPC e os efeitos das moléculas de Cu-SDM e Cu-SFZ no seu comportamento termotrópico. Todos os dados termodinâmicos referentes a ambas as transições de fases, na ausência e na presença dos complexos, estão apresentados na Tabela 2 , onde os valores das variações das entalpias calorimétricas $\left(\Delta \mathrm{H}_{\text {cal }}\right)$ e de van't Hoff $\left(\Delta \mathrm{H}_{\mathrm{VH}}\right)$ e da entropia $(\Delta S)$ da transição foram calculados de acordo com as equações desenvolvidas na seção 2.5.1.

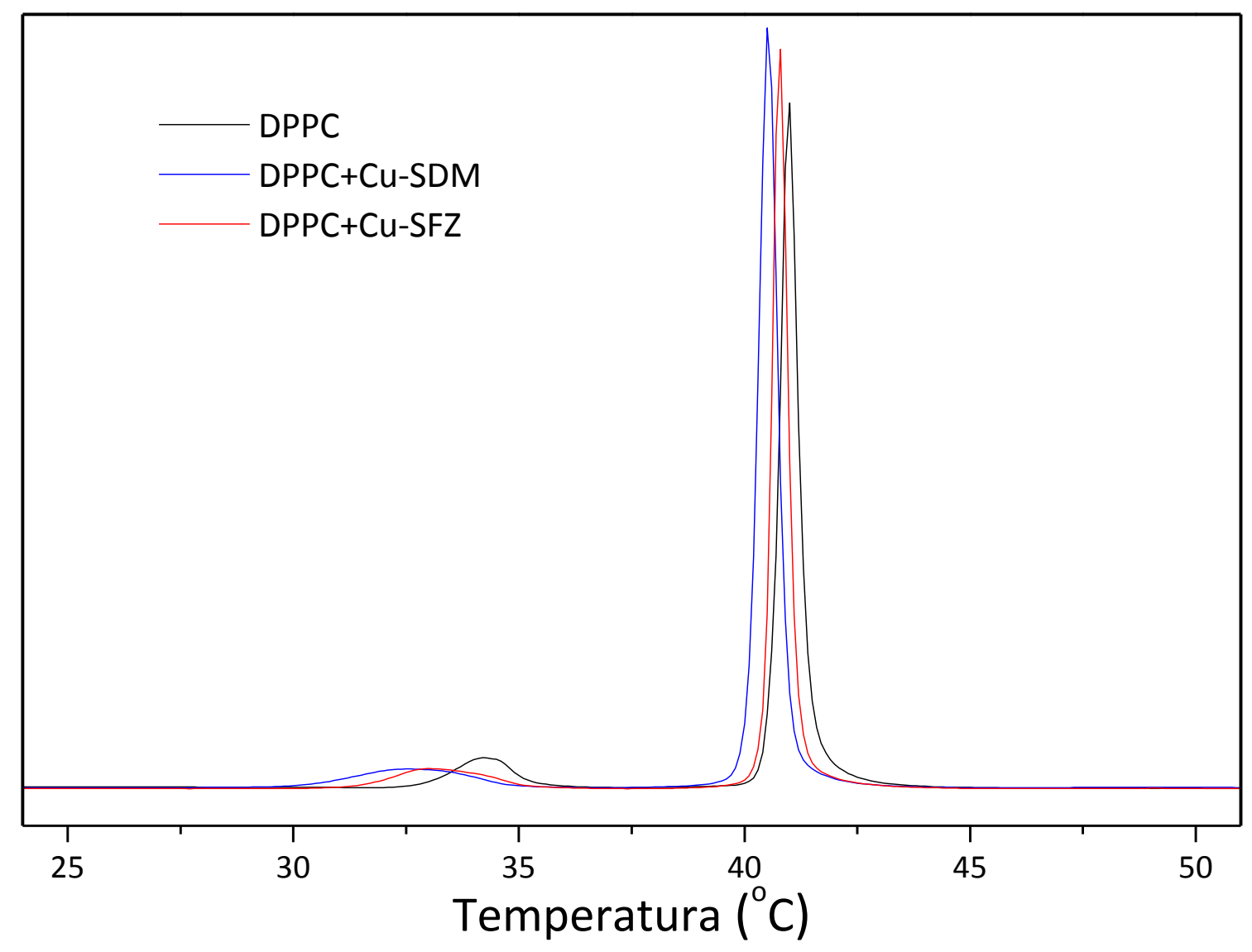

Figura 14 - Termogramas de DSC ilustrando o efeito dos complexos Cu-SDM e Cu-SFZ no comportamento termotrópico de vesículas de DPPC. 
Tabela 2 - Dados termodinâmicos obtidos da análise dos termogramas de DSC da prétransição e da transição principal das vesículas de DPPC na ausência e na presença dos complexos, onde $T_{P}$ é a temperatura da pré-transição e $T_{M}$ da transição principal.

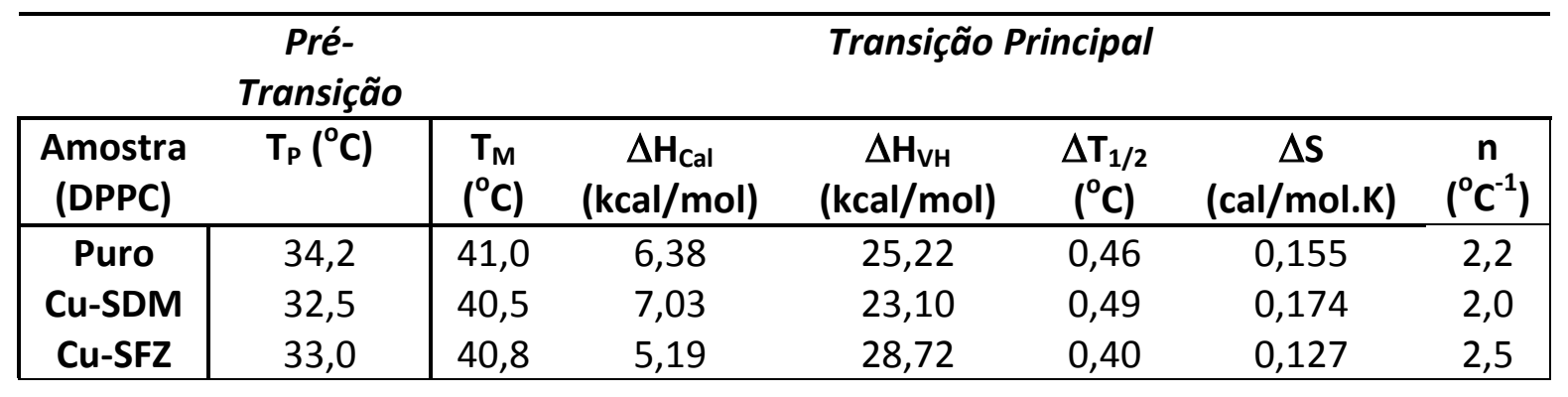

Para a análise e discussão dos dados obtidos pelo DSC utilizamos como referência o artigo de Jain e $\mathrm{Wu}$ (45) em que é apresentada uma série de alterações em termogramas, resultado da habilidade de uma variedade de pequenas moléculas em modificar o perfil da transição de fase da bicamada do fosfolipídio dipalmitoil lecitina. A comparação feita é muito útil para o entendimento do mecanismo de ação de vários solutos, lipossolúveis, nas biomembranas. Nesse trabalho, é descrita a fenomenologia das mudanças nas fases induzidas pelos aditivos, que incluem os ácidos graxos, alguns solventes orgânicos, alcanos, detergentes, ionofóros, íons inorgânicos, e alguns mais comumente usados, como marcadores de spin e sondas de membrana fluorescentes. O fato do perfil da transição de fase de uma bicamada lipídica ser modificado por um aditivo fornece a prova direta que o aditivo perturba a organização da bicamada, onde o tipo de perturbação é indicado pelo formato do perfil de transição.

Assim, um perfil de transição caracteristicamente mais largo comparado ao do perfil de transição da bicamada não modificada (tipo A) implica que o tamanho da unidade cooperativa em transição da bicamada é pequeno. Um perfil de transição cujo formato (altura, área e largura à meia altura) é quase idêntico ao do perfil para a bicamada nãomodificada e deslocado ao longo do eixo da temperatura (tipo C) implica que o tamanho da unidade cooperativa na bicamada modificada permanece o mesmo, mas o empacotamento dessas unidades pode ser perturbado a temperaturas menores. O aparecimento de um novo pico (tipo $B$ ou $D$ ) implica em uma nova fase modificada que é formada na bicamada que coexiste com a fase não modificada na bicamada contínua. As propriedades da nova fase são indicadas pelo formato e posição do novo pico. Um pico amplo ou um ombro (perfil tipo B) 
indicaria que a nova fase tem unidades cooperativas menores, que não coexistem com a fase de fosfolipídios puros. Dentro do perfil tipo $B$, podemos separá-lo ainda em $D$ ou E, pois esta nova fase poderia ser líquida (sem unidades cooperativas), e assim poderia se observar apenas o pico de transição principal que diminui com o aumento da concentração de aditivos (tipo E), ou ainda, com o aparecimento de um novo pico fino (tipo D) que indicaria que a fase modificada tem unidades cooperativas comparáveis em tamanho às da fase não modificada. Similarmente, o novo pico ao longo do eixo da temperatura indicaria se o deslocamento é para temperaturas menores ou maiores.

Jain e Wu (45) também mostram em seu estudo como determinar as possíveis localizações dos solutos em cada tipo de perfil em relação à região inserida na bicamada lipídica. Como mostrado na figura 15 , solutos que induzem perfis do tipo $D$ estão mais perto ou na interface da bicamada, perfis do tipo B estão na região do glicerol, tipo A na região do metileno (entre os carbonos 1 a 8 ) e solutos que induzem o perfil do tipo $C$ se encontram próximos ao centro da bicamada (entre os carbonos 9 a 16).

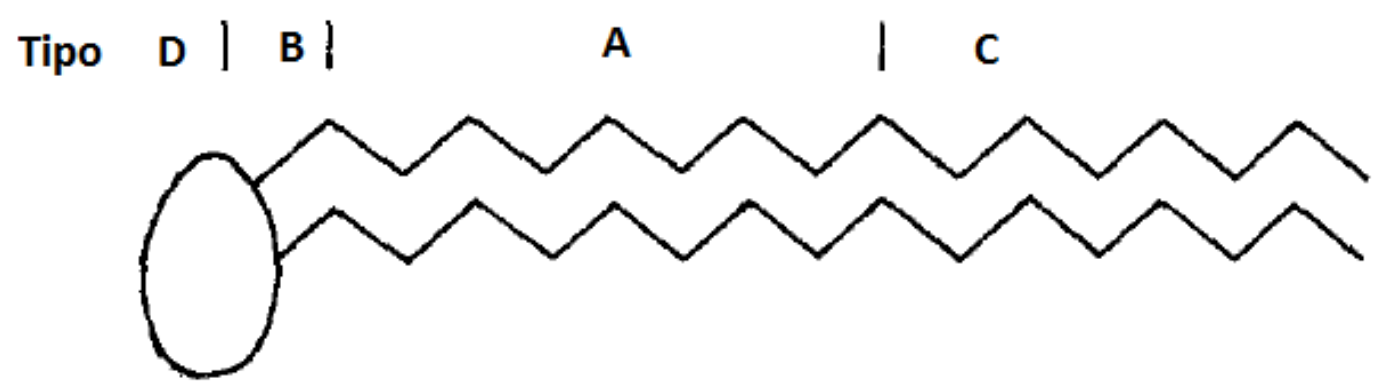

Figura 15 - Diagrama esquemático ilustrando as possíveis regiões da localização dos vários aditivos que induzem qualitativamente perfis de transição de fase distintos quando incorporados à bicamada do dipalmitoil lecitina. Solutos do tipo $D$ podem estar localizados na região próxima à interface, tipo $B$ na região do glicerol, tipo $A$ na região do metileno e tipo $\mathrm{C}$ próximos ao centro da bicamada. Figura adaptada de (45).

Pela observação da figura 16, onde é dado destaque somente para a transição principal e pelos perfis dados no artigo explicitado acima, vemos que ambos os complexos induzem um perfil que pode ser comparado amplamente com o da bicamada não modificada (DPPC puro), somente deslocado para temperaturas menores, ou seja, assumem o perfil tipo $C \downarrow$, onde a seta para baixo $(\downarrow)$ indica que ambas as temperaturas de início e de fim da transição são deslocadas para temperaturas menores. Este tipo de perfil sugere que 
as moléculas estão localizadas próximas ao centro da bicamada. Um soluto localizado no carbono 9 ou maior da cadeia acila não modifica a cooperatividade da transição, mas modifica o empacotamento dentro desta unidade cooperativa.

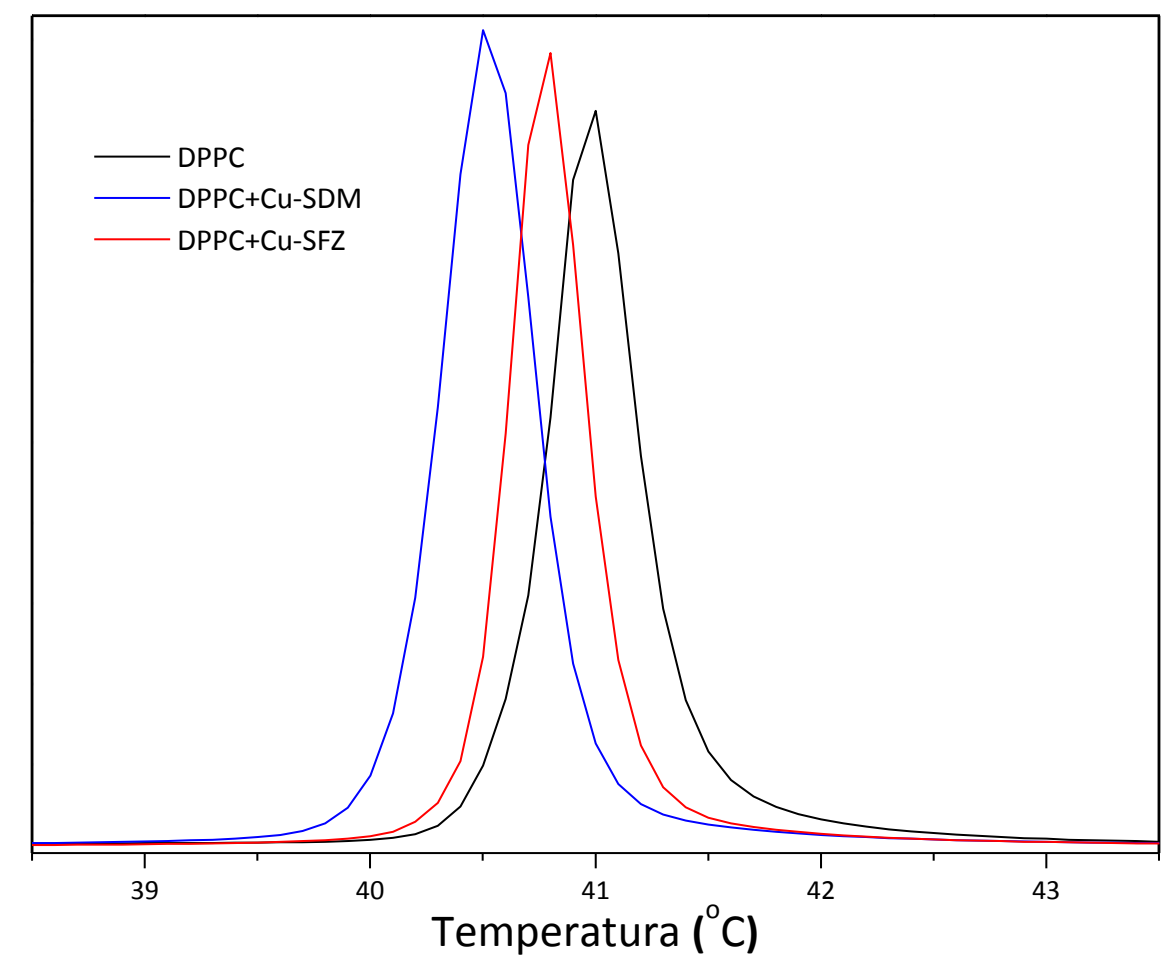

Figura 16 - Destaque do pico referente à transição de fase principal no termograma de DSC na ausência e na presença dos complexos.

Como observado os complexos quase não afetam a temperatura de transição principal, porém modificam a entalpia calorimétrica. Esta mudança em $\Delta \mathrm{H}$ é consequência da ruptura das interações de van der Waals entre as cadeias hidrocarbônicas. Isto mostra que os complexos são capazes de se intercalar entre as cadeias de ácidos graxos (63). Analisando esta alteração conjuntamente com aquelas observadas no parágrafo anterior, podemos inferir que os complexos devem interagir da seguinte maneira: primeiro "sentam" na cabeça dos fosfolipídios e se incorporam na membrana modelo com o aumento da temperatura.

Pela figura 17, podemos perceber que ambos os complexos afetam fortemente a prétransição do fosfolipídio, deslocando a temperatura de transição para valores menores e alargando o pico. Essa mudança na largura do pico da pré-transição ou em sua temperatura 
podem indicar que a estrutura rippled na parte da cabeça do lipídio mudou devido a uma interação entre a molécula e o grupo localizado na cabeça polar (64). Na interação com o DPPC, o complexo Cu-SFZ diminui a entalpia da pré-transição, que pode surgir de uma modificação na inclinação da cabeça polar do lipídio, sugerindo novamente uma interação entre o complexo e o grupo polar (63).

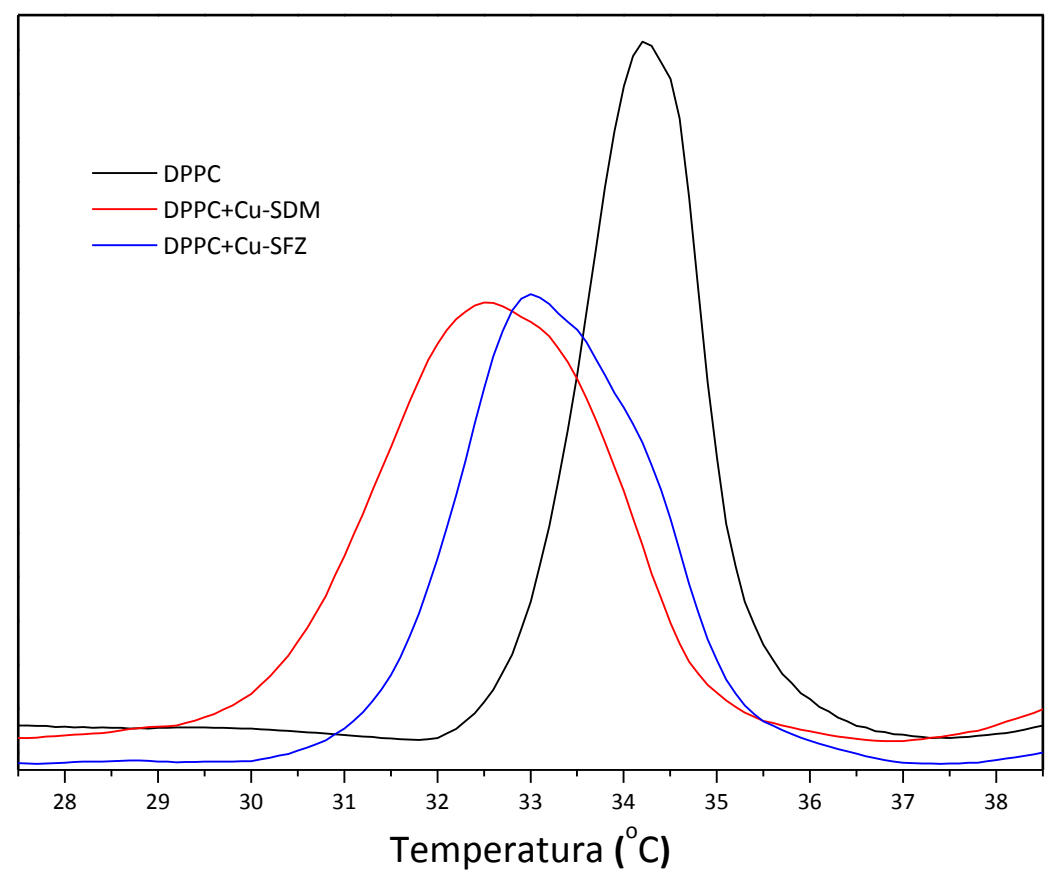

Figura 17 - Destaque do pico da pré-transição do fosfolipídio DPPC no termograma de DSC na ausência e na presença dos complexos.

\subsection{Análise dos espectros de RPE}

Com a finalidade de aprofundar os estudos anteriores, obtendo agora informações em nível molecular acerca da interação entre os complexos e miméticos de membrana, em particular, verificar como os complexos estudados interagem com as vesículas compostas por DPPC e quais os efeitos sobre a fluidez e mobilidade do fosfolipídio, foram realizadas medidas de RPE em lipossomos de DPPC contendo sondas magnéticas na ausência e na 
presença dos complexos Cu-SDM e Cu-SFZ. As mudanças foram monitoradas pelas moléculas de fosfolipídio marcadas nas posições 5, 12 e 16 da cadeia acila do fosfolipídio. Nesta seção, são apresentados os resultados da análise desses espectros baseada em parâmetros empíricos, definidos sobre o próprio espectro, como explicitado no item 0 deste trabalho. Nas subseções seguintes é feita a discussão sobre a interação dos complexos com as vesículas de DPPC e os seus efeitos em cada região lipídica estudada.

Em experimentos de RPE utilizando lipossomos contendo fosfolipídios marcados fazemos medidas em função da temperatura e, através da determinação de parâmetros empíricos relacionados com a fluidez e/ou ordenamento da membrana, construímos curvas que mostram seu comportamento termotrópico. Devemos ressaltar, entretanto, que este tipo de análise por RPE é muito pouco sensível à pré-transição dos fosfolipídios. A grande maioria dos estudos está focada na transição principal e em suas alterações quando da adição de moléculas à membrana modelo. Por isso, atribuímos nesta e nas próximas seções, todo o comportamento do sistema em estudo para temperaturas abaixo da transição principal, como sendo à fase gel.

\subsubsection{Marcador de Spin 5-PCSL}

Nas figuras 18, 19 e 20 estão apresentados os espectros para o marcador 5-PCSL na ausência dos complexos e na presença de Cu-SDM e Cu-SFZ, respectivamente. Foram realizadas medidas entre 20 e $55{ }^{\circ} \mathrm{C}$ de 5 em $5^{\circ} \mathrm{C}$ e medidas mais detalhadas entre 39 e $43{ }^{\circ} \mathrm{C}$, onde a variação foi de 0,5 em $0,5{ }^{\circ} \mathrm{C}$, devido ao fato de, neste intervalo, estarmos próximos à região da transição principal. 


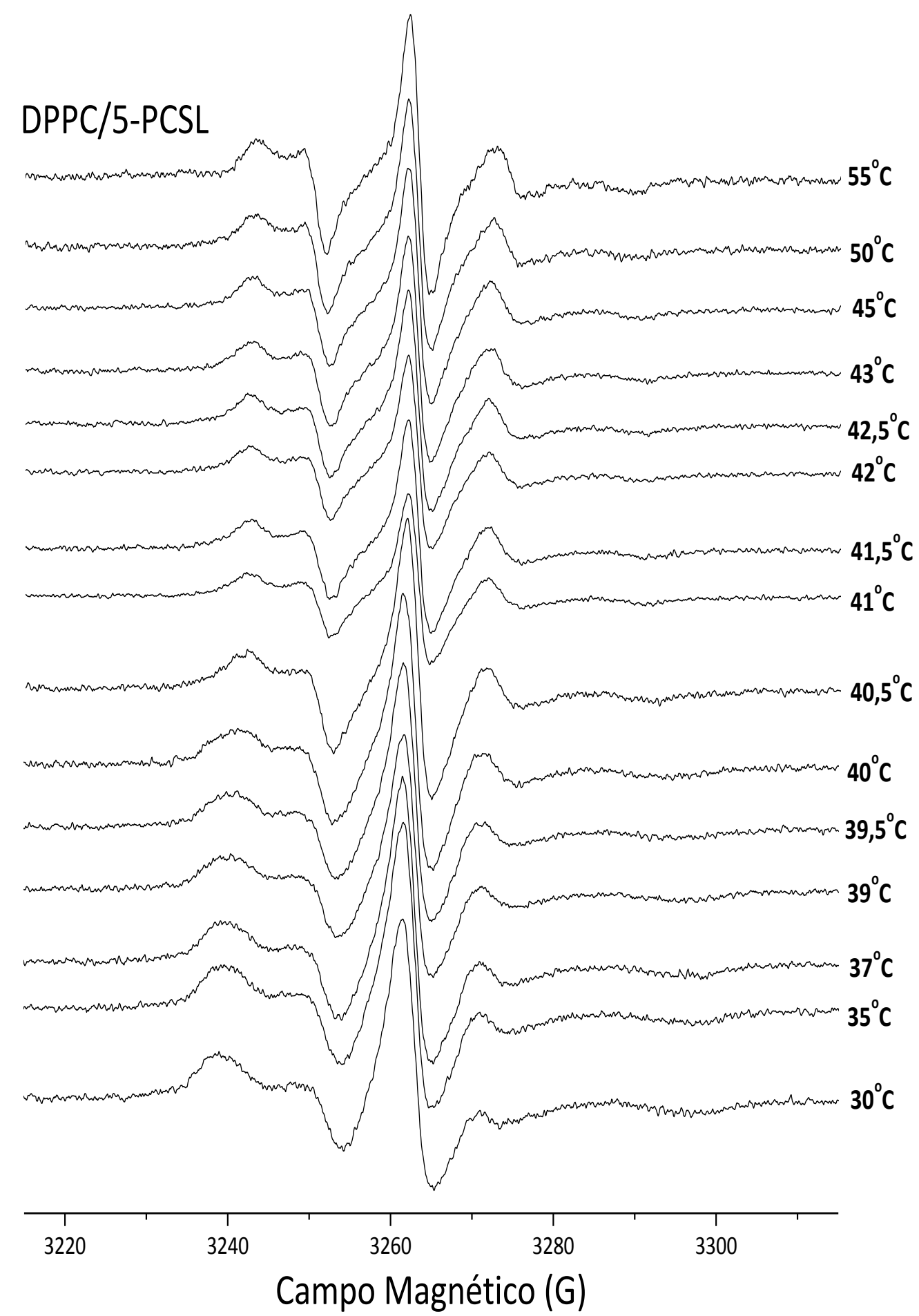

Figura 18 - Medidas de RPE com variação de temperatura dos modelos de membrana contendo DPPC e a sonda 5-PCSL. 


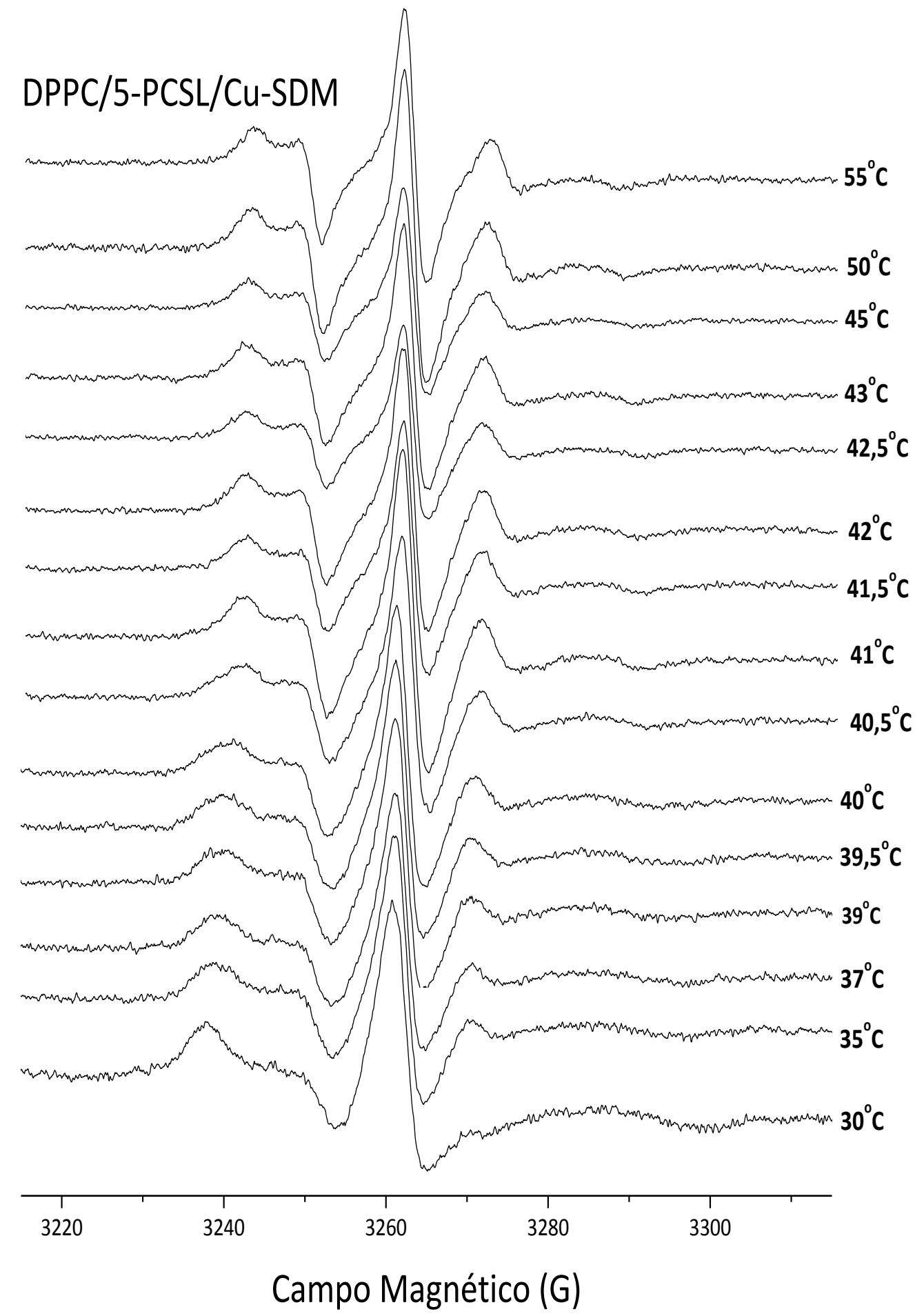

Figura 19 - Espectros de RPE do marcador 5-PCSL em dispersão lipídica de DPPC na presença do complexo Cu-SDM. 


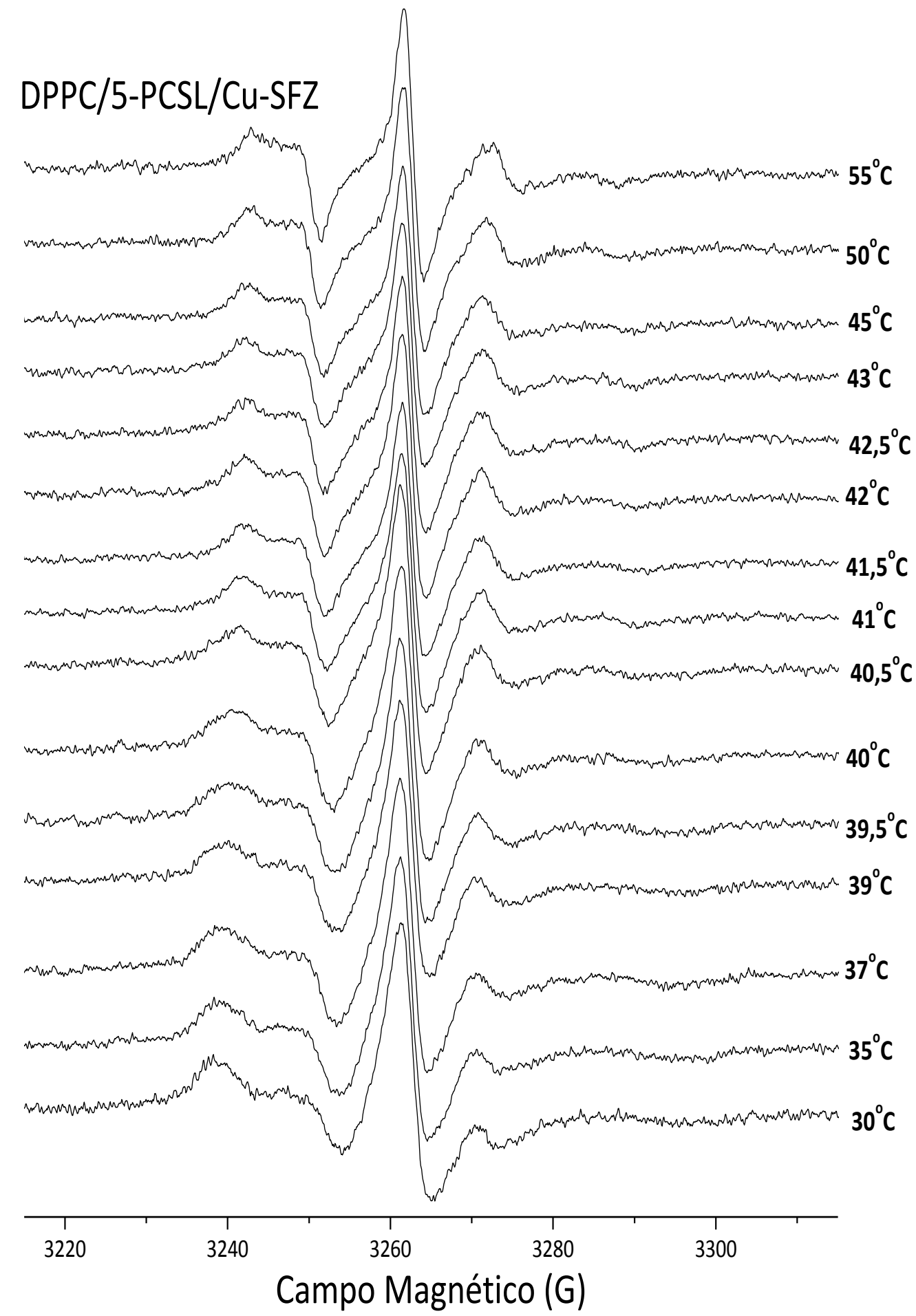

Figura 20 - Espectros de RPE do marcador 5-PCSL em dispersão lipídica de DPPC na presença do complexo Cu-SFZ. 
Na figura 21 são apresentados os espectros de RPE do marcador de spin 5-PCSL em duas temperaturas representativas das fases gel e líquido-cristalino das vesículas de DPPC na ausência e na presença dos complexos.

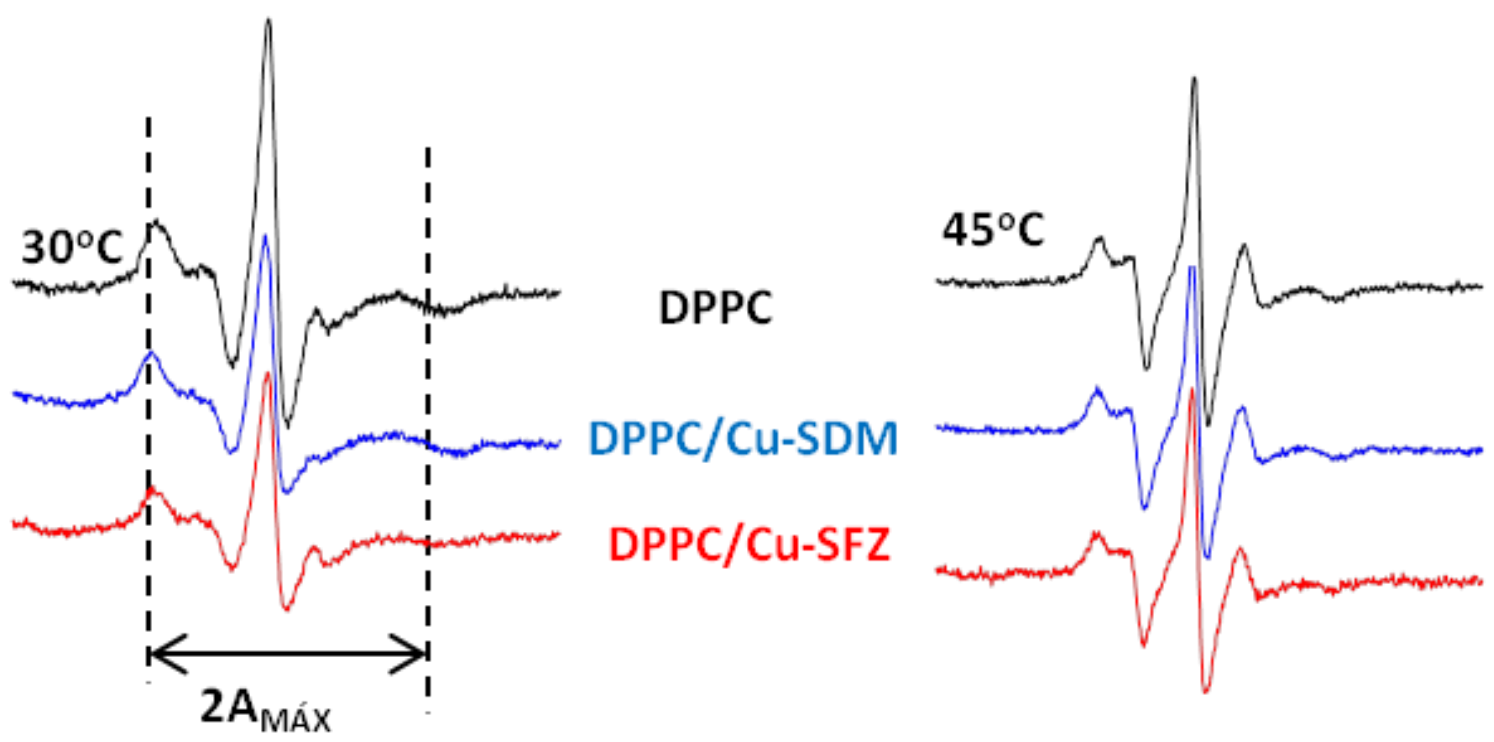

Figura 21 - Espectros de RPE do marcador 5-PCSL em dispersões lipídicas de DPPC antes e depois da adição dos complexos cobre-sulfonamidas em duas diferentes temperaturas, 30 e $45^{\circ} \mathrm{C}$. As linhas pontilhadas são guias para ajudar na percepção das mudanças espectrais.

A observação dos espectros acima evidencia mudanças na forma das linhas quando da adição dos complexos. Em particular, percebemos uma alteração na linha de campo alto dos espectros a $30{ }^{\circ} \mathrm{C}$, com alargamento considerável (que leva a um desaparecimento) dessa linha na presença do composto Cu-SFZ. Linhas espectrais mais largas estão associadas com ordem estrutural maior e/ou dinâmica de movimento menos induzidas pelo composto. Para termos uma investigação mais quantitativa do sistema em estudo, fazemos uso dos parâmetros empíricos mencionados na seção 2.5.2.3. Apresentamos nas figuras 22 e 23 a dependência com a temperatura do desdobramento hiperfino máximo ( $\left.2 A_{M A ́ x}\right)$ e do parâmetro de ordem efetivo $\left(S_{\mathrm{EFF}}\right)$ calculado a partir da equação 8. Estes parâmetros contêm contribuições da dinâmica do movimento da cadeia dos marcadores de spin. Ambos os parâmetros decrescem com o aumento da mobilidade das cadeias lipídicas ou com a diminuição do seu ordenamento. A variação abrupta dos dois parâmetros em torno de $41{ }^{\circ} \mathrm{C}$ indica a transição de fase principal. 
A figura 22 mostra que as moléculas de Cu-SDM não provocam efeito significativo na fase gel rippled (variação de temperatura entre 34 e $41{ }^{\circ} \mathrm{C}$, aproximadamente) da membrana. A fase gel tilted (temperatura inferior a aproximadamente $34{ }^{\circ} \mathrm{C}$ ) é fortemente perturbada pela presença do complexo, tendo um aumento do parâmetro de ordem efetivo, indicando uma diminuição na dinâmica e/ou aumento do empacotamento da bicamada lipídica nesta região.

A dependência do desdobramento hiperfino máximo com a temperatura não é capaz de evidenciar a mudança em $T_{M}$, o que não é de todo inesperado, já que os marcadores de spin 5-PCSL não são os mais indicados para o monitoramento das transições lipídicas em face dos espectros intrinsecamente de baixa resolução (linhas mais largas devido à sua posição em região de menor mobilidade na membrana). A superfície da bicamada é menos sensível à variação de fluidez da membrana na temperatura de transição. Sendo assim, a dependência com a temperatura dos valores de $A_{\text {Máx }}$ deve ser usada somente como um indicativo no que diz respeito a variações em $T_{M}$. 


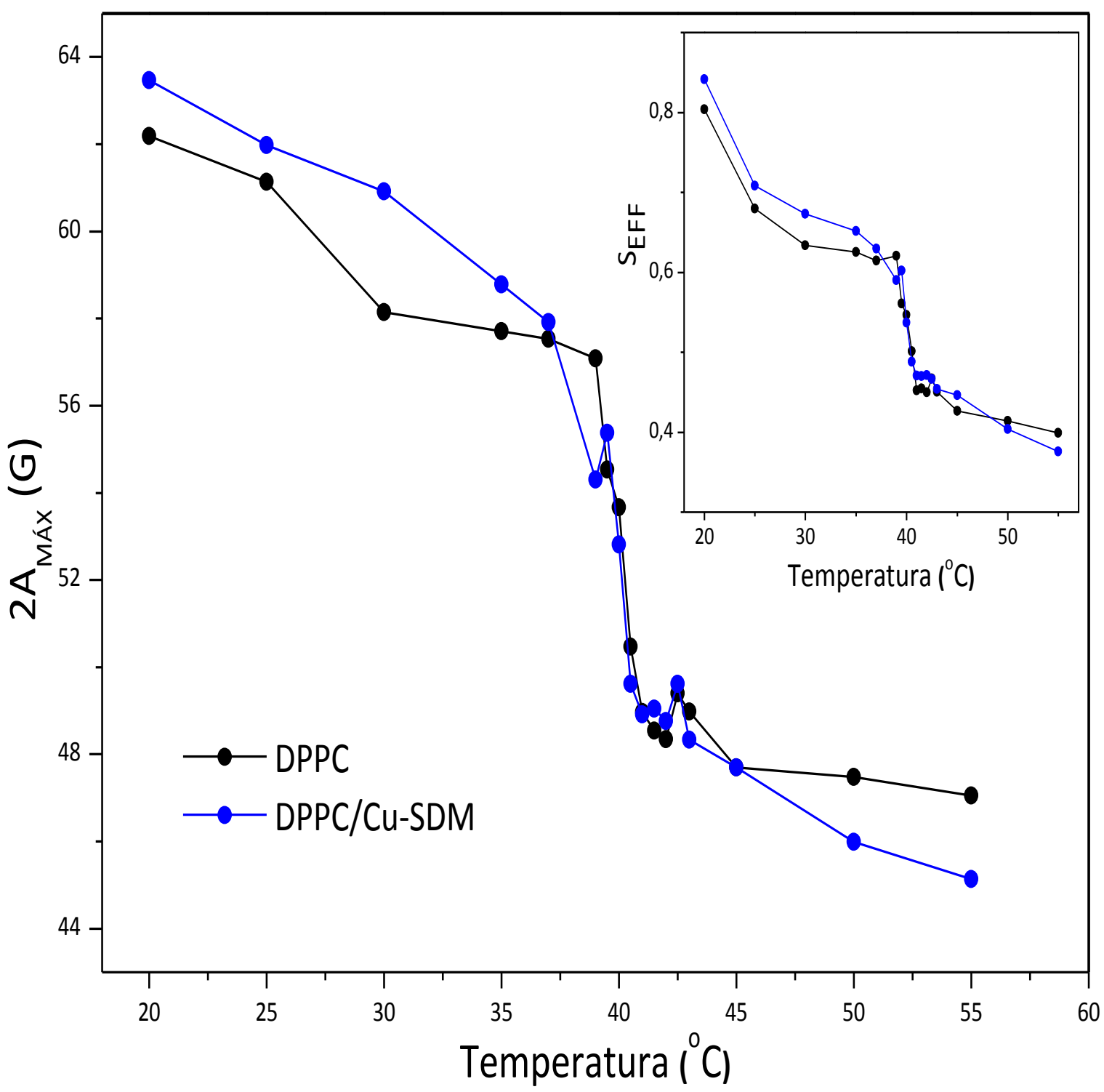

Figura 22 - Dependência com a temperatura do desdobramento hiperfino máximo e do parâmetro de ordem efetivo (inserção) do marcador de spin 5-PCSL incorporado em vesículas de DPPC, sem e com a adição do complexo Cu-SDM.

Na figura 23 vemos que as moléculas de Cu-SFZ não afetam de modo significativo a dinâmica e ordenamento do lipídio como reportados pelo parâmetro $A_{M A ́ x}$. Vale lembrar que para este complexo, há um claro alargamento da linha de campo mais alto do espectro (figura 21), o que leva a dificuldades de se medir o valor de $A_{M A ́ x}$ do espectro. A única mudança percebida é uma diminuição no parâmetro de desdobramento hiperfino máximo 
em torno de $37{ }^{\circ} \mathrm{C}$ o que pode indicar uma redução da cooperatividade da transição e outra diminuição para temperaturas acima de $50{ }^{\circ} \mathrm{C}$.

No geral, a presença dos compostos Cu-SDM ou Cu-SFZ levam a situações em que se detectam alargamentos de linhas espectrais e/ou aumento do ordenamento da fase gel dos fosfolipídios que compõem o modelo de membrana. Isto mostra que tais compostos são capazes de interagir com a vesícula lipídica e promover as alterações descritas. O aumento de ordem pode advir da maior estruturação imposta pela presença das moléculas de complexo na região próxima à posição 5 da cadeia acila dos fosfolipídios.

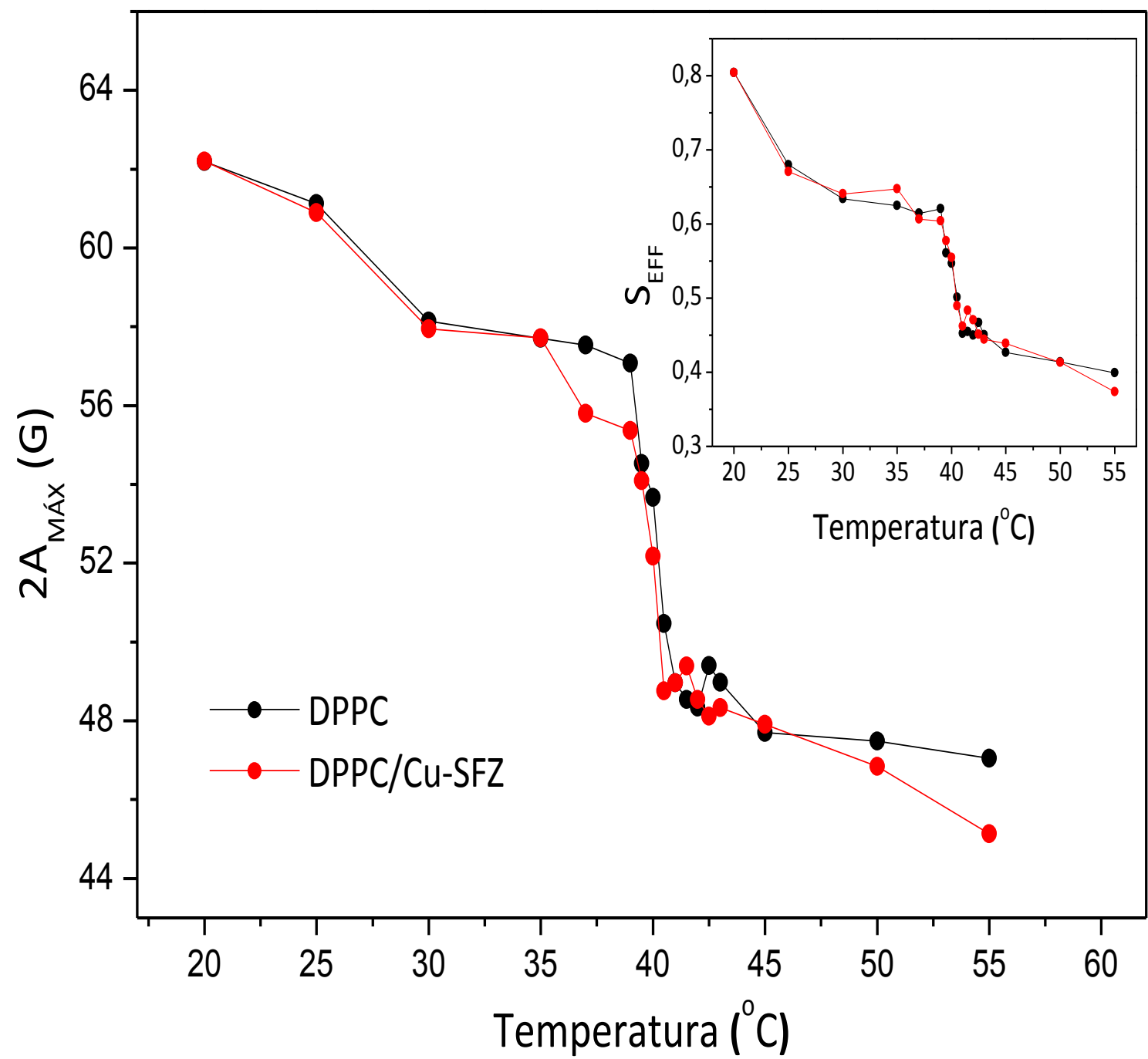

Figura 23 - Dependência com a temperatura do desdobramento hiperfino máximo e do parâmetro de ordem efetivo (inserção) do marcador de spin 5-PCSL, incorporado em vesículas de DPPC, sem e com a adição do complexo Cu-SFZ. 


\subsubsection{Marcador de Spin 12-PCSL}

Com o intuito de investigarmos as mudanças provocadas pelos complexos ao longo de toda a cadeia lipídica do DPPC, foram obtidos espectros de RPE com o marcador 12-PCSL, na ausência e na presença dos complexos (figuras 24, 25 e 26). As medidas foram realizadas entre 20 e $55{ }^{\circ} \mathrm{C}$ de 5 em $5{ }^{\circ} \mathrm{C}$ e na faixa próxima a transição principal, de 37 a $43{ }^{\circ} \mathrm{C}$, foi realizada uma variação mais minuciosa de 2 em $2{ }^{\circ} \mathrm{C}$.

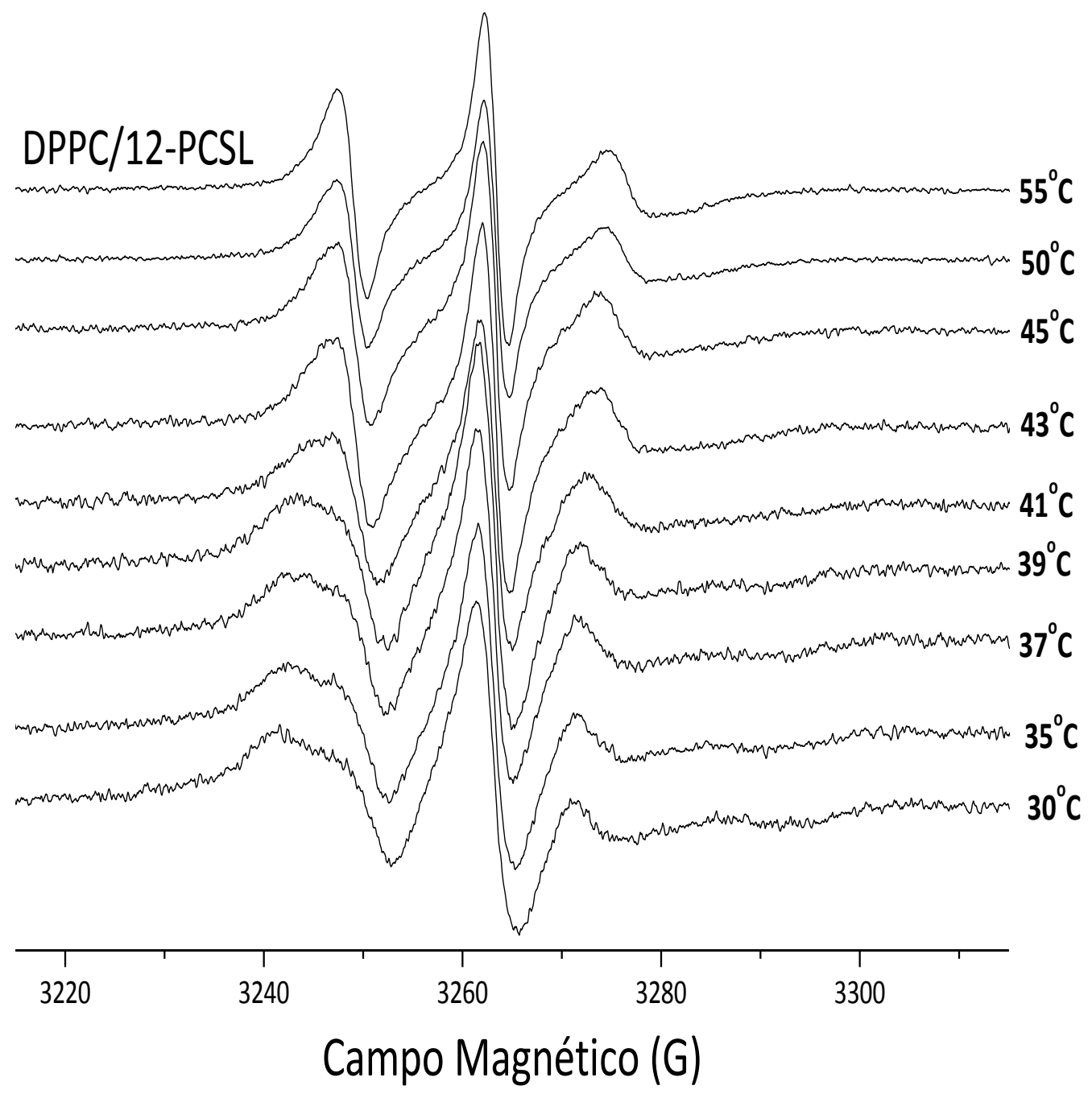

Figura 24 - Medidas de RPE com variação de temperatura dos modelos de membrana contendo DPPC e a sonda 12-PCSL. 


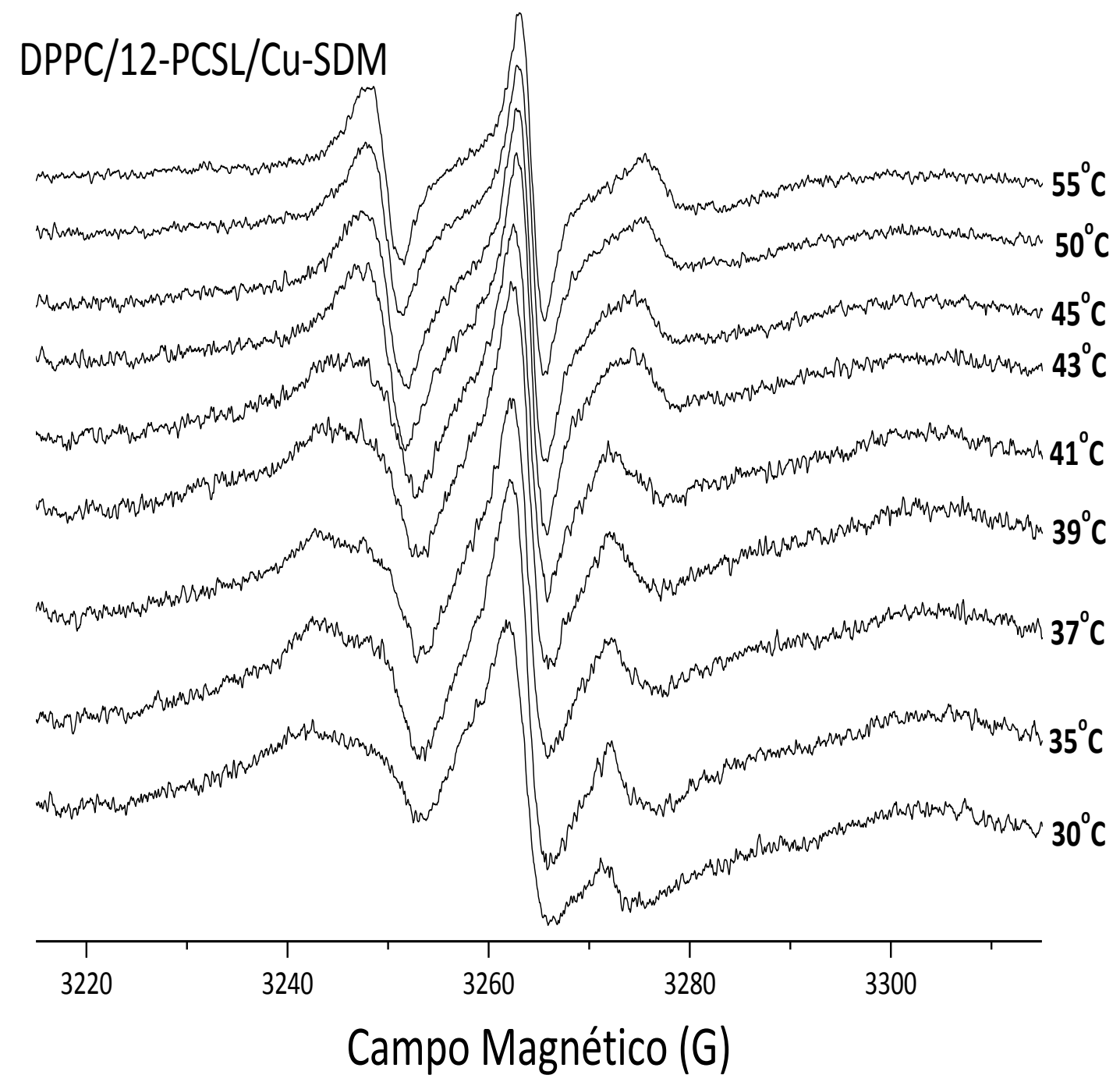

Figura 25 - Espectros de RPE do marcador 12-PCSL em dispersão lipídica de DPPC na presença do complexo Cu-SDM. 


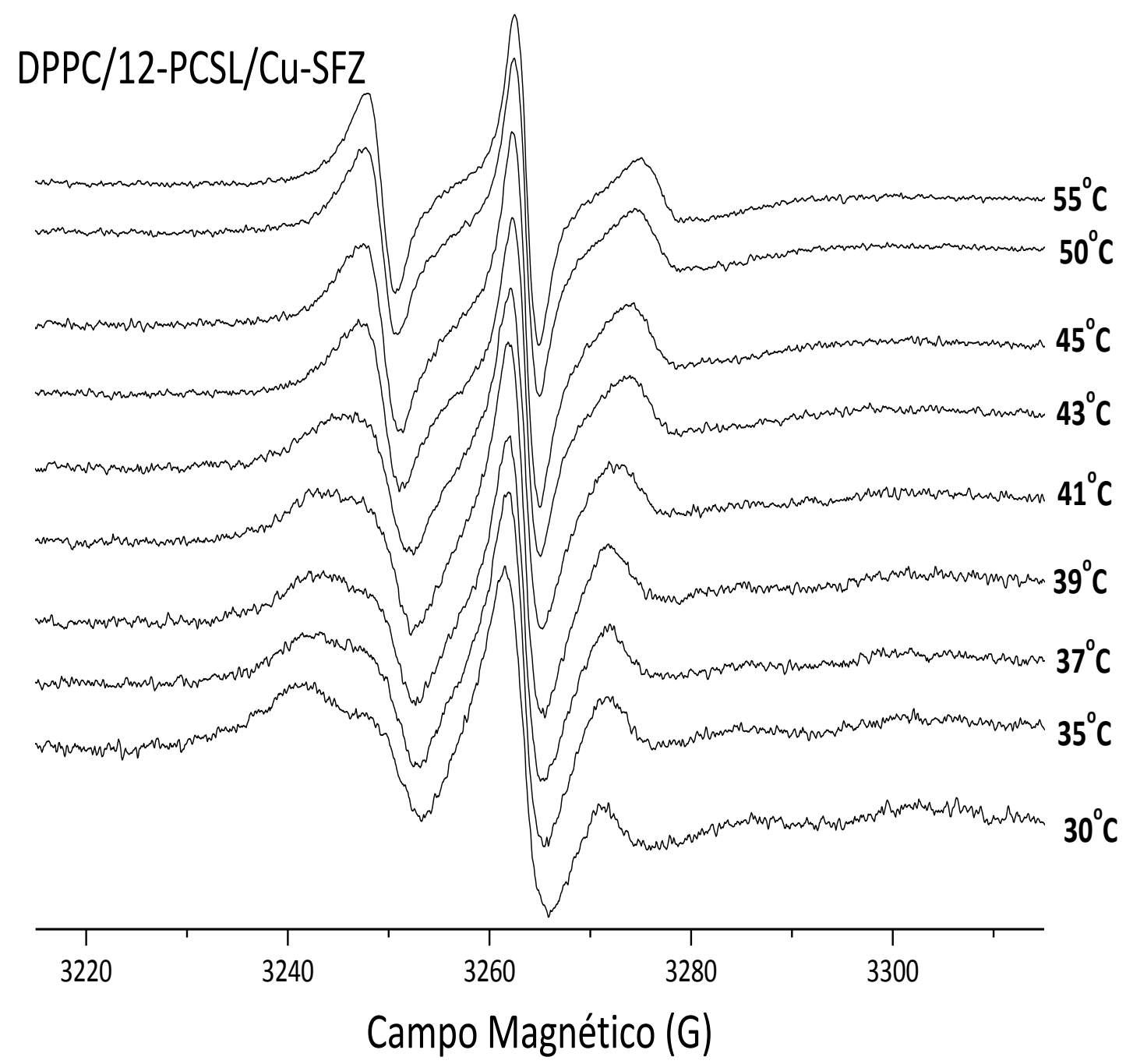

Figura 26 - Espectros de RPE do marcador 12-PCSL em dispersão lipídica de DPPC na presença do complexo Cu-SFZ.

Na figura 27 são apresentados os espectros de RPE do marcador de spin 12-PCSL em temperaturas representativas das fases gel e líquido-cristalino das vesículas de DPPC na ausência e na presença dos complexos. 

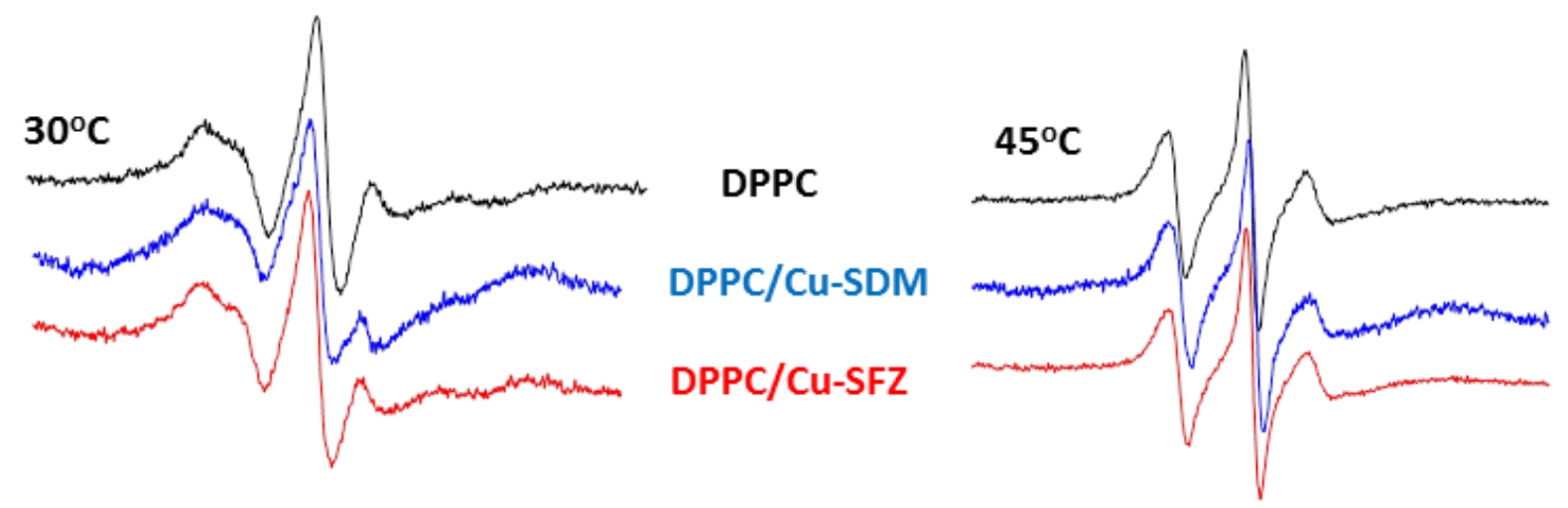

Figura 27 - Espectros de RPE do marcador de spin 12-PCSL em dispersões lipídicas de DPPC antes e depois da adição dos complexos cobre-sulfonamidas em duas temperaturas, 30 e $45{ }^{\circ} \mathrm{C}$.

Uma inspeção nos espectros da figura 27 mostra, mais uma vez, mudanças na forma de linha dos espectros de RPE medido na temperatura de $30{ }^{\circ} \mathrm{C}$. Entretanto, para o marcador 12-PCSL em temperaturas mais elevadas, o parâmetro $A_{M A ́ x}$ não pode mais ser mensurado. Para evidenciar os efeitos dos complexos sobre a dinâmica e o ordenamento dos lipídios podemos fazer uma análise do parâmetro $h_{+1} / h_{0}$ em função da temperatura, que nos fornece informações dos espectros que não são possíveis de serem percebidas somente com a sua observação. Esse parâmetro é definido na figura 13 da seção 2.5.2.3 e os valores obtidos a partir dos espectros medidos são apresentados na figura 28 para ambos os complexos.

Através da figura abaixo podemos observar a notável mudança na dependência com a temperatura do parâmetro $h_{+1} / h_{0}$ com a inserção de ambos os complexos. Podemos inferir que ambos os complexos perturbam fortemente a fase gel das membranas. A diminuição considerável dos valores do parâmetro indica uma estruturação maior das membranas na presença dos complexos, assim como reportado pelo marcador 5-PCSL. Como já mencionado anteriormente, quando este parâmetro se aproxima da unidade, o ambiente sentido pelo marcador apresenta uma maior fluidez, logo, uma redução do mesmo, indica um maior empacotamento das moléculas lipídicas e/ou uma menor mobilidade das mesmas. 


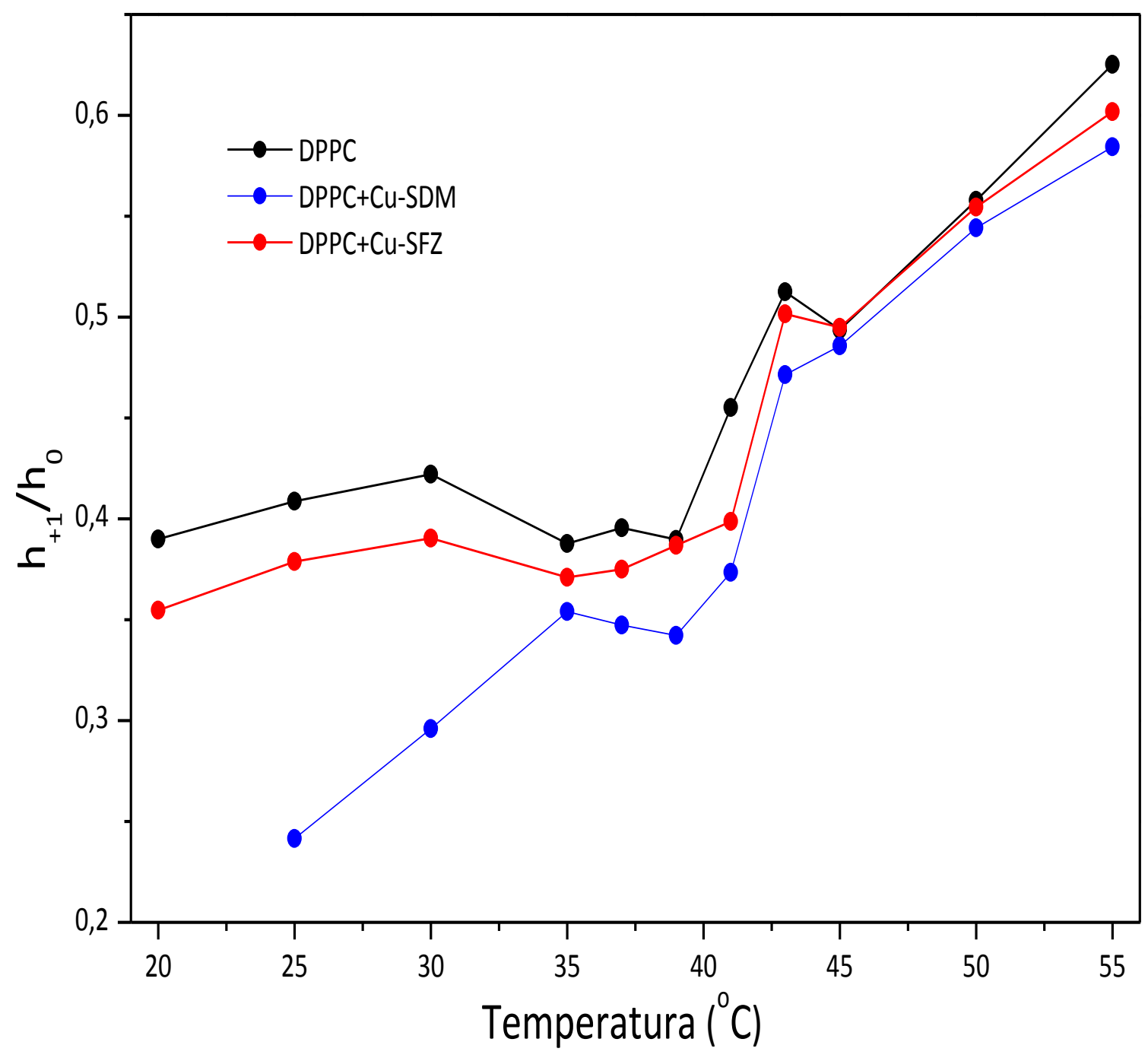

Figura 28 - Dependência do parâmetro $h_{+1} / h_{0}$ com a temperatura do marcador de spin 12PCSL em DPPC sem e com a adição dos complexos Cu-SDM e Cu-SFZ.

\subsubsection{Marcador de spin 16-PCSL}

Nas figuras 29, 30 e 31 são apresentados os espectros para o marcador 16-PCSL em vesículas de DPPC na ausência e na presença de Cu-SDM e Cu-SFZ, respectivamente. As 
medidas foram realizadas no intervalo entre 20 e $55^{\circ} \mathrm{C}$ de 5 em $5^{\circ} \mathrm{C}$ e de 0,5 em $0,5{ }^{\circ} \mathrm{C}$, para o intervalo entre 39 e $43{ }^{\circ} \mathrm{C}$, devido ao fato de estar próximo à região da transição principal.

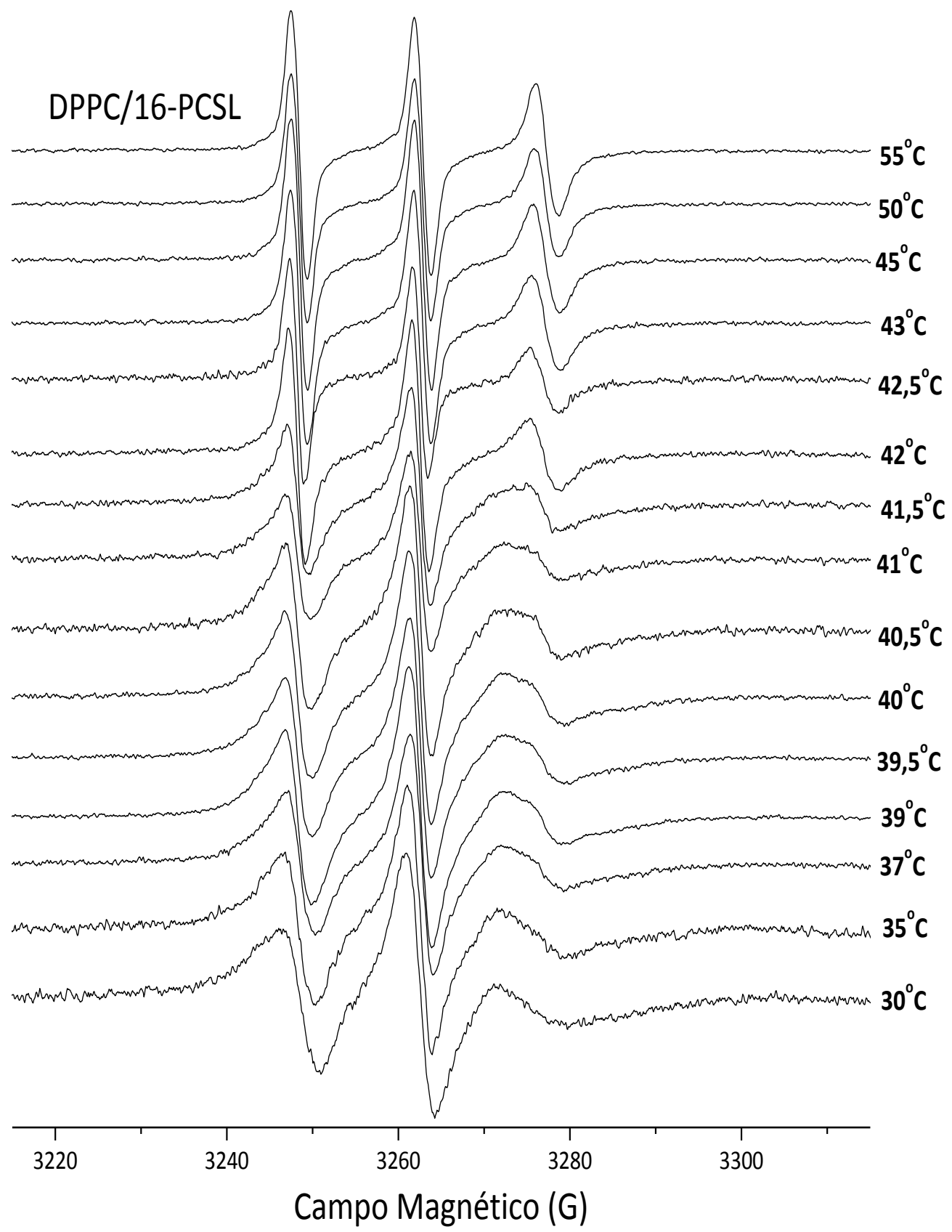

Figura 29 - Espectros de RPE do marcador 16-PCSL em dispersão lipídica de DPPC. 


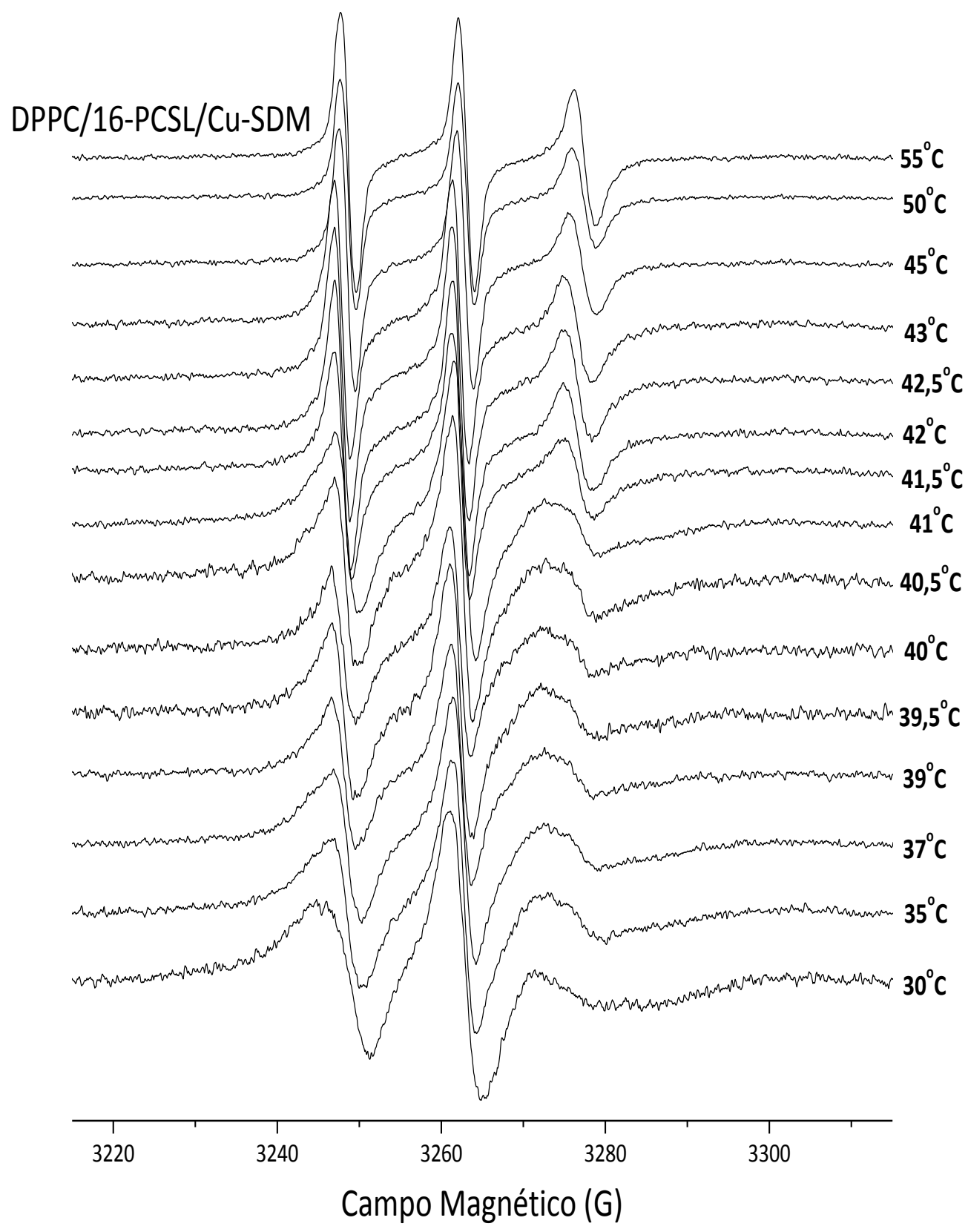

Figura 30 - Espectros de RPE do marcador 16-PCSL em dispersão lipídica de DPPC na presença do complexo Cu-SDM. 


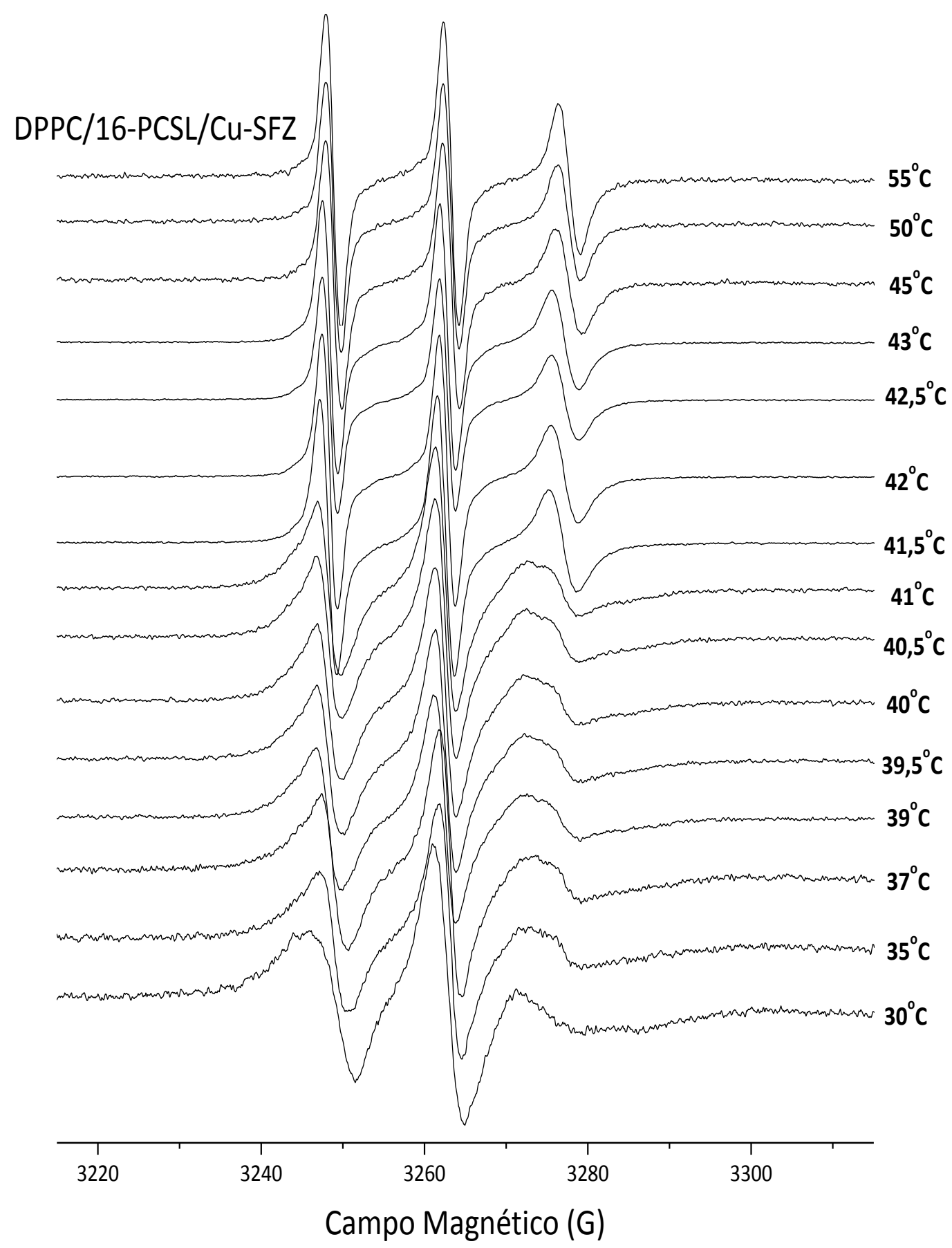

Figura 31 - Espectros de RPE do marcador 16-PCSL em dispersão lipídica de DPPC na presença do complexo Cu-SFZ.

Na figura 32 são apresentados os espectros de RPE do marcador de spin 16-PCSL nas fases gel e líquido-cristalino das vesículas de DPPC na ausência e na presença dos complexos. Percebe-se, mais uma vez, alterações na forma de linha dos espectros medidos com as vesículas lipídicas na fase gel, mas desta vez, mudanças mais sutis. A melhor definição da 
ressonância de campo mais alto com a formação de um "vale" mais largo a $30{ }^{\circ} \mathrm{C}$ é a característica mais facilmente visualizada na figura 32. Essa definição indica uma diminuição na dinâmica do marcador ou aumento na estruturação do ambiente em que se encontra a sonda quando da adição dos complexos.
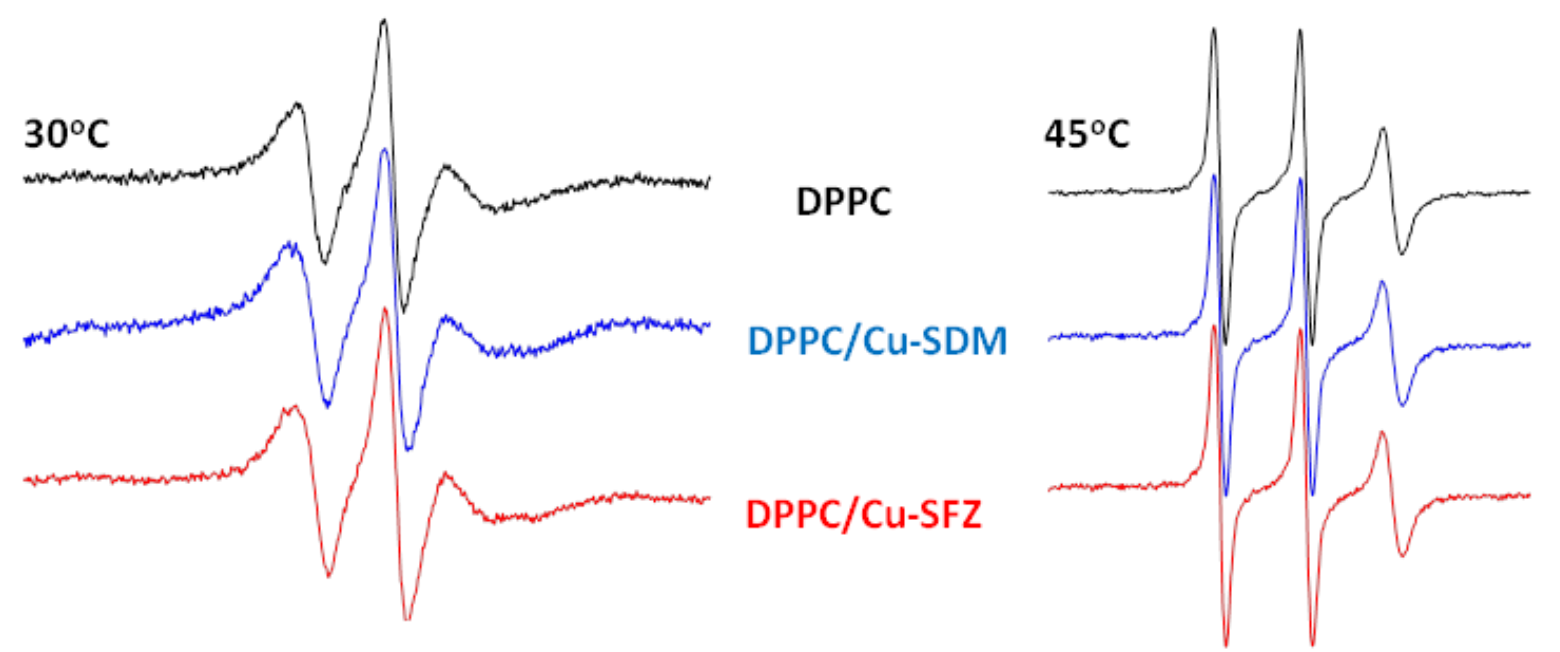

Figura 32 - Espectros de RPE do marcador de spin 16-PCSL em dispersões lipídicas de DPPC, sem e com a adição dos complexos cobre-sulfonamidas em duas temperaturas, 30 e $45^{\circ} \mathrm{C}$.

Aqui novamente é o parâmetro $h_{+1} / h_{0}$ em função da temperatura o mais adequado para uma análise dos efeitos da presença dos complexos de cobre sobre as vesículas lipídicas. Como, neste caso, temos espectros correspondentes a sondas em dinâmica mais rápida do que aquela observada nos casos anteriores, podemos também nos valer do parâmetro $h_{-1} / h_{0}$ que é medido de forma análoga aos parâmetros $h_{+1} / h_{0}$ só que utilizando a intensidade da linha de campo alto $\left(h_{-1}\right)$ e da linha de campo central $\left(h_{0}\right)$. Os valores determinados a partir dos espectros acima são apresentados nas figuras 33 e 34 para ambos os complexos. Podemos observar que as moléculas de Cu-SDM e Cu-SFZ não promovem mudanças significativas nos valores dos parâmetros. Portanto, a única hipótese que podemos levantar sobre a interação de ambos os complexos com os lipídios de DPPC, baseando-se exclusivamente nos dados obtidos por RPE, é que ambos os complexos promovem pouco, como evidenciado das leves mudanças nas formas de linhas dos espectros obtidos com as vesículas na fase gel, ou nenhum efeito sobre a região do centro da bicamada lipídica. 


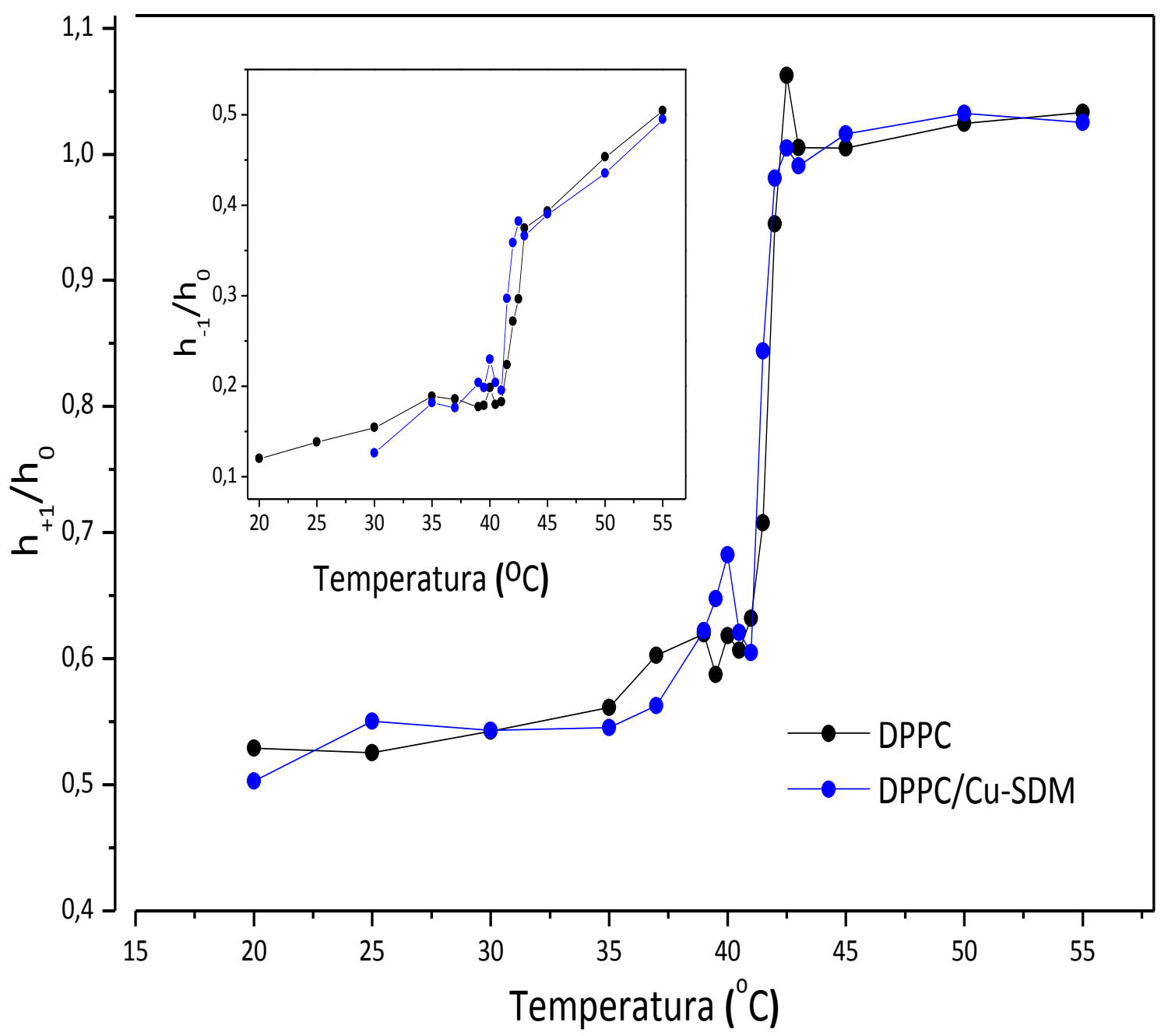

Figura 33 - Dependência dos parâmetros $h_{+1} / h_{0}$ e $h_{-1} / h_{0}$ (inserção) com a temperatura do marcador de spin 16-PCSL em DPPC, sem e com a adição do complexo Cu-SDM. 


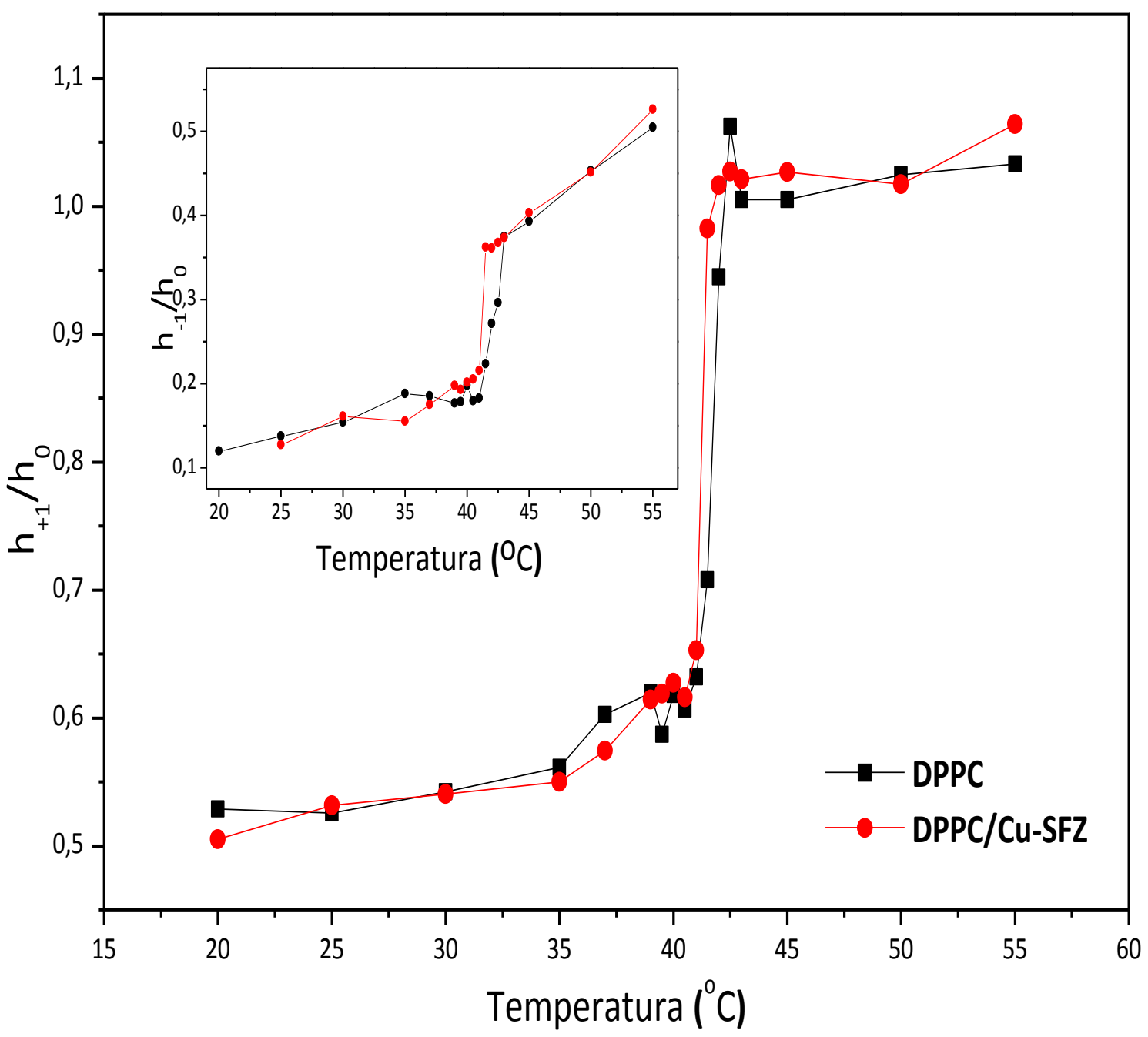

Figura 34 - Dependência dos parâmetros $h_{+1} / h_{0}$ e $h_{-1} / h_{0}$ (inserção) com a temperatura do marcador de spin 16-PCSL em DPPC, sem e com a adição do complexo Cu-SFZ.

Os resultados de RPE obtidos com as sondas magnéticas posicionadas ao longo da cadeia acila dos fosfolipídios que compõem os modelos de membrana utilizados neste trabalho mostram que o principal efeito da presença dos complexos é a indução de uma maior estruturação e/ou diminuição da dinâmica experimentada pelos fosfolipídios quando na fase gel (temperaturas abaixo da transição de fase principal). Os efeitos são mais notórios quando reportados pelas sondas localizadas nas regiões mais próximas à interface, entre o interior da vesícula lipídica e o meio aquoso externo, o que está de acordo com os resultados obtidos a partir dos termogramas de DSC. 
Além disso, observamos que as perturbações causadas pelos complexos são sempre mais claramente detectadas e, aparentemente, de maior magnitude para o complexo $\mathrm{Cu}$ SDM do que para o Cu-SFZ.

Um fato interessante observado nos espectros de RPE está no maior efeito observado quando os lipossomos de DPPC estão em sua fase gel, fase naturalmente mais ordenada do que a fase fluida. Isto pode indicar que em uma membrana celular, onde existe grande diversidade de fosfolipídios e outros componentes e em que podem coexistir domínios lipídicos com diferentes características físico-químicas, os complexos teriam preferência por interagir com domínios mais estruturados (pela presença de colesterol, por exemplo). Esta preferência por domínios mais ordenados poderia ser utilizada como uma ferramenta de direcionamento dos complexos para determinados tipo de membrana celular, assim, conferindo maior seletividade ao processo de entrega dos fármacos. 


\section{Conclusão}

O objetivo deste trabalho foi estudar a interação entre os compostos de cobre com sulfonamidas e vesículas constituídas pelo fosfolipídio DPPC. Com este intuito fizemos uso das técnicas de DSC e RPE para investigarmos as mudanças no comportamento termotrópico das vesículas lipídicas e as variações locais no ordenamento e dinâmica das cadeias lipídicas devido à incorporação dos complexos em estudo.

A partir do estudo calorimétrico foi possível conhecer o perfil termotrópico dos lipossomos na presença dos complexos Cu-SDM e Cu-SFZ. Através do estudo dos termogramas foi possível identificar as temperaturas de transição de fase, também como a entropia e entalpia envolvida em cada processo, entre outros dados.

Através da observação dos dados obtidos pelos termogramas, as medidas de DSC mostraram que os complexos afetam as transições de fase do DPPC, diminuindo a temperatura de transição de fase principal e alargando o pico da pré-transição de fase, indicando um maior desordenamento da membrana na presença dos complexos e evidenciando que há uma interação complexo-membrana. Ainda, utilizando-se dos dados dos termogramas e com a ajuda dos perfis de transição de fase principal discutidos no artigo de Jain e Wu (45) podemos supor a possível posição dos complexos no interior do modelo de membrana, onde ambos estão mais próximos à região polar da bicamada lipídica.

Com a indicação da possível ocorrência da interação, o segundo passo foi verificar o ordenamento e/ou mobilidade das cadeias lipídicas em diferentes regiões da bicamada, utilizando-se da técnica de RPE com diferentes marcadores de spin inseridos na membrana modelo. O estudo dos espectros obtidos por esta técnica gera um perfil de interação dos complexos ao longo da cadeia lipídica e em função da temperatura.

Foi mostrado que ambos os complexos induzem uma maior estruturação nos fosfolipídios quando observados abaixo da temperatura de transição principal, na fase gel, onde os efeitos mais acentuados são reportados na região mais próxima à interface, corroborando com os resultados obtidos pelo DSC, sendo que as perturbações causadas pelo complexo Cu-SDM são sempre de maior magnitude que para o complexo Cu-SFZ. 
O método convencional de análise dos espectros de RPE utilizados neste trabalho permitiu extrair as informações qualitativas necessárias sobre ambos os sistemas estudados e dentro de alguns limites, nos forneceu as informações quantitativas.

As técnicas empregadas em conjunto neste trabalho desempenharam um papel importante no entendimento da interação complexos-membrana, nos fornecendo um perfil completo de tais interações. O comportamento termodinâmico e macroscópico dos sistemas pôde ser determinado através da técnica de DSC, enquanto que o comportamento local sobre a dinâmica e empacotamento de cada região lipídica foi determinado pela técnica de RPE. Concluindo-se que essas técnicas são complementares na investigação de interações membrana-composto.

Nosso estudo foi limitado a membranas artificiais, logo nossos resultados devem ser entendidos com uma indicação das interações reais envolvidas e os efeitos causados pelos complexos em estudo em um sistema biológico, devido ao fato de serem obtidos a partir de um sistema modelo, constituídos apenas de um fosfolipídio. Entretanto, nossos resultados proporcionam, de uma maneira geral, uma maior compreensão dos mecanismos envolvidos na interação desta e outras pequenas moléculas com membranas biológicas, pois possibilitam fazer deduções em nível molecular destes sistemas.

De maneira sucinta, os resultados apontam para uma possível interação das moléculas de Cu-SDM e Cu-SFZ com a cabeça polar do lipídio e um maior efeito observado na fase com maior empacotamento dos lipossomos de DPPC, a fase gel, podendo indicar que em uma membrana biológica, onde há uma variedade de fosfolipídios e outros componentes em sua composição, podendo assim coexistir diferentes características físico-químicos ambos os complexos iriam interagir com os domínios de menor mobilidade, mais estruturados, podendo esta característica ser uma ferramenta de seletividade ao processo de transporte dos fármacos.

\section{Propostas para trabalhos futuros}

É natural, ao final de todo projeto de mestrado, devido ao curto período de tempo, indicar os próximos passos a serem seguidos para a continuação e finalização completa do 
projeto desenvolvido. Alguns aspectos que achamos interessantes serem investigados, que foram percebidos ao longo da escrita desta dissertação são:

Com relação à interação dos complexos com modelos de membranas, podem ser testadas novas composições lipídicas, usando-se outros fosfolipídios;

Um estudo mais detalhado do comportamento termotrópico das interações, variando-se as concentrações dos complexos inseridos na membrana modelo;

Além disso, fazer o estudo dos dados obtidos a partir da técnica de RPE a partir do método de simulação de espectros. 


\section{Bibliografia}

1. ANTMAN, K. H. The history of arsenic trioxide in cancer therapy. The Oncologist, n. 6, p. 12, 2001. Supplement 2.

2. WILSON, C. J.; APIYO, D.; WITTUNG-STAFSHEDE, P. Role of cofactors in metalloprotein folding. Quarterly Reviews of Biophysics, v. 37, p. 285-314, 2004.

3. RAFIQUE, S. et al. Transition metal complexes as potential therapeutic. Biotechnology and Molecular Biology Reviews, v. 5, n. 2, p. 38-45, 2010.

4. WARRA, A. A. Transition metal complexes and their application in drugs ans cosmetics. Journal of Chemical and Pharmaceutical Research, v. 3, n. 4, p. 951-958, 2011.

5. CASANOVA, J. et al. Metal complexes of sulfanilamide derivatives. Spectroscopic characterization of the dicholoro disulfathiazole methanol copper(II) complex. Inorganica himica Acta, v. 211, p. 183-186, 1993.

6. HART, E. B. et al. Iron Nutrition VII. Copper as a suplement to iron for hemoglobin building in the rat. The Journal of Biological Chemistry, v. 77, p. 797-812, 1928.

7. FRIEDEN, E. Copper and iron metalloproteins. Trends in Biochemical Sciences, v. 1, n. 12, p. $273-274,1976$.

8. UAUY, R.; OLIVARES, M.; GONZALES, M. Essentiality of copper in humans. The American Journal of Clinical Nutrition, v. 67, p. 952-959, 1998. Supplement. 
9. WANG, T.; GUO, Z. Copper in Medicine: homeostasis, chelation therapy and antitumor drug design. Current Medicinal Chemistry, v. 13, n. 5, p. 525-537, 2006.

10. LINDER, M. C.; HAZEGH-AZAM, M. Copper biochemistry and molecular biology. The American Journal of Clinical Nutrition, v. 63, p. 797-811, 1996. Supplement.

11. TURNLUND, J. R. Human whole-body copper metabolism. The American Journal of Clinical Nutrition, v. 67, p. 960-4, 1998. Supplement.

12. HOLM, R. H.; KENNEPOHL, P.; SOLOMON, E. I. Structural and functional aspects of metal sites in Biology. Chemical Reviews, v. 96, p. 2239-2314.

13. KNIGHT, S. A et al. A widespread transposable element masks expression of a yesat copper transport gene. Genes \& Development, v. 10, p. 1917-1929, 1996.

14. WEDER, J. E. et al. Copper complexes of non-steroidal anti-inflammatory drugs: an opportunity yet to be realized. Coordination Chemistry Reviews, v. 232, p. 95-126, 2002.

15. PROHASKA, J. R.; LUKASEWYCZ, O. A. Copper deficiency suppresses the immune response of mice. Science, v. 213, p. 559-561,1981.

16. CERCHIARO, G.; COSTA FERREIRA, A. M. Oxindoles and copper complexes with Oxindolederivatives as potential pharmacological agents. Journal of The Brazilian Chemical Society, v. 17, n. 8, pp. 1473-1485, 2006.

17. de BIE, P. et al. Molecular pathogenesis of Wilson and Menkes disease: correlation of mutations with molecular defects and disease phenotypes. Journal of Medical Genetics, v. 44, p. 673-688, 2007.

18. DANKS, D. M. Copper deficiency in humans. Annual Review of Nutrition, v. 8, p. 235-257, 1988. 
19. BREWER, G. J. Risks of Copper and Iron toxicity during aging in humans. Chemical Research in Toxicology, v. 23, p. 319-326, 2010.

20. LEGNAME, G. et al. Prion and doppel proteins bind to granule cells of the cerebellum. Proceedings of the National Academy of Sciences USA, v. 99, p. 16285-16290, 2002.

21. VILES, J. H. et al. Copper binding to the prion protein: structural implications of four identical cooperative binding sites. Proceedings of the National Academy of Sciences USA, v. 96, p. 2042-2047, 1999.

22. HATHAWAY, B. J.; TOMLINSON, A. A. G. Copper(II) ammonia complexes. Coordination Chemistry Reviews, v. 5, p. 1-43, 1970.

23. SCOZZAFAVA, A. et al. Anticancer and antiviral sulfonamides. Current Medicinal Chemistry, v. 10, n. 11, p. 925-953, 2003.

24. HENRY, R. J. The mode of action of sulfonamides. Bacteriological Reviews, v. 7, n. 4, p. 175-262, 1943.

25. ELLENA, J. et al. X-ray structure and EPR behavior of a new dimeric copper(II) complex with 4-amino-N-(5-methoxy-2-pyrimidinyl)benzenesulfonamide. Polyhedron, v. 26, p. 32773285, 2007.

26. TOMMASINO, J. et al. Multi-biofunctional complexes combining antiseptic copper(II) with antibiotic sulfonamide ligands: structural, redox and antibacterial study. Polyhedron, v. 30, p. 1663-1670, 2011.

27. MODELLI, M. et al. New Ni(II)-sulfonamide complexes: synthesis, structural characterization and antibacterial properties. X-ray diffraction of 
[Ni(sulfisoxazole)2 $\left(\mathrm{H}_{2} \mathrm{O}\right)_{4}$ ] $2 \mathrm{H}_{2} \mathrm{O}$ and [Ni(sulfapyridine) ${ }_{2}$ ]. Journal of Inorganic Biochemistry, v. 102, p. $285-292,2008$.

28. BLASCO, F. et al. Synthesis and spectroscopy studies of Copper(II) Nitrate of Sulfacetamide drug. Crystal structure of [Cu(Sulfacetamide)2( $\left.\left(\mathrm{NO}_{3}\right)_{2}\right]$. Antibacterial studies. Journal of Inorganic Biochemistry, v. 53, p. 117-126, 1994.

29. KREMER, E. et al. Copper complexes with heterocyclic sulfonamides: synthesis, spectroscopic characterization, microbiological and SOD-like activities: Crystal structure of [Cu(sulfisoxazole)2 $\left.\left(\mathrm{H}_{2} \mathrm{O}\right)_{4}\right] \cdot 2 \mathrm{H}_{2} \mathrm{O}$. Journal of Inorganic Biochemistry, v. 100, p. 1167-1175, 2006.

30. BORRÁS, E. et al. Coordination chemistry of sulfamethizole: crystal structures of [Cu(sulfamethizolate $\left.\left.)_{2}(\mathrm{py})_{2}\left(\mathrm{OH}_{2}\right)\right] \cdot \mathrm{H}_{2} \mathrm{O},[\mathrm{M} \text { (sulfamethizolate })_{2}(\mathrm{py})_{2}\left(\mathrm{OH}_{2}\right)_{2}\right][\mathrm{M}=\mathrm{Co}$ and $\mathrm{Ni}]$ and $\left\{\mathrm{Cu}(\text { sulfamethizolate })_{2}(\mathrm{dmf})_{2}\right\}$. Polyhedron, v. 19, p. 1859-1866, 2000.

31. KUMAR, R. et al. Inhibition of Rat Brain Protein Kinase C by Lipid Soluble Psychotropics. Neurochemical Research, v. 22, n. 1, p. 1-10, 1997.

32. REASOR, M. J.; KACEW, S. An evaluation of possible mechanisms underlying Amiodaroneinduced pulmonary toxicity. Proceedings of the Society for Experimental Biology and Medicine, v. 212, p. 297-304, 1996.

33. JUTILA, A.; RYTOMAA, M.; KINNUNEN, P. K. J. Detachment of Cytochrome $c$ by cationic drugs from membranes containing Acidic Phospholipids: comparison of Lidocaine, Propranolol, and Gentamycin. Molecular Pharmacology, v. 54, p. 722-732, 1998.

34. ZHAO, L. et al. DSC and EPR investigations on effects of cholesterol component on molecular interactions between paclitaxel and phospholipid within lipid bilayer membrane. International Journal of Pharmaceutics, v. 338, p. 258-266, 2007. 
35. SINGER, S. J.; NICOLSON, G. L. The fluid mosaic model of the structure of cell membranes. Science, v. 175, n. 4023, p. 720-731, 1972.

36. CHATEERJEE, S. N.; AGARWAL, S. Lipossomes as membrane model for study of lipid peroxidation. Free Radical Biology \& Medicine, v. 4, p. 51-72, 1988.

37. MUTZ, M.; HELFRICH, W. Unbinding transition of a biological model membrane. Physical Review Letters, v. 62, n. 24, p. 2881-288, 1989.

38. NELSON, D. L.; COX, M. M. Biological membranes and transport. In: NELSON, D. L.; COX, M. M. Lehninger principles of biochemistry. 4. ed., New York, W.H. Freeman, p. 370-420, 2005.

39. HUANG, C.; LI, S. Calorimetric and molecular mechanics studies of the thermotropic phase behavior of membrane phospholipids. Biochimica et Biophysica Acta, v. 1422, p. 273307, 1999.

40. FRÉZARD, F. et al. Lipossomas: propriedades físico-químicas e faramacológicas, aplcações na quimioterapia à base de Antimônio. Química Nova, v. 28, n. 3, p. 511-518, 2005.

41. BANGHAM, A. D. Liposomes: From Physics to Applications by D. D. Lasic. Biophysical Journal, v. 67, p. 1358-1362, 1994.

42. SCHUTZ, G. J.; SCHINDLER, H.; SCHMIDT, T. Single-molecule microscopy on model membranes reveals anomalous diffuion. Biophysical Journal, v. 73, p. 1073-1080, 1997.

43. MARSH, D.; HORVÀTH, L. I. Structure, dynamics and composition of the lipid-protein interface. Perspectives form spin-labelling. Biochimica et Biophysica Acta, v. 1376, p. 267296, 1998. 
44. DUFORCQ, J.; FAUCON, J. Intrinsic fluorescence study of lipid-protein interactions in membrane models. Binding of melittin, an amphiphatic peptide, to phospholipid vesicles. Biochimica et Biophysica Acta, v. 467, p. 1-11, 1977.

45. JAIN, M. K.; WU, N. M. Effect of small molecules on the Dipalmitoyl Lecithin liposomal bilayer: III. Phase transition in lipid bilayer. Journal of Membrane Biology, v. 34, p. 157-201, 1977.

46. SCHINDLER, H.; SEELIG, J. EPR spectra of spin labels in lipid bilayers. The Journal of Chemical Physics, v. 59, n. 4, p. 1841-1850, 1973.

47. TORRE, M. H. et al. Characterization of a $\mathrm{Cu}(\mathrm{II})$ complex of sulfadimethoxine. Journal of Inorganic Biochemistry, v. 94, p. 200-204, 2003.

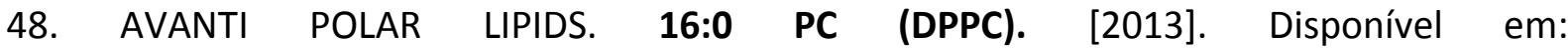
$<$ http://avantilipids.com/index.php?option=com_content\&view=article\&id=216\&ltemid=206 \&catnumber=850355>. Acesso em: 01 mar. 2013.

49. DEMETZOS, C. Differential Scanning Calorimetry (DSC): A tool to study the thermal behavior of lipid bilayers and lipossomal stability. Journal of Lipossome Research, v. 18, p. 159-173, 2008.

50. LEADBURY, J. E.; CHOWDHRY, B. Z. Biocalorimetry. Applications of calorimetry in the biological sciences. Chichester, John Wiley \& Sons, 1998.

51. MOURITSEN, O. G.; JORGENSEN, K. A new look at lipid-membrane structure in relation to drug research. Pharmaceutical Research, v. 15, p. 1507-1519, 1998.

52. ALMEIDA, P. F. F.; POKOMY, A.; HINDERLITER, A. Thermodynamics of membrane domains. Biochimica et Biophysica Acta, v. 1720, p. 1-13, 2005. 
53. BASSO, L. G. M. Interação de fármacos anti-malária com modelos de membrana. 2009. 150 f. Dissertação (Mestrado) - Instituto de Física, Universidade de São Paulo, São Carlos, 2009.

54. MABREY, S.; MATEO, P. I.; STURTEVANT, J. M. High-sensitivity scanning calorimetric study of mixtures of Cholesterol with Dirnyristoyl- and Dipalmitoylphosphatidylcholines. Biochemistry, v. 17, n. 12, p. 2464-2468, 1978.

55. CARRER, D. C.; MAGGIO, B. Phase behavior and molecular interactions in mixtures of ceramides with dipalmitoylphosphatidylcholine. Journal of Lipid Research, v. 40, pp. 19781989, 1999.

56. MARSH, D.; WATTS, A.; KNOWLES, P. F. Cooperativity of the phase transition in singleand multibilayer lipid vesicles. Biochimica et Biophysica Acta, v. 465, p. 500-514, 1977.

57. LEWIS, R. A. A. H.; MAK, N.; MCELHANEY, R. N. A Differential Scanning Calorimetry study of the thermotropic phase behavior of model membranes composed of Phosphatidylcholines containing linear satured acyl chains. Biochemestry, v. 26, n. 19, p. 6118-6126, 1987.

58. WEIL, J. A.; BOLTON, R. Electron paramagnetic resonance. 2. ed., Hoboken, Jonh Wiley \& Sons, 2007.

59. PERUSSI, J. R.; RUGGIERO, A. C.; TABAK, M. O método de marcadores de spin aplicado a bioquímica. Química Nova. p. 313-324, 1985.

60. AXEL, F. S. Biophysics with Nitroxyl Radicals. Biophysics of Structure and Mechanism, v. 2, p. 181-218, 1976. 
61. SCHNEIDER, D. J.; FREED, J. H. Calculating slow motional magnetic resonance spectra: a user's guide. In: BERLINER, L. J.; REUBEN, J. Biological magnetic resonance. New York: Plenum Publishing, 1989. v. 8, p. 1-76.

62. LORINCZY, D.; KISS, M.; BELAGYI, J. DSC and EPR study on AMP.PNP, BEFX and AIF4 containing myosin nucleotide complexes. Journal of Thermal Analysis and Calorimetry, v. 72, p. 565-572, 2003.

63. JOBIN, M. L. et al. The enhanced membrane interaction and perturbation of a cell penetrating peptide in the presence of anionic lipids: Toward an understanding of its selectivity for cancer cells. Biochimica et Biophysica Acta, v. 1828, p. 1457-1470, 2013.

64. BUDAI, M.; ZS SZABÓ, M.; SZOGYI, P. G. Molecular interactions between DPPC and morphine derivatives: a DSC and EPR study. International Journal of Pharmaceutics, v. 250, p. 239-250, 2003.

65. BILTONEM, R. L.; LICHTENBERG, D. The use of differential scanning calorimetry as a tool to characteirze liposome preparations. Chemistry and Physics of Lipids, v. 64, p. 129-142, 1993. 